\title{
Cognitive functions in schizophrenia
}

Citation for published version (APA):

Krabbendam, L. (2000). Cognitive functions in schizophrenia. [Doctoral Thesis, Maastricht University]. NeuroPsych Publishers. https://doi.org/10.26481/dis.20000609lk

Document status and date:

Published: 01/01/2000

DOI:

10.26481/dis.20000609lk

Document Version:

Publisher's PDF, also known as Version of record

\section{Please check the document version of this publication:}

- A submitted manuscript is the version of the article upon submission and before peer-review. There can be important differences between the submitted version and the official published version of record.

People interested in the research are advised to contact the author for the final version of the publication, or visit the DOI to the publisher's website.

- The final author version and the galley proof are versions of the publication after peer review.

- The final published version features the final layout of the paper including the volume, issue and page numbers.

Link to publication

\footnotetext{
General rights rights.

- You may freely distribute the URL identifying the publication in the public portal. please follow below link for the End User Agreement:

www.umlib.nl/taverne-license

Take down policy

If you believe that this document breaches copyright please contact us at:

repository@maastrichtuniversity.nl

providing details and we will investigate your claim.
}

Copyright and moral rights for the publications made accessible in the public portal are retained by the authors and/or other copyright owners and it is a condition of accessing publications that users recognise and abide by the legal requirements associated with these

- Users may download and print one copy of any publication from the public portal for the purpose of private study or research.

- You may not further distribute the material or use it for any profit-making activity or commercial gain

If the publication is distributed under the terms of Article $25 \mathrm{fa}$ of the Dutch Copyright Act, indicated by the "Taverne" license above, 


\section{Cognitive functions in schizophrenia}

Neuropsych Publishers, Maastricht 
(c) Lydia Krabbendam, Maastricht 2000

ISBN $90-75579-10 \% 1$

Cover design: Unigraphic

Misstration: "Pierrot", Henny van Sonsbeek, 1991

Uit: "De spiegel van de clown", expositie april - september 2000, PMS Vijverdal, Maastricht

Met dank aan de ouders van Henny van Sonsbeek

Lay-out: Femie Kengen

Production: Datawyse | University Press Maastricht

Newropsych Pwblishers is a nonprofit organization which aims at promoting the science of 'Brain and Behavior' and improving the application of the products of this science in health care and education. Neuropsych Publisher accomplishes these aims by publishing books, dissertations and other products of scientific activity, by disserninating ectucational materials and publication of tests, assessment scales and other psychometric instruments in the field of Neuropsychology. Neuropsychiatry and other areas within the domain of Brain and Behavior.

Postal address:

Neuropsych Publishers

Department of Psychiatry and Neuropsychology

Maastricht University

P.O. Box 616

NL-6200 MD Maastricht

The Netherlands 


\section{Cognitive functions in schizophrenia}

\section{PROEFSCHRIFT}

ter verkrijging van de graad van doctor aan de Universiteit Maastricht, op gezag van de Rector Magnificus, Prof. dr. A.C. Nieuwenhuijzen Kruseman, volgens het besluit van het College van Decanen,

in het openbaar te verdedigen op

vrijdag 9 juni 2000 om 14.00 uur

door

LYDIA KRABBENDAM

geboren op 10 juni 1971 te Beverwijk 


\section{Promotor}

Prof. dr. J. Jolles

Co-promotor

Dr. M.M.A. Derix

\section{Beoordelingscommissie}

Prof. dr. H.L.G.J. Merckelbach (voorzitter)

Prof. dr. R. Kahn (Universiteit Utrecht)

Prof. dr. H.H.J. Kolk (Katholieke Universiteit Nijmegen)

Prof. dr. M.H.J. Maes

Dr. J.J. van Os

The studies described in this thesis were carried out at the Maastricht Brain \& Behavior Institute of the Maastricht University (department of Psychiatry and Neuropsychology) and the Psychomedical Center Vijverdal Maastricht.

Publication of this thesis was financially supported by: Jansen-Cillag B.V., Pfizer B.V., AstraZeneca B.V, and UCB Pharma B.V. 


\section{Contents}

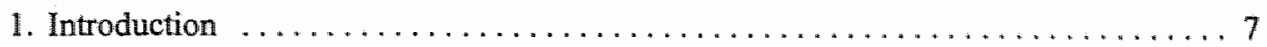

Outline and aims of the studies $\ldots \ldots \ldots \ldots \ldots \ldots \ldots \ldots \ldots$

2. Cognitive deficits in schizophrenia: a short review of previous studies $\ldots \ldots \ldots \ldots 13$

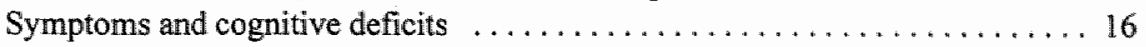

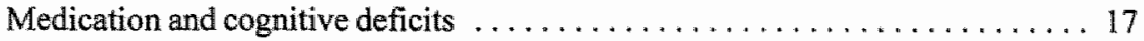

Brain abnormalities and cognitive deficits $\ldots \ldots \ldots \ldots \ldots \ldots \ldots \ldots$

3. The role of processing speed in memory performance in patients with schizophrenia . 25

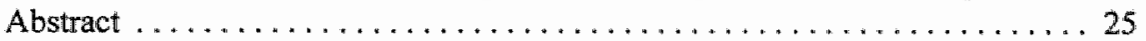

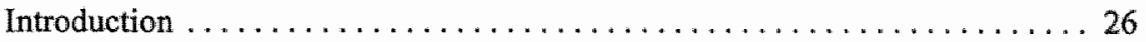

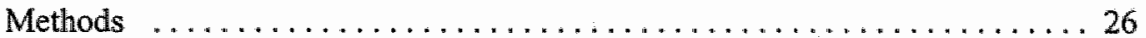

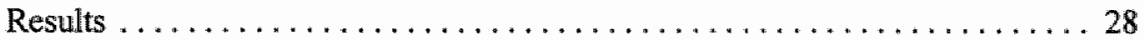

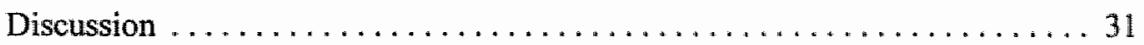

4. Cognitive performance and MRI temporal lobe volume in patients with schizophrenia 35

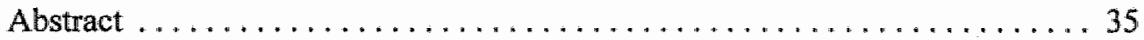

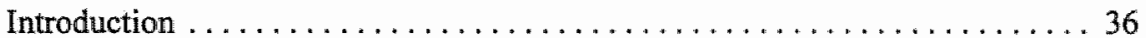

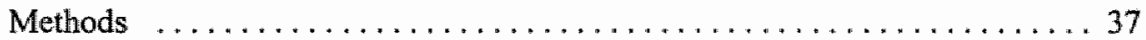

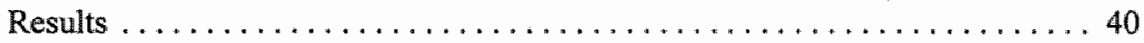

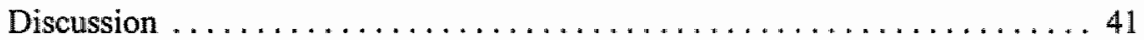

5. Cognitive performance in patients with schizophrenia and their first-degree relatives . 45

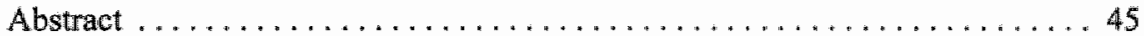

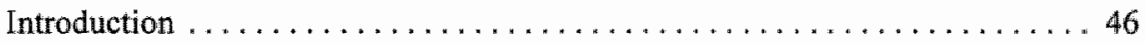

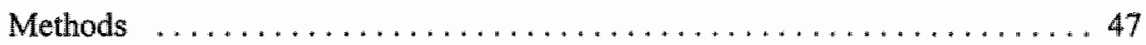

Results ........................................ 49

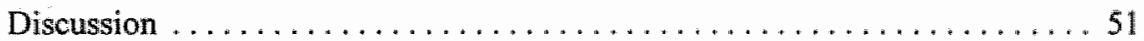

6. Cognitive performance and white matter lesions in patients with schizophrenia and

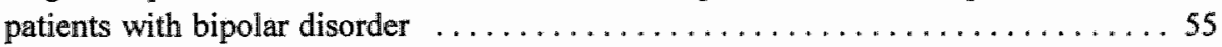

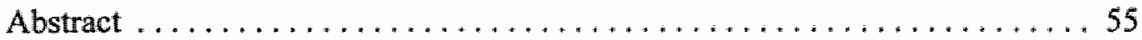

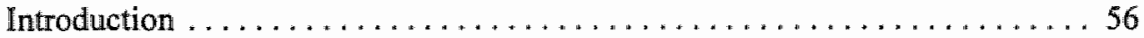

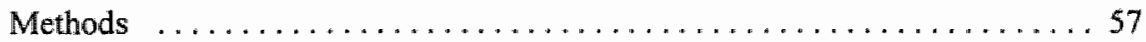

Results ......................................6 60

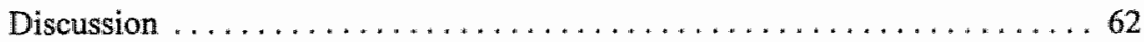


7. Cognitive performance and tardive dyskinesia in patients with schizophrenia ... 69

Abstract ...................................... 69

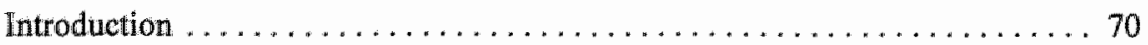

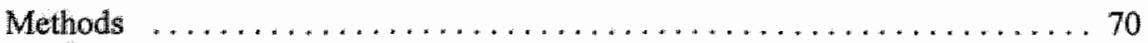

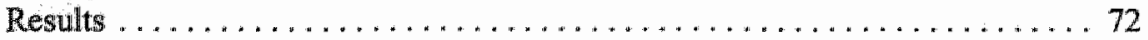

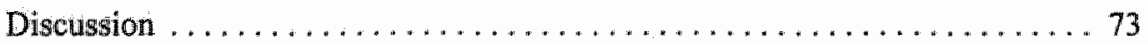

8. Deficits of executive functions in patients with schizophrenia $\ldots \ldots \ldots \ldots \ldots \ldots$

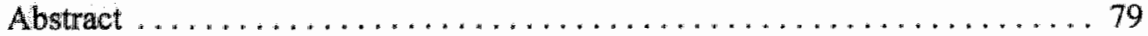

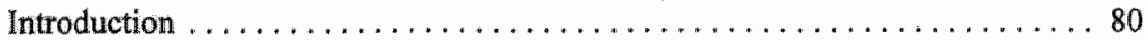

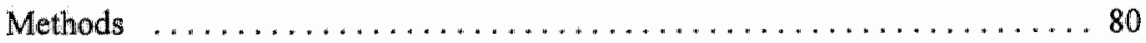

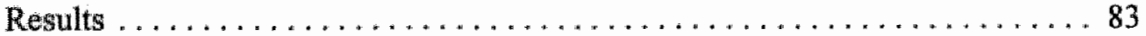

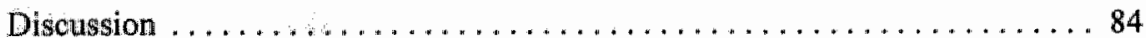

9. Epilogue . . . . . . . . . . . . . . . . . . . . . . . . . . . . . . . . 89

Summary and implications of findings $\ldots \ldots \ldots \ldots \ldots \ldots \ldots \ldots \ldots$

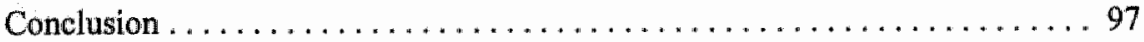

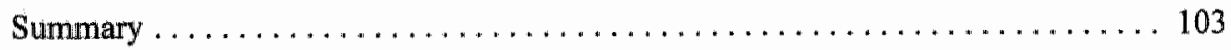

Samenvatting ...................................... 109

Dankwoord ........................................ 115

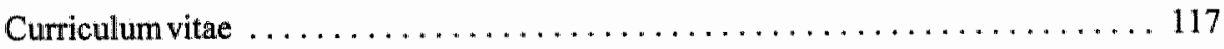

List of publications . .............................. 119 


\section{Introduction}

Schizophrenia is characterized by a severe disintegration of the mind. This leads to various phenomena, such as delusions, hallucinations, disorganized behavior, cognitive impairments, avolition, and alogia. These characteristics are generally divided into two groups: negative symptoms, which refer to the absence of certain functions that should be present in a healthy individual, for example, avolition, and positive symptoms, which are not present in a healthy individual, for example, delusions (see Andreasen et all, 1994, for a review). Both types of symptoms can occur in one patient. Schizophrenia is a major psychiatric disorder; the point prevalence, expressed as the number of cases per 1000 persons at risk, is estimated between 1.4 and 4.6 , and the incidence rate, that is the annual number of new cases in a defined population per 1000 individuals at risk, is between 0.16 and 0.42 (Jablensky, 1995).

The disorder is currently viewed within a neurodevelomental model. The onset of psychotic symptoms typically occurs in early adulthood, but according to the neurodevelopmental model the disorder begins already during prenatal development. More specifically, it is hypothesized that a failure occurs during the period of cell migration, leading to non-optimal connections between brain areas (Murray \& Lewis, 1987; Weinberger, 1987). The onset of psychotic symptoms is so much later, because only then the affected part of the brain matures and is called "on line" (Weinberger, 1987).

The abnormal connectivity may lead to the psychotic symptoms via a disturbance of basic cognitive processes. Accordingly, numerous studies have yielded evidence for cognitive deficits in patients with schizophrenia. In fact, when a group of patients with schizophrenia is compared to a group of healthy controls on a neuropsychological test battery, performance of the patient group will be worse on almost any of the tests. This has led some authors to conclude that schizophrenia is associated with a generalized cognitive impairment (e.g.* Blanchard \& Neale, 1994; Mohamed, Paulsen, O'Leary, Arndt \& Andreasen, 1999). Yet, several studies have attempted to move beyond this generalized impairment to search for specific disturbances of cognitive processes (e.g., Frith, 1995; Gold, Randolph, Carpenter, Goldberg \& Weinberger, 1992; Schatz, 1998). 
The cognitive functions that are frequently mentioned as being specifically compromised in schizophrenia include attention (Braff, 1993; Nuechterlein, Dawson \& Green, 1994), memory (Landra, 1994; McKenna et al., 1990), executive functions (Mlorice Delahunty, 1996; Shallice, Burgess \& Frith, 1991), and working memory, the type of memory that is active for a short period of time to perform a particular task (Goldman Rakic, 1994). There is sufficient evidence that the deficits in these domains cannot be ascribed to the effects of general factors, such as psychopathology and intellectual deterioration or to the side-effects of antipsychotic medication (Braff, 1993; Mortimer, 1997). Also, several of the deficits persist during clinical remission, which suggests that they are part of a lasting vulnerability to the disorder (Cantor Graae, Warkentin \& Nilsson, 1995; Nuechterlein et al., 1994).

The cognitive research in schizophrenia is relevant in several ways. First, it provides clues to the type of brain abnormalities that are implicated in schizophrenia (e.g., Pantelis et al., 1997, Weinberger, Aloia, Goldberg \& Berman, 1994). For example, on the basis of the cognitive performance, Pantelis et al. have suggested that fronto-striatal circuits may be implicated. Second, this research yields insight into the cognitive mechanisms that underlie the various symptoms of schizophrena, for example, the hypothesis that impaired self-monitoring underlies certain hallucinations (Frith, 1995; Strauss, 1993). Third, this research reveals important determinants of functional outcome, for example, the presence of a verbal memory deficit is related to social and vocational outcome (Green, 1996). Thus, the cognitive perspective can provide a means to integrate the biological and behavioral aspects of this complex disorder (Green, 1998). This thesis takes this assumption as its starting point. In particular, cognitive dysfunctions in schizophrenia are examined in relation to neurobiological abnormalities and to functioning in daily life.

\section{Outline and aims of the studies}

Schizophrenia is associated with a wide range of cognitive deficits. Given the long list of documented cognitive deficits, the challenge is not to identify even more deficits, but to search for some unifying or integrative factors that are central to the cognitive impairment. This can yield insight into the neurobiological abnormalities and the behavioral disorders seen in patients with schizopturenia.

A short review of previous studies is provided in chaprer 2. It is concluded that patients with schizophrenia may have specific deficits in several cognitive domains, notably, attention, memory, and executive functions. These deficits are to a large extent independent from current psychiatric symptomatology and they cannot be ascribed to the effects of medication. In an attempt to delineate a key cognitive dysfunction, current cognitive research has focused on the concept of working memory. A dysfunction of working memory seems to have much potential to explain the range of cognitive abnormalities associated with schizophrenia. 
The role of processing speed in the memory performance in schizophrenia

In chapter 3 of this thesis, another plausible, yet relatively neglected, candidate for a key dysfunction in the cognitive impairment in schizophrenia is considered, namely, the speed of information processing. Despite the fact that mental slowness is a robust correlate of schizophrenia, few studies have explicitly investigated the impact of slowness on other functions. The aim of the study described in chapter 3 was (i) to investigate whether memory deficits in schizophrenia can be accounted for by a decrease in processing speed and (ii) if so, whether this can be ascribed to sensorimotor or cognitive aspects of speed.

\section{Specific versus generalized cognitive deficits in schizophrenia}

A related issue that continues to provoke debate is whether the cognitive impairment can be characterized better in terms of global or specific deficits. This question is the main focus of chapter 4. In connection with the previous chapter, this issue was examined using cognitive speed as the starting point. The study question was whether cognitive speed in schizophrenia is characterized by a general slowing or by a disproportionate increase in time for certain types of information processing. In this study, timed tests were used that involve subtasks of increasing complexity. The more demanding subtasks inwolve working memory. This hierarchical design of the tests enabled us to differentiate between generalized and specific slowing of information processing speed.

\section{Abnormalities of temporal and limbic structures in schizophrenia}

Brain imaging in schizophrenia has yielded evidence for a range of cerebral disturbances. On the basis of CT scan- and MRI-studies, there is convincing evidence for a decrease in overall brain volume and enlargement of the lateral ventricles, and possibly abnomalities of temporal and limbic structures in schizophrenia. It has been hypothesized that a circuitry involving the prefrontal and temporal and limbic areas underlies the impairment of working memory in schizophrenia. The study described in chapter 4 also investigated the relation between the possible specific slowing on tasks of working memory and the volume of temporal and limbic structures as measured with MRI.

\section{Cognitive vulnerability indicators for schizophrenia}

The studies reported in chapters 3 and 4 investigated patients with schizophrenia in relatively stable remission. This means that the deficits observed are part of a lasting vulnerability and are independent of psychotic episodes. Still, some degree of psychopathology often persists during remission, which may contribute to poor cognitive performance. A more powerful design to identify indicators of vulnerability is therefore the study of relatives of patients with 
schizophrenia, who have a risk of developing schizophrenia about 10 times that of the general population. In chapter 5 a study is described in which the cognitive performance of patients with schizophrenia and their first-degree relatives was compared to that of controls from the general population. The aim of this study was to investigate whether the pattern of deficits in relatives parallels that found in patients with schizophrenia.

\section{Specificity of cognitive deficits in schizophrenia versus bipolar disorder}

Relatively little is known about the specificity of the cognitive deficits in schizophrenia compared to other psychiatrie disorders. This question is particularly relevant with regard to mood disorders, because it has been suggested that mood disorders and schizophrenia are related diseases. The study described in chapter 6 was designed to examine the cognitive functioning of patients with bipolar disorder, patients with schizophrenia, and healthy controls. All patients were assessed during clinical remission, because clinically significant levels of psychopathology may exert nonspecific influences on cognitive function.

\section{White matter lesions in schizophrenia and bipolar disorder}

The large body of research focusing on the decreased volume of brain structures in schizophrenia has recently been complemented by studies addressing the incidence of white matter lesions. There is some evidence for an increased frequency of white matter lesions in bipolar disorder and in schizophrenia, but whether these lesions are related to the cognitive deficits is not clear. White matter lesions can cause damage to fibre tracts and as such can lead to a functional disconnection between brain regions, which in turn may lead to a range of cognitive deficits. The study described in chapter 6 also addressed the prevalence and severity of white matter lesions in patients with schizophrenia and bipolar disorder in relation to the cognitive deficits.

\section{Cognitive deficits and tardive dyskinesia in schizophrenia}

Some, but not all, patients with schizophrenia develop tardive dyskinesia during the course of the treatment with neuroleptic medication. Tardive dyskinesia is characterized by involuntary, choreoathetoid movements of the orofacial region, limbs, and trunk. Several studies have reported an excess of cognitive impairment in patients with tardive dyskinesia. This suggests that the presence of cognitive deficits in a patient with schizophrenia may indicate a heightened sensitivity to the adverse action of neuroleptic medication. However, it is not clear whether this vulnerability occurs in the form of a global or a specific cognitive deficit, such as frontal executive functions or memory. The goal of the study described in chapter 7 was to specify the association between cognitive dysfunctions and tardive dyskinesia. 


\section{Deficits of executive function in schizophrenia}

Deficits of executive functions have a marked impact on daily life. Yet, they are difficult to assess with standard neuropsychological test procedures, because of the structured nature of these procedures. The Behavioural Assessment of the Dysexecutive Syndrome (BADS; Wilson, Alderman, Burgess, Emslie \& Evans, 1996; Krabbendam \& Kalff, 1997) is directed at the everyday problems which arise as a result of impaired executive functioning. The BADS presents the subject with a series of unstructured tasks that are designed to reflect daily life situations. The aim of the study described in chapter 8 was to investigate whether the BADS can identify executive deficits in schizophrenia and whether performance on this test is related to daily life functioning.

Chapter 9 provides a summary of the findings and a discussion of implications for further research and for clinical practice. 


\section{References}

Andreasen, N. C. Nopoulos, P. Schuli, S, Miller, D, Gupta, S, Swayze, V, \& Flaum, M. (1994). Positive ard negative symptoms of schizophinenia: Past, present, and future. Acta Pycharica Scandinavica, 90 (suppl 384), 51-59.

Wanchard, J. J. \&ealle, M. (1994), The neuropsychological signature of schizophreniat Generalized or differential deficit? Amentcan Jaurnal of Psythiatry $151,40-48$.

Braf, D. L, (1993), linformation proeessing and attention dysfunctions in schizophrenia. Schizophrenia Bullewin, 19, $233-259$.

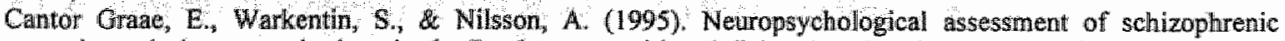
patients duning a psychotio episode: Persistent cognitive deficit? Acta Pspchiatrica Scandinavica, 91,283 288.

Frith, $C, D .(1995)$. The coggitive abnormalities anderlying the symptomatology and the disability of patients with schizophrenia. International Clinical Psychophamacology, 10 (suppl 3), 87-98.

Gold, J. M, Randolph, C., Carpenter, C. J., Goldberg; T. E., \& Weinberger, D. R. (1992). Forms of memory failure in schizophrenia. Journal of Abromol Psychology, 101, 487-494.

Goldman-Rakic , P. S. (1994). Working memory dysfunction in schizophrenta. Jowrnal of Neturopsychiatry and Clinical Meurosciences; $6,348-357$.

Green $_{n}$ M. F. (1996). What are the functional consequences of neurocognitive deficits in schizophrenia? Arterican Jound of Psychiatry, 153, 321-330.

Green, M. 1. (1998). Schizophrenia from a newrocognitive perspective: Probing the impenetrable darkness. Boston: Allyn and Bacon.

Jablensky, A. (1995). Schizophrenia: The epidemiological horizon. In S. R. Hirsch \& D. R. Weinberger (Eds.), Schizophrenia, (pp. 206-252). Oxford: Blackwell Science.

Krabbendan, L. \& Kalff, A. C. (1997). The Behovioural Assessment of the Dysexecutive Syndrome - Dutch version. Lisse, the Netherlands: Swets \& Zeitlinger.

Landro., N. I. (1994). Memory function in schizophrenia. Acta Psychatrica Scandinavica, 90 (suppl 384). 87. 94.

McKenna, P. J., Tamlyn, D., Lund, C. E., Mortimer, A. M. Hammond, S. \& Baddeley, A. D. (1990). Amnesic syndrome in schizophrenia. Psychalogical Medicine, 20, 967-972.

Mohamed, S., Paulsen, J. S., O'Leary, D., Amd, S., \& Andreasen, N. (1999). Generalized cognitive deficits in schizophrenia: A study of first-wisode patients. Archives of General Psychiory, 56, 749-754.

Morice, $\mathbb{R}$, \& Delahumty, A. (1996). Frontal/executive impairments in schizophrenia. Schizophrenilo Bulletin, $22,125-137$.

Mortimer, A. M. (1997). Cagnitive function in schizophrenia - Do neuroleptics make a difference? Pharmacology, Biochemistry and Behowior, 56, 789-795.

Murray, R. M. \& Lewis, S. W. (1987). is schizophrenia a neurodevelopmental disorder? British Medical Jowinal, 295, 681-682.

Nuechtertein, K. H., Dawson, M. E., \& Green, M. F. (1994). Information processing abnormalities as neuro* psychological vulnerability indicators to schizophirenila. Acta Psychiatrica Scandinavica, 90 (suppl 384), 7179.

Pantelis, C., Barnes, T. R., Nelson, H. E., Tanner, S., Weatherley, L., Owen, A. M., \& Robbins, T. W. (1997). Frontal-striatal cognitive deficits in patients with chronic schizophrenia. Brain $120, \quad$ 823-1843.

Schatz, J. (1998). Cognitive processing, efficiency in schizophrenia: Generalized vs domain specific deficits. Sohizophrenta Research, 30, $41-49$.

Shallice, T. Burgess, P. W, \& Fith, C. D. ("991). Can the neuropsychological case-study approach be applied to schizophrenia? Psychological Medicine, 21,661-673.

Strauss, M. E. (1993). Relations of symptoms to cognitive deficits in schizophrenia. Schizophrenia Bulletin, $19,215-231$.

Weinberger, D. R. (1987). Implications of nomal brain development for the pathogenesis of schizophrenia. Apohnes of General Psychiativy, 44, 660-669.

Weinberger, D. R., Aloia, M. S, Goldberg, T. E., \& Berman, K. F. (1994). The frontal lobes and schizophrenia. Jownal of Newropsychioly and Clinical Neurosciences, $6,419-427$.

Wilson, B. A., Alderman, N., Burgess, P. W., Emslie, H. E, \& Evans, J. J. (1996). Behcrvioural Assessment of the Dysexecutive Symdrome. Bury St Edmunds, England: Thames Valley Test Company. 


\title{
Cognitive deficits in schizophrenia
}

\author{
A short review of previous studies
}

In the neurocognitive perspective of schizophrenia, neurobiological abnormalities lead to disturbances in basic cognitive processes which in turn lead to the various signs and symptoms of the disorder. Accordingly, numerous studies have yielded evidence for a broad range of deficits in patients with schizophrenia. Yet, it appeared that adding more and more deficits to this list did not contribute significantly to the elucidation of the disorder. Therefore, recent studies have tried to move beyond this generalized impairment to search for specific disturbances of cognitive processes. These deficits may have potential to explain the range of cognitive and behavioral disorders in schizophrenia. In addition, they may provide clues to the nature of the brain abnormalities that are implicated. The following review is not meant to be a comprehensive overview of this research, but instead focuses on illustrative types of deficits in the domains that are consistently mentioned as being compromised in schizophrenia, namely, attention, memory, and executive functions. A dysfunction of working memory is discussed as a possible central factor in the cognitive impairment in schizophrenia.

\section{Attention}

Attention is a multifactorial construct which includes focused and sustained attention as well as the ability to shift (Allen et al., 1997). Sustained attention has received particular attention in schizophrenia research. A widely used test is the Continuous Performance Test (CPT), in which stimuli, usually letters or digits, are presented briefly one at a titne in a random order (Addington \& Addington, 1997, Nuechterlein, Buchsbaum \& Dawson, 1994; Van den Bosch, Rombouts \& van Asma, 1996). The subject has to respond when a certain target stimulus appears. Patients with schizophrenia usually display reduced sensitivity on the CPT, both on simple tasks and on conditions with additional perceptual or memory load (Nelson, Sax \& Strakowski, 1998a; Nuechterlein et al., 1994). Deficits of sustained attention may contribute to other cognitive deficits, including visual and verbal memory (Chen et al., 1997).

The ability to shift and to focus can be assessed with the Trail Making Test (TMT; Reitan, 
1958), and the Stroop Color-Word Test (SCWT; Stroop, 1935). Both tests require the shifting of mental set and the suppression of irrelevant responses to conform to changing task demand. Part B of the TMT requires the tracking of both numbers and letters and the continuous shifting between both concepts. The SCWT has an interference component which requires the subject to inhibit an automatic response (word reading) in favor of a less salient aspect (color naming). Impaired performance of patients with schizophrenia as compared to healthy controls on TMT and SCWT has been demonstrated repeatedly (e.g., Barch \& Carter, 1998, Everett, Laplante \& Thomas, 1989, Liddle \& Morris, 1991), both in neuroleptically naive and in previously treated patients (Saykin et al., 1994).

\section{Memory}

Memory impairment in patients with schizophrenia has been reported in several studies (Landro, 1994; McKenna et al., 1990; Saykin et al., 1991). A recent meta-analysis of 70 studies documented a significant and wide-ranging deficit, which was not due to potential confounding factors such as medication status, age, and severity of psychopathology (Aleman, Hijman, De Haan \& Kahn, 1999). Verbal memory, including story recall and word list learning, seems to be more severely affected than nonverbal memory (Saykin et al., 1991), although this difference was not significant in the meta-analysis by Aleman et al. (1.999). Free recall is particularly affected, (Beatty, Jocic, Monson \& Staton, 1993; Paulsen et al, 1995), indicating a deficit of retrieval of information. However, impaired recognition is sometimes observed, at least in the more severely disturbed patients (Clare, McKenna, Mortimer \& Baddeley, 1993; Landro, 1994), which suggests that consolidation of information may also be impaired. Since there is no disproportionate deficit on delayed compared to immediate recall, the rate of forgetting appears to be normal (Aleman et al., 1999).

Memory is a complex function, the breakdown of which may be due to several processes. Attempts to delineate these processes have focused on the role of attention. The results are somewhat ambiguous (see Landro, 1994, for a review). Nuechterlein and Dawson (1984) have argued that deficits in sustained and focused attention underlie the defective memory performance of patients with schizophrenia. In contrast, Kenny and Meltzer (1991) found that attention, summarized in a score derived from several attention tests, could not account for the impaired recall performance. One recent study showed that memory perfomance in schizophrenia was related to processing speed (Brebion, Amador, Smith \& Gorman, 1998), which supports the notion that processing speed may underlie the memory deficit analogous to the presumed role of speed in age differences in memory and other cognitive functions (Salthouse, 1996). 


\section{Executive functions}

The executive functions comprise capacities for volitional activity, forward planning, cognitive flexibility, and self-regulation (Lezak, 1995). The most widely used test of executive functions is the Wisconsin Card Sorting Test (WCST; Berg, 1948; Heaton, 1981). The WCST is a complex test involving concept formation, working memory, cognitive flexibility and selfregulation. A large amount of literature suggests impaired performance in schizophrenia in terms of increased numbers of perseverative errors and fewer categories achieved on this test, when compared to healthy controls (Goldberg, Torrey, Berman \& Weinberger, 1994; Haut et al., 1996; Morice, 1990; Sullivan et al., 1993). However, performance on the WCST seems to be heterogeneous (Braff et al., 1991) with poor performance restricted to a subgroup of patients characterized by the presence of other cognitive deficits (Bellini et al., 1991; Goldstein, Beers \& Shemansky, 1996), and negative symptoms, slowed reaction time and more hospitalizations (Butler, Jenkins, Sprock \& Braff, 1992). There is also some preliminary evidence for large intra-subject variability (Seidman et al., 1991), but this study used relatively small samples and so results have to be confirmed in larger samples. Given the complexity of the WCST, several studies have attempted to identify specific processes that underlie test performance. Gold et al. (1997) have suggested that working memory, assessed by a novel measure called "letter-number span", is a critical determinant of WCST performance. In the study by Rossi et al. (1997) a significant correlation between WCST perseverative errors and time spent on the interference test of the Stroop Color-Word test was observed and the authors concluded that these tests have the involvement of mental control and cognitive flexibility in common. Other authors, however, have directed attention to the unusual and strong relationship between performance on the WCST and general intellectual ability, aging, and education, which suggests that nonspecific factors account for a substantial proportion of WCST performance (Heinrichs, 1990; Stratta et al., 1993).

The Tower of London (TOL; Shallice, 1982) is a test of forward planning. The subject is presented with problems that can be resolved by decomposition into subgoals. Impaired performance on this task, reflected in fewer solutions achieved in the minimum number of steps, was reported by several studies (Morice \& Delahunty, 1996; Pantelis et al., 1997). The TOL was used as a stimulant for left mesial frontal activation in the SPECT-study by Andreasen et al. (1992). Both neuroleptically naive and nonnaive, relatively chronically ill patients, who were medication-free at the time of assessment, had a mean performance significantly below that of the control group.

It has been difficult to develop satisfactory methods for demonstrating and quantifying executive functions, because the structured nature of most neuropsychological examinations gives the patient unsufficient opportunity to make use of these functions (Lezak, 1982). Moreover, the standard tests tend to focus on individual components of executive functioning. Yet, what 
is impalired in patients with impaired executive functions, is the ability to initiate, integrate, and monitor the use of these components (Shallice \& Burgess, 1991). Patients with gross difficulties in daily life may therefore perform within normal limits on the standard executive tests. Recently, a test battery has been developed, with the aim of being able to predict which everyday problems would arise as a result of impaired executive functioning. The Behavioural Assessment of the Dysexecutive Syndrone (BADS; Wilson, Alderman, Burgess, Emslie \& Evans, 1996; Krabbendam \& Kalf, 1997) presents the subject with a series of unstructured tasks that are designed to reflect daily life situations. A recent study suggested that the BADS can indeed identify executive deficits in schizophrenia (Evans, Chua, McKenna \& Wilson, 1997).

\section{Working memory}

Attempts to delineate a key dysfunction in the broad cognitive impairment in schizophrenia have focused on the construct of working memory, the type of memory that is active and relevant only for a short period of time and is defined in content and duration by the action it subserves (Fleming et al., 1997; Fuster, 1989; Goldman Rakic, 1994). Working memory accounts for the abillity to guide behavior by cognitive representations in the face of varying degrees of distraction, and thus to base behavior on thoughts and intentions rather than on direct stimulation. Fuster (1989) has distinguished three functions of working memory, a retrospective function or action memory, a prospective function or preparatory set, and control of interference. Several aspects of the impaired performance of patients with schizophrenia described above can be understood as a breakdown in one of these functions. For example, the Wisconsin Card Sorting Task is sensitive to a failure of retrospective memory, as it requires the temporal retention of information for current intentional behavior (Goldman Rakic, 1994). Failure of the prospective memory function is evident on tasks that require internal programming without aid of external cues, for example the Tower of London (Shallice, 1982). Control of interference can be observed on tests requiring inhibition of inappropriate responses, for example the Stroop Color-Word Test (Liddlle \& Morris, 1991).

\section{Symptoms and cognitive deficits}

Attempts to relate the cognitive deficits in schizophrenia to particular symptoms or subtypes have yielded inconsistent results. There is some evidence that the positive and negative dimensions are related to distinct patterns of deficits, positive symptoms being associated with auditory processing deficits, and negative symptoms with visual/motor and planning dysfuntions (Berman et al., 1997; Strauss, 1993). Further, a substantial number of studies have found that cognitive deficits are associated with negative symptoms, but not with positive symp- 
toms (Capleton, 1996; Hawkins et al., 1997; Liddle \& Morris, 1991; Voruganti, Heslegrave \& Awad, 1997). Some studies have documented a relation between cognitive deficits and symptoms of disorganization (Liddle \& Morris, 1991; Van der Does, Dingemans, Linszen, Nugter \& Scholte, 1996). It has also been suggested that the cognitive deficits are secondary to a motivational deficit in schizophrenia (Schmand, Kuipers, Van der Gaag, Bosveld et al., 1994). Finally, several other studies have found that cognitive deficits are independent from both negative and positive symptoms (Dalby, Williams, Dickson \& Yuen, 1994; Goldberg \& Weinberger, 1996). In accordance with this, longitudinal studies have indicated that the deficits persist during clinical remission (Cantor Graae, Warkentin \& Nilsson, 1995; Goldberg et al, 1993; Nopoulos, Flashman, Flaum, Arndt \& Andreasen, 1994; Nuechterlein, Dawson \& Green, 1994). Likewise, subtle cognitive deficits may occur in individuals who have an increased risk for developing schizophrenia, but who are not ill themselves, namely biological relatives of patients with schizophrenia (see Kremen et al., 1994, for a review). Taken together, these results suggest that the cognitive impairment is at least to some extent independent from the symptoms of schizophrenia.

\section{Medication and cognitive deficits}

Several methodological and ethical problems complicate the assessment of the effects of antipsychotic medication on cognition. For example, discontimuation or delay of drug treatment to study the course of cognitive functioning is often not advisable. Nevertheless, several lines of evidence suggest that the effects of antipsychotic medication on cognitive functioning are minor. First, neuroleptically naive patients with schizophrenia had a similar pattern of cognitive deficits as did previously treated patients (Saykin et al., 1994). Also, frontal hypoactivity was present in a group of neuroleptically naive patients (Andreasen et al,, 1997). In another study, a substantial dose-reduction of antipsychotic medication did not have marked effects on cognitive functioning (Seidman et al., 1993). Further, Allen et al. (1997) found that chronic haloperidol treatment did not affect the structure of attentional deficits in patients with schizophrenia. In contrast to what has been found in healthy individuals ( $K$ ing, 1994), there may even be a slight positive effect of antipsychotic medication on attention in patients with schizophrenia (Goldberg \& Weinberger, 1996). This is particularly the case with the atypical antipsychotics like clozapine and risperidone (Hoff et al., 1996; Meyer Lindenberg et al., 1997; Stip \& Lussier, 1996). Yet, some other functions, particularly memory, were found to deteriorate slightly after treatment with clozapine, an effect which is often ascribed to the anticholinergic properties of this drug (Goldberg et al., 1993; Hoffet al., 1996). 


\section{Brain abnormalities and cognitive deficits}

Imaging studies suggest that subtle structural pathology contributes to the development of schizophrenia. On the basis of CT sean- and MRI-studies, there is convincing evidence for a decrease in overall brain wolume and enlargement of the lateral ventricles in schizophrenia (Chua \& McKenna, 1995; Lawrie \& Abukmeil, 1998). Further, a meta-analysis of 18 studies indicated a bilateral volumetric reduction of the hippocampus and more tentatively of the amygdala (Nelson, Saykin, Flashman \& Riordan, 1998b). Volume reductions have also been observed in the thalamus (Andreasen et al., 1994a) and in areas of the prefrontal cortex, although the average magnitude of differences between patients and controls is modest (Andreasen et al., 1994b; Goldman Rakic \& Selemon, 1997; Zakzanis \& Heinrichs, 1999). Functional neuroimaging studies have yielded evidence for hypoactivity in the prefrontal areas, particularly in relation to negative symptoms (Andreasen et al., 1997; Wolkin et al., 1992). In studies of patients at rest, the evidence for this hypofrontality is rather inconsistent, but more robust results have been obtained under conditions of cognitive task activation (Carter et al., 1998; Chua \& McKenna, 1995; Weinberger \& Berman, 1996; Zakzanis \& Heinrichs, 1999).

The brain abnormalities are believed to reflect an early disorder of brain development, which occurs long before the illness is clinically manifest (Murray \& Lewis, 1987; Weinberger, 1987). Neurobiological findings, such as the absence of gliosis and the static nature of the structural abnormalities are more consistent with a developmental disorder then with a neurodegenerative process during adult life. In particular the evidence of cytoarchitectural disorganization of the cortex is consistent with a defect in cortical development during the second trimester of gestation, which may implicate a failure of neuronal migration in the entorhinal cortex (Weiniberger, "19y3). A'bnormải migration woulia "iead to aberrant patterns of corticali connections, which can account for the diffuse neurobiological abnormalities in schizophrenia (Bullmore, Frangou \& Murray, 1997).

Findings concerning the relationships between cognitive performance and structural parameters have been inconsistent. Cognitive impairment was not related to temporal lobe volume in some studies (e.g., DeLisi et al., 1995; Seidman et al., 1994), whereas another study found a correlation between performance on several tasks and the volumes of the parahippocampal gyrus and the posterior superior temporal gyrus (Nestor et al., 1993). In a study involving monozygotic twin pairs, Goldberg and colleagues (1994) reported a strong association between the volume of the left hippocampus and a parameter of verbal memory in the affected twin. Significant inverse relationships between the volumes of specific prefrontal areas and indices of memory, attention, and executive functions have also been reported (Baaré et al., 1999; Seidman et al., 1994). In the study by Seidman et al., reduction in the volume of the left dorsolateral prefrontal cortex was significantly associated with worse performance on 
measures of set-shifting, abstract reasoning, and visual and verbal memory. Smaller right dorsolateral prefrontal cortex was significantly correlated with a measure of vigilance. Baare et all. reported significant correlation betweens smaller left and right prefrontal gray matter volumes and impaired performance on tasks of verbal and visual memory and semantic fluency.

In sum, patients with schizzophrenia may have specific deficits in several cognitive domains, notably, attention, memory, and executive functions. The cognitive deficits are to a large extent independent from current psychiatric symptomatology and they cannot be completely ascribed to the effects of medication. Although it is not clear which brain abnormalities are associated with the cognitive impairment, there is converging evidence for involvement of frontal and temporolimbic structures. In an attempt to delineate the key cognitive dysfunction, current cognitive research has focused on the concept of working menory. A dysfunction of working memory seems to have much potential to explain the range of cognitive abnormalities associated with schizophrenia. 


\section{References}

Addington, $J_{*}$ \& Addington, D. (1997), Attentional vulnerability indicators im schizophrenia and bipolar disorder: Schizophrenia Research, 23, 197-204.

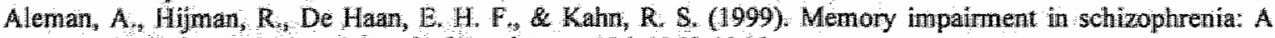
meta-analyws. American Jow hat of Psychatry, 156, 1358-1366.

Allen, D. W, Gilbertson; M. W wan Kammen, D. P., Kelley, M. E, Gurklis, J. A., Jr, \& Barry, E I. (1997). Chronic haloperidol treatment does not affect structure of attention in schizophrenia. Schizophrenia Resiearch, $25,53-6 \%$.

Andreasen, N. C., And, S., Swayze, V. N., Cizadlo, T, Flaum, M., OLeary, D., Ehrhard, J. C., \& Yuh, W. T. (1994a). Thalamic abnormalities in schizophrenia visualized through magnetic resonance image averaging. Sclence, 260, 294-298:

Andreasen, N, C., Flashman, L L Flaum, M, Andt, S, Swayze, W. N., Oleary, D. S., Ehrhardt, J. C., \& Yuh, W. T. (1994b). Regional brain abnormalities in schizophrenia measured with magnetic resonance imaging. $J A M A 1,272,1763-1769$.

Andreasen, $N_{,} C_{\text {. }}$ O'Leary, D. S., Flaum, M., Nopoulos, P., Watkins, G. L., Boles Ponto, L. L., H Hichwa, R. D. (1997). Hypofrontality in schizophrenia: Distributed dysfunctional circuits in neuroleptic-naive patients. Lancet, 349, 1730-17334.

Andreasen, N. C., Rezai, K., Alliger, R., Swayze, V. W. d., Flaum, M., Kürchner, P., Cohen, G., \& O'Leary, D. S. (1992). Hypofrontality in treuroleptic-naive patients and in patients with chronic schizophrenia. Assessment with xenoi 133 single-photon emission computed tomography and the Tower of London. Archives of General Psychiairy, 49, 943-958.

Baare, W. F. C.y Hulshoff Pol, H. E., Hijman, R., Mali, W. P. T., Viergever, M. A., \& Kahn, R. S. (1999). Volumetric analysis of frontal lobe regions in schizophrenia: Relation to cognitive function and symptomatology. Bhological Psychiary, 45, 1597-1605.

Barch, D. M., Carter, C. S. (1998). Selective attention in schizophrenia: Relationship to verbal working memory. Schizophrenta Research, 33, 53-61.

Beatty, W. W. Jocic, Z., Monson, N., \& Staton, R. D. (1993). Memory and frontal lobe dysfunction in schizophremir and schizoaffectiwe disorder. Journal of Nervows and Mewtal Disease, 181, 448-453.

Bellini, L., Abbruzzese, M., Gambini, O., Rossi, A., Stratta, P., \& Scarone, S. (1991). Frontal and callosial meuropsychological performances in schizophrenia. Further evidence of possible attention and mnesic dysfunctions Schizophrenia Research, 5, 115-121.

Berg. E. A. (1948), A simple objective technique for measuring flexibility in thinking. Journal of General Psychology, 39, 15-22,

Berman, 1., Viegner, B., Merson, A., Allan, E., Pappas, D., \& Green, A. I. (1997). Differential relationships between positive and negative symptoms and neuropsychological deficits in schizophrenia. Schizophrenia Research, 25,1-10.

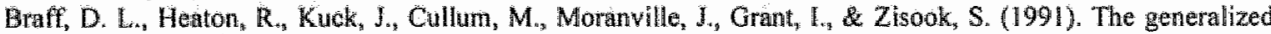
patten of neuropsychological deficits in outpatients with chronic schizophremia with heterogeneous Wisconsin Card Sorting Test results. Arohiwes of General Psychatry, $48,891-898$.

Brebion, G., Amador, X., Smith, M. J. \& Gorman, J. M. (1998). Memory impaiment and schizophrenia: The rolle of processing speed. Schizophrewa Research, 30,31-39.

Bullmore, E. T., Frangou, S. Murray. R. M. (1997). The dysplastic net hypothesis: An integration of cevelopmental and dysconnectivity theories of schizoplurenia. Schizophenta Resecrech, 28, 143-156.

Butler, R. W. Jenkins, M. A., Sprock, J., Braff, D. L. (1992). Wisconsin Card Sorting Test deficits in chronic paranoid schizophrenu. Evidence for a relatively discrete subgroup? Schizophrenia Research, 7.169 176.

Cantor Grage, E., Warkentin, S., N Nilsson, A. (1995). Neuropsychological assessment of schizophrenic patients dirirg a psychotic episode: Persistent cognitive deficit? Acta Psychiatrica Scandinavica, $9 I^{2} 283$. 288.

Capleton, R. A. (1996). Cognitive function in schizophrenia: Association with negative and positive symptons. Psychological Reports, 78, 123-128.

Carter, C. S., Perlstein, W., Ganguli, R., Brar, J, Mintum, M., \& Coluen, J. D. (1998). Functional hypofrontality and working memory dysfunction in schizophrenia. Americam Jowrwal af Psychiary, 155, 1285-1287.

Chen, E. Y., Lam, L. C., Cher, R. Y., Nguyen, D. G., Chan, C. K., \& Witkins, A. J. (1997). Neuropsychological correlates of sustained attertion in schizophrenia. Schizophrenia Research, 24, 299-310.

Chua, S. E , Mckenna, P. J. (1995). Schizophrenia a brain disease? A critical review of structural and functional cetebral abnormality in the disorder. British Jounal of Psychiary, 166, 563-582. 
Clare, L., McKenna, P. J., Mortimer, A. M., \& Baddeley, A. D. (1993). Memory in schizophrenia What is impaired and what is preserwed? Neuropsychologia, 31, 1225-1241.

Dalby, J. T., Williams, R., Dickson, $R$, Y Yuen, $O$. (1994). Cognitive decline in schizophrenic patients: Relationship to other symptoms. Journal of Psychiatry and Neuroscience, 19, 381-382.

DeLisi, L. E., Tew, W., Xie, S., Hoff, A. L., Sakuma, M., Kushner, M., Lee, G., Shedlack, K., Smith, A. M., \& Grimson, R. (1995). A prospective follow-up study of brain morphology and cognition in firstepisode schizophrenic patients: Preliminary findings. Biological Psychiatry, 38, 349-360.

Evans, J. J., Chua, S. E., McKenna, P. J., \& Wilson, B. A. (1997). Assessment of the dysexecutive syndrome in schizophrenia. Psyehological Medicine, 27,635-646.

Everett, J., Laplante, L., \& Thomas, J. (1989). The selective attention deficit in schizophrenia: Limited resources or cognitive fatigue? Journal of Nervous and Mental Disease, 177, 735-738.

Fleming, K., Goldberg, T. E., Binks, S., Randolph, C., Gold, J. M., \& Weinberger, D. R. (1997). Visuospatial working memory in patients with schizophrenia. Biological Psychiatry, 41, 43-49.

Fuster, J. M. (1989). The prefrontal corfex. (2nd ed.). New York: Raven.

Gold, J. M., Carpenter, C., Randolph, C., Goldberg, T. E., \& Weinberger, D. R. (1997). Auditory working memory and Wisconsin Card Sorting Test performance in schizophrenia. Archives of General Psychiarry, 54, 159-165.

Goldberg, T. E., Greenberg, R. D., Griffin, S. J., Gold, J. M., Kleinman, J. E., Pickar, D., Schulz; S. C., \& Weinberger, D. R. (1993). The effect of clozapine on cognition and psychiatric symptoms in patients with schizophrenia. British Jourmal of Psychiaty, 162, 43-48.

Goldberg, T. E., Torrey, E. F., Berman, K. F., \& Weinberger, D. R. (1994). Relations between neuropsyclological performance and brain morphological and physiological measures in monozygotic twins discordant for schizophrenia. Psychiarry Research, 55,51-61.

Goldberg, T. E., \& Weinberger, D. R. (1996). Effects of neuroleptic medications on the cogmition of patients with schizophrenia: A review of recent studies. Journal of Clinical Psychiatry, 57 (suppl 9), 62-65.

Goldman Rakic, P. S. (1994), Working memory dysfunction in schizophrenia. Journal of Neuropsychiatry and Clinical Neurosciences $6,348-357$.

Goldman Rakic, P. S., \& Selemon, L. D. (1997). Functional and anatomical aspects of prefrontal pathology in schizophrenia. Schizophrenia Bulletin, 23, 437-458.

Goldstein, G., Beers, S. R., \& Shemansky, W. J. (1996). Neuropsychological differences between schizophrenic patients with heterogeneous Wisconsin Card Sorting Test performance. Schizophrenia Research, 2l, 13-18 .

Haut, M. W., Cahill, J., Cutlip, W. D., Stewenson, J. M., Makela, E. H., \& Bloomfield, S. M. (1996). On the nature of Wisconsin Card Sorting Test performance in schizophrenia. Psychiatry Research, 65, 15-22.

Hawkins, K. A., Hoffman, R. E., Quinlan, D. M., Rakfeldt, J., Docherty, N. M., \& Sledge, W. H. (1997). Cognition, negative symptoms, and diagnosis: A comparison of schizophrenic, bipolar, and control samples. Journal of Neuropsychiatry and Climical Newrosciences, 9, 81-89.

Heaton, R. K. (1981). A manual for the Wisconsin Card Sorting Test. Odessa: Psychological Assessment Resources.

Heinrichs, R. W. (1990). Variables associated with Wisconsin Card Sorting Test performance in neuropsychiatric patients referred for assessment. Neuropsychiatry, Neuropsychology, and Behovioral Neurology, 3, 107 112

Hoff, A. L., Faustman, W. O. Wieneke, M., Espinoza, S., Costa, M., Wolkowitz, O., \& Csemansky, J. G. (1996). The effects of clozapine on symptom reduction, neurocognitive function, and clinical management in treatment-refractory state hospital schizophrenic in patients. Neuropsychopharmacology, 15, 361-369.

Kenny, J. T., \& Meltzer, H. Y. (1991). Attention and higher order cortical functions in schizophrenia. Journal of Neuropsychiatry and Clinical Neurosciences, 3, 269-275.

King. D. J. (1994). Psychomotor impairment and cognitive disturbances induced by neuroleptics. Acra Psychiatrica Scandinawica, 89 (suppl 380), 53-58.

Krabbendam, L., \& Kalff, A. C. (1997). The Behavioural Assessmemt of the Dysexecutive Syndrome - Dutch version. Lisse, the Netherlands: Swets \& Zeitlinger.

Kremen, W. S., Seidman, L. J., Pepple, J. R, Lyons, M. J., Tsuang, M. T., \& Faraone, S. V. (1994), Neuropsychological risk indicators for schizophrenia: A review of family studies. Schizophrenia Bulletin, 20, 103. 119.

Landro, N. I. (1994). Memory function in schizophrenia. Acta Psychiatrica Scandinavica, 90 (suppl 384), 87. 94.

Lawrie, S. M., \& Abukmeil, S. S. (1998). Brain abnomality in schizophrenia. British Journal of Psychiatry, $172,110-120$.

Lezak, M. D. (1982). The problem of assessing executive functions. International Journal of Psychology, 17, 281-297. 
Lezaik, M. D. (1995). Newapopychological assessment. (Grd ed.). New York, Oxford: Oxford Uniwersity Press:

Liddle, P. F., \& Morris, D. L. (1991). Schizophrenic syndromes and frontal lobe performance. British Journal of Psychiatry, 158, 340-345.

McKenna, P. J., Tamlyn; D., Lund, C. E., Mortimer, A. M., Hammond, S., Baddeley, A. D. (1990), Amnesic syndrome in schizophrenta: Psychological Medicine, 20, 967-972.

Meyer Lindenberg, $A_{\text {w. }}$ Gruppe, $H$, Bauer, U, Lis, $S_{4,}$ Krieger, S., Gallhofer, B. (1997). Improvement of cognitive function in schizophrenic patients receiving clozapine or zotepine: Results from a double-blind study. Pharmacopsychiatry, 30,35-42.

Morice, R. (1990) "Cogmitive inflexibility and prefrontal dysfunction in schizophrenia and mania. British Jowrinal of Psychiatry, $157,50-54$.

Morice, R., \& Delahunty, A. (1996). Frontal/executive impairments in schizophrenia. Schizophrenia Bulletin, $22,125-137$.

Murray, R. M., \& Lewis, S. W. (1987). Is schizophrenia a neurodevelopmental disorder? British Medical Jownal, $295,681-682$.

Nelson, E. B., Sax, K.W., Strakowski, S. M. (1998a). Attentional performance in patients with psychotic and noipsychotic majou depression and schizophrenia. American Journal of Psychiarry, 155, 137-139.

Nelson, M. D., Saykin, A. J., Flashman, L. A. \& Riordan, H. J. (1998b). Hippocampal volume reduction in schizophirenta as assessed by magnetic resonance imaging. Archives of General Pychiatry, 55, 433-440.

Nestor, P. G., Shenton, M. E., McCarley, R. W., Haimson, J., Smith, R. S., ODonnell, B., Kimble, M., Kikinis, R., \& Jolesz, F. A. (1993). Neuropsychological correlates of MRI temporal lobe abnormalities in schizophrenia. American Journal of Psychiatry, 150, 1849-1855.

Nopoulos, P., Flashman, L., Flaum, M., Arndt, S., \& Andreasen, N. (1994). Stability of cognitive functioning early in the course of schizophrenia. Schizophremia Research, 14, 29-37.

Nuechterlein, K. H., Buchsbaum, M. S., \& Dawson, M. E. (1994). Neuropsychological vulnerability to schizophrenia. In A. S. David \& J. C. Cutting (Eds,), The neuropsycholagy of schizophrenia. Hove: Lawrence Erlbaum Associates.

Nuechterlein, K. H.o \& Dawson, M. E. (1984). Information processing and attention in the development of schizophrenic disorders. Schizophrenia Bulletin, 10, 160-203.

Nuechterlein, K. H., Dawson, M. E., \& Green, M. F. (1994). Informatiom-processing abnormalities as neuropsychological vulnerability indicators to schizophrenia. Acta Psychiatrica Scandinavica, 90 (suppl 384), 7179 .

Pantelis, C., Barnes, T. R., Nelson, H. E., Tanner, S., Weatherley, L., Owen, A. M., \& Robbins, T. W. (1997). Frontal-striatal cognitive deficits in patients with chronic schizophrenia. Braim, 120, 1823-1843.

Paulsen, J. S., Heaton, R. K., Sadek, J. R., Perr, W., Delis, D. C., Braff, D., Kuck, J., Zisook, S., \& Jeste, D. V. (1995). The nature of learning and memory impairments in schizophrenia. Journal of the International Neuropsychological Society, 1, 88-99.

Reitan, R. M. (1958). Validity of the Trail Making Test as an indication of organic brain damage. Perceptual and Motor Skills, $8,271-276$.

Rossi ${ }_{11}$ A., Daneluzzo, E. Mattei, P., Bustini, M., Casacchia, M., \& Stratta, P. (1997). Wisconsin card sorting test and Stroop test performance in schizophrenia: A shared construct. Neuroscience Letters, 226, 87-90.

Salthouse, T. A. (1996). The processing-speed theory of adult age differences in cognition. Psychalogical Review, 103, $403-428$.

Saykin, A. I., Gur, R. C, Gur, R. E., Mozley, P. D., Mozley, L. H., Resnick, S. M., Kester, D. B., \& Stafiniak, P. (1991): Neuropsychological function in schizophrenia. Selective impairment in memory and learning. Archives of General Psychiary, 48, 618-624.

Saykin, A. J., Shtasel, D. L., Gur, R. E., Kester, D. B., Mozley, L. H., Stafiniak, P., \& Gur, R. C. (1994). Neuropsychological deficits in neuroleptic naive patients with first-episode schizophrenia. Archives of General Psychiatry, 51, 124-131.

Schmand, $B_{n,}$ Kuipers, T., Van der Gaag, M., Bosweld, J., et al. (1994). Cognitive disorders and negative symptoms as correlates of motivational deficits in psychotic patients. Psychological Medicine, 24, 869-884.

Seidman, L. J., Pepple, J. R., Faraone, S. V., Kremen, W. S., Cassens, G., McCarley, R. W., \& Tsuang, M. T. (1991). Wisconsin Card Sorting Test performance over time in schizophrenia. Preliminary evidence from clinical follow-up and neuroleptic reduction studies. Schizophrenia Research, 5, 233-242.

Seidman, L. J., Pepple, J. R., Faraone, S. V., Kremen, W. S., Green, A. I., Brown, W. A., \& Tsuang, M. T. (1993). Neuropsychological performance in chronic schizophrenia in response to neuroleptic dose reduction. Biological Psychiatry, 33, 575-584.

Seidman, L. J., Yurgelun Todd, D., Kremen, W. S., Woods, B. T., Goldstein, J. M., Faraone, S. V., \& Tsuang, M. T. (1994). Rellationship of prefrontal and temporal lobe MRI measures to neuropsychological performance in chronic schizophrenia. Biological Psychiatry, 35, 235-246. 
Shallice, T. (1982). Specific impaiments of planning. Philosophical Transwations of the Royal Saciety of Londom. Series B: Biological Sciences, 298, 199-209.

Shallice, T., \& Burgess, P. W. (1991). Deficits in strategy application following frontal lobe damage in man. Brain, $114,727-741$.

Stip, E., Lussier, L. (1996). The effect of risperidone on cognition in patients with schizophrenia Camadian Journal of Psychiatry, 41 (suppl 2), S35-40.

Stratta, P., Rossi, A., Mancini, F, Cupillari, M., Mattei, P.s \& Casacchia, M. (1993). Wisconsin Card Sorting Test performance and educational level in schizophrenic and control samples. Neuropsychiatry, Neuropsychology, and Behovioral Nezurology, 6, 149-153.

Strauss, M. E. (1993). Relations of symptoms to cognitive deficits in schizophrenia. Sehizophremia Bulletin, 19, $215-231$.

Stroop, J. R. (1935). Studies of interference in serial verbal reactions. Journal of Experimental Psychology, 18, $643-662$.

Sullivan, E. V., Mathalon, D. H., Zipursky, Z. B., Kersteen-Tucker, Z., Knight, R. T., \& Pfefferbaum, A. (1993). Factors of the Wisconsin Card Sorting Test as measures of frontal-lobe function in schizophrenia and in chronic alcoholism. Psychiatry Research, 46, 175-199.

Van den Bosch, R. J., Rombouts, R. P., \& van Asma, M. J. (1996). What deternines contimuous performance task performance? Schizophrenia Bwlletin, 22, 643-651.

Van der Does, A. J., Dingemans, P. M., Linszen, D. H., Nugter, M. A., \& Scholte, W. F. (1996). Symptoms, cognitive and social functioning in recent-onset schizophrenia: A longitudinal study. Schizophrenio Research, 19,61-71.

Voruganti, L. N., Heslegrave, R. J., \& Awad, A. G. (1997). Neurocognitive correlates of positive and negative syndromes in schizophrenia. Canadian Journal of Psychiarry, 42, 1066-1071.

Weinberger, D. R. (1987). Implications of normal brain development for the pathogenesis of schizophrenia. Archives of General Psychiatry, $44,660-669$.

Weinberger, D. R. (1995). Schizophrenia as a neurodevelopmental disorder. In S. R. Hirsch \& D. R. Weimberger (Eds.), Schizophrenia, (pp. 293-323). Oxford: Blackwell Science.

Weinberger, D. R., \& Berman, K. F. (1996). Prefrontal function in schizophrenia: Confounds and controversies. Philosophical Transaction of the Royal Saciety of London, 35I, 1495-1503.

Wilson, B. A., Alderman, N., Burgess, P. W., Emslie, H. E., \& Evans, J. J. (1996). Behawioural Assesswnent of the Dysexecutive Syndrome. Bury St Edmunds, England: Thames Valley Test Company.

Wolkin, A., Sanfilipo, M., Wolf, A. P., Angrist, B., Brodie, J. D., \& Rotrosen, J. (1992). Negatiwe symptoms and hypofrontality in chronic schizophrenia. Archives of General Psychiatry, 49, 959-965.

Zakzanis, K. K., \& Heinrichs, R. W. (1999). Schizophrenia and the frontal brain: A quantative review. Jourmal of the International Neuropsychological Society, 5, 556-566. 


\title{
The role of processing speed in memory performance in patients with schizophrenia
}

\begin{abstract}
This study investigated whether memory deficits in schizophrenia can be accounted for by a decrease in processing speed, analogous to the assumed mediating role of processing speed in age differences in memory. Thirty patients with schizophrenia and 30 healthy controls were administered tests of verbal memory, sensorimotor speed, general processing speed, and attentional span. The patients performed significantly worse than the controls on all tests. Hierarchical multiple regression analyses indicated that general speed could account for a substantial part of the group differences in immediate recall $(77 \%)$. The effect of speed on memory remained significant after correction for genemal intelligence and attentional span. Cognitiwe instead of sensorimotor aspects of speed were responsible for the effect on memory. Iit is concluded that general speed of processing is an important determinant of memory performance in schizophrenia.
\end{abstract}

1L. Krabbendan, J. Jolles, M.M.A. Derix, J.wan Os. Based on the Maastricht Psychosis Study (MAPS, J. wan Os et al.) 


\section{Introduction}

Memory impaiments in schizophrenia are increasingly considered to be a primary neuropsychological feature of the disorder, rather than being secondary to symptomatology, psychoactive medication or general decline (Clare, McKenna, Mortimer \& Baddeley, 1993; Landro, 1994; Saykin et al., 1991). Attempts to delineate the cognitive processes that can account for this memory impairment have focused on the role of attention. The results are somewhat ambiguous (see Landro, 1994, for a review). Nuechterlein and Dawson (1984) have argued that deficits in sustained and focused attention underlie the defective memory performance of patients with schizophrenia. In contrast, Kenny and Meltzer (1991) found that attention, summarized in a score derived from several attention tests, could not account for the impaired. recallperformance.

In cognitive aging research, the hypothesis that age differences in memory and other cognitive functions can be ascribed to reduced speed of information processing has received much support (Salthouse, 1996). Few studies have explicitly investigated the impact of slowness on other functions in schizophrenia, despite the fact that mental slowness is a robust correlate of schizophrenia (Braff, 1993; Schatz, 1998). Indeed, one recent study showed that memory perfomance in schizophrenia was related to processing speed, supporting the notion that processing speed might underlie the memory deficit (Brébion, Amador, Smith \& Gorman, 1998).

The mediating role of processing speed can be investigated by using statistical control measures, i.e., hierarchical multiple regression analysis (Salthouse, 1996). Using this method, many studies have shown that the age-related variance in cognition is substantially reduced after controlling for speed (e.g., Bryan \& Luszcz, 1996; Salthouse, 1993). The aim of the present study was (i) to investigate whether memory deficits in schizophrenia can be accounted for by a decrease in processing speed and (ii) whether the influence of processing speed can be ascribed to sensorimotor or cognitive aspects of speed. The memory impairment in schizophrenia encompasses multiple aspects of memory, for example, semantic memory (Chen, Wilkins \& McKenna, 1994), working memory (Goldman Rakic, 1994), source memory (Stirling, Hellewell \& Quraishi, 1998), and episodic memory (Clare et al., 1993). In this study, we focused on recall from episodic memory.

\section{Methods}

\section{Subjects}

Thirty patients with schizophrenia and 30 healthy controls participated in the study. The diagnosis was made by the computer program OPCRIT (McGuffin, Farmer \& Harvey, 1991), 
on the basis of current and lifetime recordled symptomatology. The OPCRIT program generates diagnoses of a range of operational systems for schizophrenia. For this study, we used the DSM III-R diagnosis (American Psychiatric Association, 1987). Patients were necruited from the social psychiatric service of the Regional Institute for Ambulant Mental Health Care (RIAGG), Maastricht, and the ambulatory clinic of the psychiatric hospital Vijverdal, Maastricht, the Netherlands. All patients were in remission or in partial remission defined as not in need of hospital admission. The control subjects were recruited from the general population through random mailings in the local area from a listing of all eligible individuals in the general population. None of the controls had a history of psychotic illness and none of them used psychotropic medication. Subject characteristics are shown in Table 1. Patients and controls were matched for age, sex, and educational level. Educational level was measured on an 8-point scale, ranging from primary school to university degree (De Bie, 1987). The mean total score of the patient group on the Brief Psychiatric Rating Scale (BPRS; Overall \& Gortham, 1962) was $40.9(\mathrm{SD}=10.8)$.

Inclusion criteria were (i) age 20 to 60 years, (ii) sulficient command of the Dutch language to understand instructions and informed consent, (iii) normal results on a physical examination, ECG, and laboratory tests. Exclusion criteria were (i) endocrine, cardiovascular, or brain disease, (ii) use of allcohol in excess of five standard units per day, (iii) weekly use of illicit drugs, and (iv) history of head injury with loss of consciousness. Written informed consent was obtained from all subjects.

Table 1. Subject characteristics

\begin{tabular}{|c|c|c|c|c|c|c|}
\hline & \multicolumn{2}{|c|}{$\begin{array}{l}\text { Patient } \\
(\mathrm{N}=30)\end{array}$} & \multicolumn{2}{|c|}{$\begin{array}{l}\text { Contral } \\
(\mathrm{N}=30)\end{array}$} & \multirow[b]{2}{*}{ t-walue } & \multirow[b]{2}{*}{$\mathrm{p}$} \\
\hline & Mean & (SD) & Mean & (SD) & & \\
\hline age & 33.6 & $(7.0)$ & 36.5 & $(7.9)$ & 1.47 & 0.15 \\
\hline $\operatorname{sex}(M / F)$ & $16 / 14$ & & $15 / 15$ & & 0.071 & 0.80 \\
\hline level of education 2 & 3.9 & $(1.6)$ & 4.0 & $(1.5)$ & 0.34 & 0.74 \\
\hline IQ score & 102.5 & (13.2) & 115.3 & $(10.8)$ & 4.11 & 0.00 \\
\hline Brief Psychiatric Rating Scale & 40.9 & $(10.8)$ & 25.7 & (2.6) & 7.36 & 0.00 \\
\hline age at onset ${ }^{3}$ & 22.8 & $(6.3)$ & - & & & \\
\hline
\end{tabular}

TChi-square test

2 measured on ary 8-poimt scalle, ranging from primary schoof to university degrete

3 based an age at which first psychiatric symptoms emerged

\section{Neuropsychological assessment}

The neuropsychological assessment comprised tests of memory, sensorimotor speed, general speed of information processing, and attentional span. The Auditory Verbal Learning Task (AVLT; Brand \& Jolles, 1985) was used to evaluate retrieval from episodic memory (total 
immediate recall as well as delayed recall). To assess sensorimotor speed, a simple paper-and pencil task was used which requires subjects to cross out small circles arranged in a larger circle (the basic version of the Coneept Shifting Test, CST; Houx, Vreeling \& Jolles, 1991). To assess general speed of information processing the Letter Digit Substitution Test (LDST) was used, which is a modified version of the Symbol Digit Modalities Test (Smith, 1968). The Digit Span backward from the Wechsler Adult Intelligence Scale (Wechsler, 1955) was used as a measure of attentionall span (Lezak, 1995, p. 357-368). To obtain a measure of general intelligence the shortened form of a widely used Dutch intelligence test, the Groningen Intelligence Test (GIT; Luteijn \& van der Ploeg, 1983) was used. This test yields results that are comparable to those of the Wechsler Adult Intelligence Scale (Wechsler, 1955). Three subtests have proven to be a good approximation of fullscale IQ (Luteijn \& wan der Ploeg, 1983).

\section{Statistical analysis}

All statistical analyses were performed using SPSS for Macintosh, version 6.1 (SPSS, Inc. Chicago). Differences in subject characteristics were analysed using Student $t$-tests for independent samples. Cognitive task performance in the patient group and the control group was analysed in a between-group design using multivariate analysis of variance (MANOVA) with age and sex as a covariate. The dependent variables were AVLT total immediate recall, AVLT delayed recall, sensorimotor speed (basic version of CST), general speed (LDST), and attentional span (Digit span backward).

Associations between the cognitive measures were computed for each group separately by using Pearson correlation coefficients. To assess the extent to which sensorimotor speed, LDST, Digit span, and general intelligence mediated the memory deficits associated with schizophrenia, a series of hierarchical multiple regression analyses were performed. Separate analyses were done for total immediate recall and delayed recall.

\section{Results}

Prior to analysis, the cognitive variables were examined for fit between their distributions and the assumptions of multivariate analysis, using the SPSS Frequencies and Regression programs. By using the Mahalanobis distance, one case from the patient group was identified as a multivariate outlier with $\mathrm{p}<0.001$ and was excluded from further analysis.

The groups differed significantly with regard to IQ score $(t=4.11, \mathrm{p}=0.00$, Table 1$)$. MANOVA indicated a significant multivariate main effect of group on cognitive performance $(F=6,89, \mathrm{df}=5,50, \mathrm{p}=0.00$, Pillai's test). Univariate $F$-tests indicated that the performance of the patients with schi-zophrenia was significantly worse than that of the control subjects 
on all cognitive measures ( $\mathrm{p}$-values were in the range from 0.00 to 0.01 ). Mean (SD) performance scores were as follows: on the AVLT total recall (number of words) 48.9 (8.0) and 55.3 (6.9) for the patient group and the control group respectively; on the AVLT delayed recall $10.1(2.4)$ and $12.0(2.3)$ respectively; for sensorimotor speed (seconds) $6.3(2.2)$ and $5.3(0.9)$ respectively; for LDST (total number completed) 48.0 (11.1) and 60.0 (8.6) respectively; and for Digit Span backward (maximum span) 5.6 (1.6) for the patient group and 7.4 (2.1) for the control group.

Table 2. Pearson correlations per group between toral recall, delayed recall, LDST, sensorimotor speed, and Digit Span backward

\begin{tabular}{|c|c|c|c|c|c|}
\hline Measurel & $\begin{array}{l}\text { Total } \\
\text { recall }\end{array}$ & $\begin{array}{l}\text { Delayed } \\
\text { recall }\end{array}$ & LDST & $\begin{array}{l}\text { Sensorimotor } \\
\text { speed }\end{array}$ & Digit Span backward \\
\hline $\begin{array}{l}\text { Patient }(\mathrm{N}=29) \\
\text { Delayed recall }\end{array}$ & $.78^{* * *}$ & - & & & \\
\hline LDST & $.48^{* *}$ & .22 & - & & \\
\hline Sensorimotor speed & .32 & .08 & $.58^{* *}$ & - & \\
\hline Digit Span backward & 31 & .25 & $.40^{*}$ & $.51^{* *}$ & - \\
\hline IQscore & .31 & .05 & $.49^{* *}$ & $.50^{\text {*t* }}$ & $.46^{\prime \prime}$ \\
\hline \multicolumn{6}{|l|}{ Control $(\mathrm{N}=30)$} \\
\hline Delayedrecall & $.77^{* * *}$ & - & & & \\
\hline LDST & .16 & .15 & - & & \\
\hline Sensorimotor speed & .07 & .08 & $.40^{*}$ & - & \\
\hline Digit Span backward & .31 & .28 & $.38^{*}$ & .13 & - \\
\hline IQ score & .09 & .01 & .34 & .35 & 32 \\
\hline
\end{tabular}

I All cognitive measures were coded such that higher scores meanit better performance

$" p<.05, * p<.01 ; * * 0<001$

Pearson correlations between cognitive measures are shown in Table 2 . In the patilent group, total recall correlated significantly with LDST performance, such that better recall was associated with faster performance. Also, significant correlations were found between total immediate recall and delayed recall, and between LDST, sensorimotor speed, Digit Span backward, and IQ score. In the control group, total immediate recall correlated significantly with delayed recall, and LDST correlated with sensorimotor speed and with Digit Span.

Results from the hierarchical multiple regression analyses for total immediate recall are shown in Table 3. Group accounted for $16.1 \%$ of the variance in recall performance when entered first (Equation 1, Table 3). Equation 2 shows that LDST significantly contributed to the variance in recall $(22.7 \%)$ and reduced the variance in recall predicted by group (16.1\%) to a nonsignificant $3.7 \%$ a reduction of $77 \%$. Equation 3 shows that sensorimotor speed contributed $8.4 \%$ to the variance when entered first and reduced the group-related wariance to $11.3 \%$ (a 
$30 \%$ reduction). Digit Span backward accounted for $19.2 \%$ of the variance in recall when entered first and reduced the variance in recall predicted by group to $5.5 \%$ (a $66 \%$ reduction, Equation 4). Equation 5 shows that after sensorimotor speed was partialled out, LDST contimued to contribute significantly to the variance $(14.4 \%)$. Entering sensorimotor speed into the equation along with LDST reduced the group-related variance to $3.7 \%$, which was a similar reduction in variance to that found after LDST was entered alone (Equation 2). After Digit Span backward was entered, LDST contributed a significant $8.6 \%$ to the variance in recall (a $62 \%$ reduction relative to the explained variance unique by LDST, Equations 2 and 6). After controlling for LDST, Digit Span backward contributed 5.1\% to the variance in recall (a $73 \%$ reduction relative to the explained variance unique by Digit Span backward, Equations 4 and 7). After IQ score was entered, LDST contributed a significant $10.8 \%$ to the variance in recall (a $52 \%$ reduction relative to the unique explained variance of LDST, Equations 2 and 8 ). After controlling for LDST, the IQ score no longer significantly contributed to the variance in recall $6.8 \%$, a $94 \%$ reduction relative to the explained variance unique by IQ score). Age did not contribute significantly to the variance in recall and, when entered first, did not change the pattern of results (data not shown).

Table 3. Hierarchical multiple regression analyses predicting total word recall from group, LDST, sensorimotor speed, and Digit Span $(n=59)$

\begin{tabular}{lllll}
\hline Equation & Variable & $R^{2}$ & $R^{2}$ change & $F$ change \\
\hline 1 & Group & .161 & - & $10.96^{* *}$ \\
2 & LDST & .227 & - & $16.76^{* * *}$ \\
3 & Group & .264 & .03 .7 & 2.79 \\
3 & Sensorimotor speed & .084 & - & $5.19^{*}$ \\
4 & Group & .197 & .113 & $7.90^{* * *}$ \\
& Digit Span backward & .192 & - & $13.55^{* * *}$ \\
5 & Group & .247 & .055 & $4.08^{*}$ \\
& Sensorimotor speed & .084 & - & $5.19^{*}$ \\
& LDST & .228 & .144 & $10.47^{* * *}$ \\
6 & Group & .265 & .037 & 2.75 \\
& Digit Span backward & .192 & - & $13.55^{* * *}$ \\
& LDST & .279 & .086 & $6.71^{*}$ \\
7 & Group & .298 & .020 & 1.54 \\
& LDST & .227 & - & $16.76^{* * *}$ \\
& Digit Span backward & .279 & .051 & 3.98 \\
8 & Group & .298 & .020 & 1.54 \\
& IQscore & .132 & - & $8.73^{* *}$ \\
& LDST & .241 & .108 & $7.97^{* *}$ \\
& Group & .269 & .028 & 2.07 \\
\hline
\end{tabular}

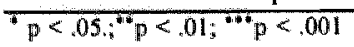


The hierarchical multiple regression analyses for delayed recall indicated that group accounted for a significant $14.3 \%$ of variance in delayed recall performance $(F=9.3, \mathrm{df}=1,57, \mathrm{p}<$ $0.05)$. The strongest predictor of delayed recall was total immediate recall $\left(R^{2}=65.2 \%, F=\right.$ $106.8, \mathrm{df}=1,57, \mathrm{p}=0.00$ ). Entering this variable in the equation reduced the variance associated with the other predictors to a non-significant level (data not shown), including the variance associated with group (a $98 \%$ reduction).

\section{Discussion}

The results show that general processing speed can account for a large part (77\%) of the group differences in immediate recall performance. This suggests that the impaired recall performance in schizophrenia is mediated by speed of processing. The effect of slowing on recall apparently does not primarily reflect sensory and motor aspects, but involves speed measures that require more cognitive operations. That is, after the effect of sensorimotor speed had been controlled for, general speed continued to contribute significantly to the variance in recall performance. Moreover, sensorimotor speed did not account for more of the group-related variance than that accounted for by general speed.

Attentional span contributed significantly to the group differences in immediate recall performance. In fact, general speed and attentional span had a large proportion of the group related variance in recall performance in common. However, general speed explained more of the variance in recall performance predicted by attentional span than vice versa. Furthermore, significant residual variance associated with general speed was found after the variance associated with attentional span had been controlled for. This suggests that the measure of general speed reflects a more basic construct with regard to memory deficits in schizophrenia than the measure of attentional span. This interpretation is consistent with the pattern of results obtained by Brebion et al. (1998) that correlations between speed of processing and memory remained significant after partialling out attentional span. Although general intelligence accounted for a significant part of recall performance, this contribution almost disappeared when the analysis controlled for general processing speed. In contrast, processing speed still contributed to variance in recall after general intelligence was partialled out. This is further support for a basic role of processing speed in recall performance.

These studies should, of course, be repeated. Whereas we used only one measure for each cognitive construct, with the exception of IQ score, future research should develop composite scores of cognitive functioning, because these may offer more robust measures of the cognitive domains. A limitation of our approach is that we cannot rule out that some other factor influenced both the speed of processing and the memory performance, for example, motivation. 
A.lso, it is possible that mental slowing is not the critical mediating factor. Instead, it may only be the manner in which differences in processing efficiency become manifest in speed tests, while some other factor determines these differences in efficiency. Both alternative explanations cannot be ruled out on the basiss of the present results. These limitations notwithistanding, the results do indicate that a measure of general speed reflects a basic determinant of memory performance, more so than the measures of both attentional span and general intelligence.

Salthouse (1996) has hypothesized a mechanism for the mediating role of processing speed in age differences in memory performance. The basic idea of this "simultaneity mechanism" is that a slower speed of information processing results in a loss of the products of early processing by the time that later processing is completed. As a consequence, relevant information may no longer be available when it is needed. Such a disturbance would affect not only memo$r y$, but also a range of other cognitive functions. However, the internal dynamics implicated in this simultaneity mechanism can obviously not be directly inferred from performance on speed tests: Still, the simultaneity mechanism is attractive, not least because the way this mechanism accounts for the role of processing speed is closely linked with the idea of a breakdown of working memory. Working memory refers to the active maintenance of task-relevant information. Several authors have expressed the view that a dysfunction of working memory is central to the cognitive impairment associated with schizophrenia (Goldman Rakic, 1994; Servan-Schreiber, Cohen \& Steingard, 1996). In the next chapter, we report a study, in which we administered tests that involve aspects of working memory, starting with processing speed as the basic parameter of performance, to patients with schizophrenia. 


\section{References}

American Psychiatric Association (1987). Diagnastic and statistic manual of mental disorders. (3rd rev. ed.). Washington, D.C.: author.

Braff, D. L. (1993). Information processing and attention dysfunctions in schizophrenia. Sohizophremia Bulletin, 19. $233-259$.

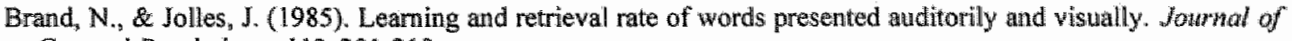
Genteral Psychology, $112,201-210$.

Brébion, G., Amador, X., Smith, M. J., \& Gorman, J. M. (1998). Memory impaiment and schizophrenia: The role of processing speed. Schizophrenia Research, 30, 31-39.

Bryan, J., \& Luszcz, M. A. (1996). Speed of information processing as a mediator between age and free-recall performance. Psychology and Aging, 11, 3-9.

Chen, E. Y., Wilkins, A. J., \& MCKenna, P. J. (1994). Semantic mernory is both impaired and anomalous in schizophrenia. Psychological Medicine, 24, 193-202.

Clare, L., McKenna, P. J., Mortimer, A. M., \& Baddeley, A. D. (1993). Memory in schizophrenia: What is impaired and what is preserved? Neuropsychologia, 31. 1225-1241.

De Bie, S. E. (1987). Standaardvragen 1987: Voarstellen woor uniformering van vraagstellingen naar achtergrondkenmerken en interviews [Standand questions 1987: Proposal for uniformization of questions ragarding backgrownd variables and interviews7. (2nd ed.). Leiden: Leiden University Press.

Goldman Rakic, P. S. (1994). Working memory dysfunction in schizophrenia. Joumal of Neuropsychiatry and Clinical Neurosciences, 6. 348-357.

Houx, P. J., Vreeling, F. W., \& Jolles, J. (1991). Age-associated cognitive decline is related to biological lifeevents. In K. Iqbal, D. R. C. McLachlan, B. Winblad, \& H. M. Wisniewski (Eds.), Alzheiner's Disease: Basic mechanisms, diagnosis and therapiatic strategies, (pp. 353-359). Chichester: Willey.

Kenny, J. T., \&eltzer, H. Y. (1991). Attention and higher order cortical functions in schizophrenia. Journal of Neuropsychiatry and Clinical Newrosciences, 3, 269-275.

Landre, N. I. (1994). Memory function in schizophrenia. Acta Psychiatrica Scandinavica "90, (suppl 384), 8794 .

Lezak, M. D. (1995). Neuropsychological assessment. (3rd ed.). Oxford: Oxford University Press.

Luteijn, F, \& van der Ploeg, F. A. E. (1983). Handleiding Groninger Intelligentietest (GIT) [Manual Groningen Intelligence Test]. Lisse, The Netherlands: Swets \& Zeitlinger.

McGuffin, P., Farmer, A. E., \& Harvey, 1. (1991). A poly-diagnostic application of operational criteria in psychotic illness: Development and reliability of the OPCRIT program. Archives of General Psychiatry; 48, $764-770$.

Nuechterlein, K. H., \& Dawson, M. E. (1984). Information processing and attention in the development of schizophrenic disorders. Schizophrenia Bulletin, 10, 160-203.

Overall, J. E., \& Gorham, D. E. (1962). The brief psychiatric rating scale. Psychological Reports, 10, 799-812.

Salthouse, T. A. (1993). Speed mediation of adult age differences in cognition. Developmental Psychology, 29 , $722-738$

Salthouse, T. A. (1996). The processing-speed theory of adult age differences in cognition. psychological Review, 103, 403-428.

Saykin, A. J., Gur, R. C., Gur, R. E., Mozley, P. D., Mozley, L. H., Resnick, S. M., Kester, D. B., \& Stafiniak, P. (1991). Neuropsychological function in schizophrenia. Selective impairment in memory and learning. Archives of Geweral Psychiatry, 48, 618-624.

Schatz, J. (1998). Cognitive procesing efficiency in schizophrenia: Generalized vs domain specific deficits. Schizophrenia Research, 30, 41-49.

Servan-Schreiber, D., Cohen, J. D., \& Steingard, S. (1996). Schizophrenic deficits in the processing of context. A test of a theoretical model. Archives of General Psychiatry $53.1105-1112$.

Smith, A. (1968). The Symbol Digit Modalities Test; A neuropsychological test for enomic sereening of learning and other cerebral disorders. Learning Disorders, 36, 83-91.

Stirling, J. D., Hellewell, J. S. E., \& Quraishi, N. (1998). Self-monitoring dysfunction and the schizophrenic symptoms of alien control. Psychological Medicine, 28,675-683.

Wechsier, D. (1955). Wechsler Adult Intelligence Scale. Manual. New York: Psychological Corporation. 
$\therefore \quad \therefore \quad \therefore \quad \therefore$ 


\title{
Cognitive performance and MRI temporal lobe volume in patients with schizophrenia ${ }^{1}$
}

\begin{abstract}
The aim of the study was to identify whether specific deficits in cognitive processing are present in schizophrenia and whether these are related to the volume of temporal and limbic structures. Twenty-seven outpatients with schizophrenia were compared with 19 matched controls. In comparison to the controls, patients performed complex tasks disproportionately worse than they performed tasks tapping simple functions. No group differences were found with regard to temporal and limbic volume. Volume of the parahippocampal gyrus was correlated with cognitive performance. The findings are interpreted as evidence for a dysfunction in the maintenance of task-relevant information and the inhibition of irrelevant information.
\end{abstract}

1L. Krabbendam, M.M.A. Derix, A. Honig, E. Vuurman, R. Havermans, J. Wilmink, J. Jolles. Cognitive performance and MRI temporal lobe volume in patients with schizophrenia. Journal of Neuropsychiatry and Cfinical Neturosciences, in press 


\section{Introduction}

Cognitive deficits in schizophrenia may occur across a range of cognitive domains (Blanchard \& Neale, 1994, Braff et al., 1991). The widespread nature of the cognitive deficit has raised debate concerning the question whether there is a specific or a general cognitive deficit. The domains that are frequently mentioned to be differentially compromised include attention (Braff, 1993; Mirsky, Yardley, Jones, Walsh \& Kendler, 1995), memory (Goldberg, Torrey, Berman \& Weinberger, 1994; McKenna et al., 1990), and executive functions (Evans, Chua, McKenna \& Wilson, 1997; Morice \& Delahunty, 1996). However, most neuropsychological tests involve several cognitive functions, and so it is particularly difficult to identify specific cognitive deficits on the basis of impaired test performance.

The present study explored the issue of specific versus general cognitive deficits by using tests of information processing speed. Cognitive speed in schizophrenia may be characterized by general slowing, or, alternatively, by a disproportionate increase in time for certain types of information processing. To investigate the degree to which the slowing of cognitive speed is generalized, two timed tests were used, that involve subtasks with increasing complexity. The extra time needed to complete the more demanding subtasks is regarded as a function of the particular task variation. These tests were the Concept Shifting Test (CST; Houx, Vreeling \& Jolles, 1991), and the Stroop Color-Word Test (SCWT; Stroop, 1935).

An advantage of both the SCWT and the CST is that they are relatively short, which reduces the possibility that fatigue may affect performance. If cognitive fatigue would still occur, performance of the second part of the test would be slower than for the first part. The present study examined the possible effects of test duration on the SCWT by comparing speed of performance for the first and the second parts of the test, according to the procedure described by Klein et al. (Klein, Ponds, Houx \& Jolles, 1997).

The cognitive deficits of patients with schizophrenia have been linked to disturbed frontal lobe functioning (Frith, 1996; Gold, Goldberg \& Weinberger, 1992; Goldman-Rakic, 1994), and to changes in the temporal and limbic structures connected to the frontal areas (Bilder \& Szeszko, 1996; Chua \& MoKenna, 1995; Nelson, Saykin, Flashman \& Riordan, 1998). Bilder and Szeszko argue that a "medial frontolimbic" deficit is central to schizophrenia, which might be marked by a decrease in the volume of the anterior hippocampus. The present study investigated whether cognitive processing in schizophrenia is characterized by a general or by a specific slowing and whether this deficit can be related to abnomalities of the temporal and limbic structures. 


\section{Methods}

\section{Subjects}

Twenty-seven patients with schizophrenia and 19 healthy controls were included in the study. The patients were recruited from the social psychiatric service of the Regional Institute for Ambulant Mental Health Care (RIAGG), Maastricht, the psychiatric department of the University Hospital, Maastricht, and the ambulatory clinic of the psychiatric hospital Vijverdal, Maastricht, the Netherlands. Patients were diagnosed according to DSM-IV criteria (American Psychiatric Association, 1994) by a psychiatrist. The diagnosis was werified according to the Composite International Diagnostic Interview (CIDI; World Health Organization, 1993) by a trained neuropsychologist or psychiatrist. Subject characteristics are shown in Table 1. Patients and controls were matched for age, sex, and educational level. Educational level was measured on an 8-point scale, ranging from primary school to higher vocational training and university degree (De Bie, 1987). All subjects were right-handed. All patients were outpatients at the time of the assessment and all received stable doses of antipsychotic medication (mean dose in chlorpromazine equivalents $=335 \mathrm{mg} ; \mathrm{SD}=212$ ). Mean total score in the patient group on the Brief Psychiatric Rating Scale (BPRS; Overall \& Gotham, 1962) was $44.4(\mathrm{SD}=10.5)$. The groups did not differ with regard to height (Table 1$)$. This variable was incorporated in the analysis as a covariate to correct for differences in brain size.

The control subjects were recruited via newspaper advertisements. None of the controls had a history of psychiatric illness or evidence for brain pathology or other major physical pathology, and none of them used psychotropic medication. Exclusion criteria for both groups were a history of CNS illness, head injury that caused unconsciousness for more than 1 hour; any other serious physical illness, and heavy alcohol or drug abuse over the last 12 months. Written informed consent was obtained from all participants.

Table 1. Subject characteristics

\begin{tabular}{|c|c|c|c|c|c|c|}
\hline & \multicolumn{2}{|l|}{$\begin{array}{l}\text { Patient } \\
(n=27)\end{array}$} & \multicolumn{2}{|c|}{$\begin{array}{l}\text { Control } \\
(n=19)\end{array}$} & \multirow[b]{2}{*}{ t-walue } & \multirow[b]{2}{*}{$\mathbf{p}$} \\
\hline & Mean & (SD) & Mean & (SD) & & \\
\hline age & 35.9 & $(8.6)$ & 36.0 & $(9.4)$ & 0.04 & 0.97 \\
\hline $\operatorname{sex}(M / F)$ & $13 / 14$ & & $9 / 10$ & & 0.001 & 0.96 \\
\hline level of education 2 & 4.4 & $(1.4)$ & 4.5 & (1.3) & 0.20 & 0.84 \\
\hline IQ score & 99.5 & (14.1) & 115.6 & $(11.5)$ & 4.21 & 0.00 \\
\hline Height $(\mathrm{cm})$ & 175.4 & $(7.0)$ & 176.6 & (7.4) & 0.57 & 0.57 \\
\hline
\end{tabular}

Thi-square test

2 measured on an 8-point scale, ranging from primary school to university degree 


\section{Procedure}

The following cognitive tesits were administered to all subjects: Stroop Color-Word Test (SCWT; Stroop; 1935), Concept Shifting Test (CST; Houx et al., 1991), and three subtests of the Groningen Intelligence Test (GIT, Luteijn \& wan der Ploeg, 1983).

The Stroop Color-Word Test involves three subtests which display a hundred stimuli each: color names, colored patches, and color names printed in incongruously colored ink (cards I-III respectively). Subjects are requested to read (card I) or to name colors (card II and III) as fast as possible Performance on card III is largely determined by the time needed to discard irrelevant but wery salient information (verbal), in favor of a less obvious aspect (color naming). During the course of the task speed of performance is recorded after 4 lines and after 10 lines, which makes it possible to investigate time-on-task effects:

The Concept Shifting Test is a modified wersion of the Trail Making Test (TMT; Reitan, 1958), designed to avoid several methodological problems with the TMT. It consists of three parts. On each test sheet, 16 small circles are grouped in a larger circle. In the smaller circles the test items (numbers in part $\mathrm{A}$, letters in part $\mathrm{B}$, or both numbers and letters in part C) appear in a fixed random order. Subjects are requested to cross out the items in the right order as fast as possible. Part $\mathrm{C}$ requires the subject to alternatively cross out digits and letters, so performance on this part reflect concept shifting ability.

To obtain a reliable measure of formal intelligence three subtasks of the Groningen Intelligence Test (GIT) were administered. The GIT is a test of general intelligence that is used in the Netherlands as much as the Wechsler Adult Intelligence Scale (Wechsler, 1955).

\section{Magnetic Resonance Imaging}

Images were acquired on a 1.5 Tesla MRI scanner (Philips ACS, Eindhoven, the Netherlands). The scanning protocol consisted of a coronal inversion recovery T1-weighted sequence, perpendicular to the long axis of the hippocampus with a slice thickness of $3 \mathrm{~mm}$ (TR/TI/TE $2100 / 300 / 18 \mathrm{msec}_{\text {, matrix }} 256 \times 179$, field of view $23 \mathrm{~cm}, \mathrm{NEX} 2$, turbofactor 3 , acquisition time $6: 53$ minutes). The images were transferred to a standalone SUN workstation and examined with a semi-automatic Gyroview software package containing a manual contouring function (Gyroview-HR software version 2.1-2 1994, Philips Medical Systems, Eindhoven, The Netherlands). Regions of interest (ROIs) were outlined on each slice and multiplied by the slice thickness. Volumes of each ROI were derived by summing the relevant consecutive slice volumes.

ROIs were the anygdala, hippocampus, parahippocampal gyrus, and temporal lobe. Anatomic guidelines for delineation of the ROIs were established using whole brain sections and coronal serial sections (from the Laboratory of Pathological Anatomy of the University Hospital Maastricht), an anatomical atlas (Duvernoy, 1991), and previously published guidelines 
on MRI volume measurements of temporal labe structures (Bartzokis et al., 1993; Watson et al., 1992). In some slices it was difficult to distinguish between the amygdala and the hippocampus. Therefore we decided to divide the amygdala-hippocampus complex into the amygdala - anterior hippocampus and the posterior hippocampus. MRl scans were not available for two patients and two control subjects.

All measurements were done by the same rater, who was blind to diagnosis and cognitive test results. To assess reliability, scans of eight subjects were measured twice by the same rater with a period of at least 3 weeks between the two measurements. Intraclass correlation coefficients (ICC) were calculated. The reliability of the measurements of the posterior hippocampus was considered insufficient (ICC $<0.75)$ and these data were excluded from further analyses. ICCs of all other structures ranged from 0.85 to 0.98 , indicating good test-retest reliability.

\section{Statistical analysis}

All statistical analyses were performed using SPSS for Macintosh, version 6.1 (SPSS, Inc. Chicago). Performance on the SCWT and CST was analysed using multivariate analysis of variance (MANOVA). The subject's sex was incorporated as a between-subjects factor in this analysis, as well as in the analysis of the MRI-data, because of possible sex differences in schizophrenia (Castle, Sham, Wessely \& Murray, 1994). To investigate effect of test level MANOVA with a repeated measures design was performed for SCWT and CST separately, with group ( 2 levels) as the between-subjects variable and level of test difficulty (3 levels) as the within-subjects variable. Contrasts were defined to compare the first with the second level of the task and also the second with the third level.

Time-on-task effects on the SCWT part III were analysed by calculating mean time to complete a line in the first part of the test and in the second part. Speed ratios were calculated by dividing the mean time needed to complete the first part by the mean time needed to complete the second part; a score of 1 thus means that a subject performed equally well on the first half and the second half of the test. To investigate the influence of general ability on cognitive test: performance, a post hoc analysis was performed which excluded those subjects with lower than average $\mathrm{IQ}$-score.

The MRI measures were analysed using multivariate analysis of variance (MANOVA) with group and sex as between-subjects factors and laterality as a within-subjects factor. To correct for differences in brain size, height was incorporated as a covariate. Relationships between cognitive performance and MRI measures were computed for each group separately by using Pearson's correlation coefficient. All tests were two-tailed. 


\section{Results}

Multivariate analysis of variance showed significant main effects for group on the CST and SCWT $(F=2.99, d f=6,37, p=0.017$, Pillai's test $)$. No interaction was found between group and sex $(F=0.51$, df $=6,37, \mathrm{p}=0.794)$. Univariate $F$-tests revealed that group differences in speed of performance were significant for all measures $(F=5.69, \mathrm{~d} f=1,42, \mathrm{p}=0.022$ for SCWT I; $F=11.26_{*} \mathrm{df}=1,42, \mathrm{p}=0.002$ for SCWT II; $F=11.18, \mathrm{df}=1,42, \mathrm{p}=0.002$ for SCWT III $F=15.06, \mathrm{df}=1,42, \mathrm{p}=0.000$ for $\mathrm{CST} \mathrm{A} ; F=11.09, \mathrm{df}=1,42, \mathrm{p}=0.002$ for $\mathrm{CST} \mathrm{B}_{*}$ and $F=13.57, \mathrm{df}=1,42, \mathrm{p}=0.001$ for CST C). There were no differences in the number of errors made by the two groups on any test. In Figures 1 and 2 completion time is depicted as a function of subtask for SCWT and CST respectively. The interaction between group and task difficulty was significant for SCWT II vs. SCWT III $(F=7.74$, df $=1,44, p=0.008)$, but not for SCWT I ws. SCWT II $(F=1.99$, df $=1,44, \mathrm{p}=0.166)$. Similarly, a significant interaction was found between group and task difficulty for CST B vs. CST C $(F=7.00, \mathrm{df}=$ $1.44, \mathrm{p}=0.011)$, but not for CST A vs. CST B $(F=0.21, \mathrm{df}=1,44, \mathrm{p}=0.646)$.

Time-on-task effects on the SCWT III were investigated by calculating the speed ratios. Both the patients with schizophrenia and the control subjects needed relatively more time to complete the second test part, as indicated by speed ratios less than 1 (mean $=0.89 ; \mathrm{SD}=$ 0.14 for the patients with schizophrenia, and mean $=0.91 ; \mathrm{SD}=0.08$ for the controls). The effect of time on task performance did not differ between the groups, as indicated by the lack of significant interaction between group and time $(F=1.51, \mathrm{df}=1,44 \mathrm{p}=0.23)$.

In a post hoc analysis eight subjects from the schizophrenia group with lower than average IQ score $(<95)$ were excluded. This analysis yieldled similar results as the analysis with the whole group, both witli regard to the main group effect $(F=2.94, \mathrm{df}=6,31, \mathrm{p}=0.022)$, as well ass the interaction effect of group and test level for both SCWT and CST.

Multivariate analysis of variance showed no differences between the two groups in the volume of brain structures $(F=0.90, \mathrm{df}=6,32, \mathrm{p}=0.508$, Pillai's test). There was no interaction between group and $\operatorname{sex}(F=0.90, \mathrm{df}=6,32, \mathrm{p}=0.510)$, nor between group and laterality $(F=0.21, \mathrm{df}=2,39, \mathrm{p}=0.812)$. In the patient group, the volume of the left parahippocampal gyrus was inversely correlated with performance on SCWT III $(R=-0.57, p=0.004)$. Performance on the other cognitive tasks did not correlate with the volume of any of the brain regions investigated. In the control group, no significant correlations were found between brain structure volume and cognitive test performance. 
$\operatorname{time}(\sec )$

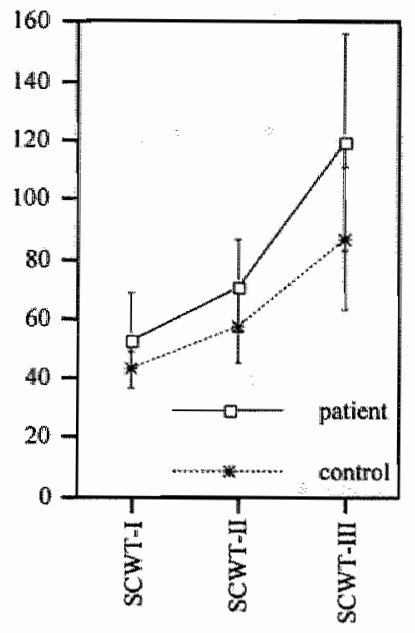

Figure 1. Performance on Stroop Color-Word Test in patients and controls time (sec)

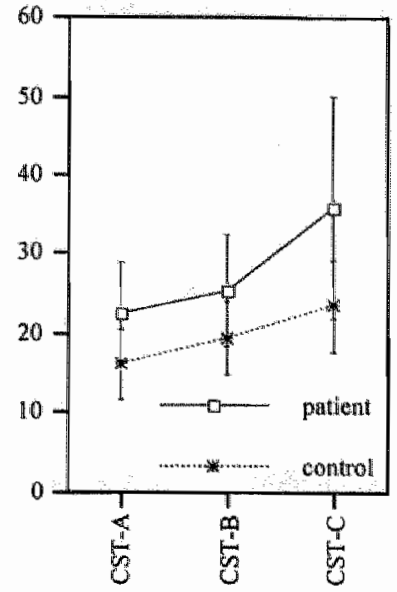

Figure 2. Performance an Concept Shifhing Test in patients and healthy controls

\section{Discussion}

This study shows that patients with schizophrenia are disproportionately slower than control subjects on complex cognitive processing tasks, above a general slowness on simple tasks. This pattern of impairment was also present in a subsample of patients who had an average or above average IQ score. Further, the impaired performance of patients with schizophrenia on the SCWT was not primarilly due to the waning of mental effort. Although a time-on-task ef fect was present, with performance being typically more rapid on the first part of the test, this was also seen in the control group.

The complex subtasks of the SCWT and the CST involve the maintaining of a certain cognitive set over time and the inhibition of inappropriate responses. The specific slowing in this type of processing is in accordance with recent proposals that the core cognitive deficit in schizophrenia is an impairment in maintaiming contextual information, or working memory, and in using that information to inhibit inappropriate responses. Using a computer simulation model of the Stroop task, Servan-Schreiber and coworkers have demonstrated that a single dis turbance to the module that is responsible for representing the context produces changes in performance similar to those observed in schizophrenia (Cohen \& Servan Schreiber, 1993; Servan-Schreiber, Cohen \& Steingard, 1996). This suggests that a deficit in the processing of context may underlie various cognitive impairments associated with this disorder. This hypo- 
thesis could be tested in future studies by examining whether deficits on tasks which involve maintenance of context can account for deficits in other cognitive domains.

Contrary to our hypothesis, the wolume of temporal and limbic structures was not smaller in subjects with schizophrenia than in control subjects. The same finding has been reported in other studies (DeLisi et al.,1995; Swayze, Andreasen, Alliger, Yuh \& Ehrhardt, 1992; Young et al, 1991). However, a recent meta-analysis of 18 studies did reveal a bilateral volumetric reduction of the hippocampus and more tentatively of the amygdala (Nelson et all., 1998). It is possible that the lack of differences in our study is related to characteristics of the patient group, such as relatively mild symptomatology. As yet, however, there is no clear evidence that temporal lobe abnormality is predominantly present in any particular subgroup of patients (Chua \& McKenna, 1995).

We found a significant association between the volume of the parahippocampal gyrus and performance on the SCWT III. A significant association between parahippocampal gyrus and cognitive performance has been reported before (Nestor et al., 1993). This result is in accordance with a disturbance in the circuitry connecting dorsolateral prefrontal and temporal and limbic areas, a network which is thought to be responsible for the active maintenance of taskrelevant information (Bilder \& Szeszko, 1996). However, in our study only one correlation between cognitive performance and brain structure volume was significant, the possibility of a chance finding thus cannot be excluded and the finding will need to be replicated.

All patients included in our study used antipsychotic medication, which may have influenced cognitive performance. Recent reviews have suggested, however, that neuroleptics have no marked negative effects on cognition (Goldberg \& Weinberger, 1996; King, 1990). Instead, performance may sometimes improve following neuroleptic treatment, possibly because patients receiving medication are more cooperative (Goldberg \& Weinberger, 1996).

The present study supports the presence of a disproportionate deficit in the complex processing of information in schizophrenia. This deficit can be explained as a dysfunction in the processing of context (Servan-Schreiber et al., 1996). It is possible that this deficit is related to a decrease in the volume of the medial temporal areas, but this finding needs to be replicated. 


\section{References}

American Psychiatric Association (1994). Diagnostic and statistic manial of mentol disorders (4th ed.). Washington, D.C.: author.

Bartzokis, $G_{2}$, Mintz, J., Marx, P., Osbom, D., Gutkind, D., Chiang, F, Phelan, K., \& Marder, S. R. (1993) Reliability of in vivo measures of hippocampus and other brain structures using MR. Magnetic Resoname Imaging $11,993-1006$.

Bilder, R. M., \& Szeszko, P. R. (1996). Structural neuro-umaging and neuropsychological inmairments. In C. Pantelis, H. E. Nelson, \& T. R. E. Bames (Eds.), Schizophrenia. A newropsychological perspective, (pp. 279.298). Chichester: Wiley.

Blanchard, J. J. \& Neale, J. M. (1994). The neuropsychological signature of schizophrenia: Generallized or differential deficit? American Journal of Psychatry, $15 I_{\text {, 40-48. }}$

Braff, D. L. (1993). Information processing and attention dysfunctions in schizophreaia. Schizophrewia Bulletin, $19,233-259$.

Braff, D. L., Heaton, R., Kuck, J., Cullum, M., Moranville, J., Grant, I., \& Zusook, S. (1991). The generalized pattern of neuropsychological deficits in outpatients with chronic schizophrenia with heterogeneous Wisconsin Card Sorting Test results. Archives of General Psychiatry, 48, 891.898

Castle, D. J., Sham, P. C. Wessely, S., Murray, R. M. (1994). The subtyping of sctizophrenin in men and women: A latent class analysis. Psychological Medicine, 24, 41-51.

Chua, S. E., \& McKenna, P. J. (1995). Schizophrenia-a brain disease? A critical review of structural and functional cerebral abnormality in the disorder. British Journal of Psychiaty, 166, 563-582.

Cohen, J. D., \& Servan Schreiber, D. (1993). A theory of dopamine function and its role in cognitive deficits in schizophrenia. Schizophrewia Bulletin, 19.85-104.

De Bie, S. E. (1987). Standaardwragen 1987: Foorstellen voor wafiormering van vraagshellingen noar achter grondkenmerken en interviews [Standard questions 1987. Proposal for uniformization of questions regarding background variables and interviews]. (2nd ed.). Leiden: Leiden University Press.

DeLisi, L. E., Tew, W., Xie, S., Hoff, A. L., Sakuma, M., Kushner, M., Lee, G. Shedlack, Ku, Smith, A. M., \& Grimson, R. (1995). A prospective follow-up study of brain norphology and cognition in firstepisode schizophrenic patients: Preliminary findings. Biological Psychiatry, 38, 349-360.

Duvernoy, H. (1991). The human brain Surface, three-dimensional sectional anatomy and MR. Vienna: Springer-Verlag.

Evans, J. J., Chua, S. E., McKenna, P. J., \& Wilson, B. A. (1997). Assessment of the dysexecutiwe syndrome in schizophrenia. Psychological Medicine, 27, 635-646.

Frith, C. (1996). Neuropsychology of schizophrenia. What are the implications of intellectual and experientia! abnormalities for the neurobiology of schizophrenia? British Medical Bulletin, 52, 618-626.

Gold, J. M., Goldberg, T. E., \& Weinberger, D. R. (1992). Prefrontal function and schizophrenic symptoms. Neuropsychiatry Newropsychology, and Behowioral Neurology, 5, 253-261.

Goldberg, T. E., Torrey, E. F., Berman, K. F. \& Weinberger, D. R. (1994). Retations between netiropsychologitcal performance and brain morphological and physiological measures in monozygotic twins discondiumb for schizophrenia. Psychialry Research, 55,51-61.

Goldberg, T. E., \&e Weinberger, D. R. (1996). Effects of neuroleptic medications on the cognition of patients with schizophrenia: A review of recent studies. Journal of Clinical Psychiatry, 57 (supp/ 9), 62-65.

Goldman-Rakic, P. S. (1994). Working memory dysfunction in schizophrenia. Jowrid of Neuropsychiary and Clinical Neurosciences, $6,348-357$.

Houx, P. J., Vreeling, F. W., \& Jolles, J. (1991). Age-associated cognnitive decline is related to biologicall lifeewents. In K. Iqbal, D. R. C. McLachlan, B. Wimblad, H. M. Wisniewski (Eds.), Alzheimer's Disease: Basic mechamisms, diagnosis and therapeutic strategies, (pp. 353-359). Chichester: Wiley.

King, D. J. (1990). The effect of neuroleptics on cognitive and psychomotor function. British Jownol of Psychiary, 157, 799-811.

Klein, M., Ponds, R. W. H. M., Houx, P. I., \& Jolles, J. (1997). Effects of test duration on age-related differences in Stroop Interference. Journal of Clinical and Experimental Neuropsychology, 18, 77.82.

Luteijn, $F_{*}$ \& van der Ploeg, F. A. E. (1983). Handleiding Groninger Intelligentietest (GIT) (Manual Groningen Intelligence Test]. Lisse, The Netherlands: Swets \& Zeitlinger.

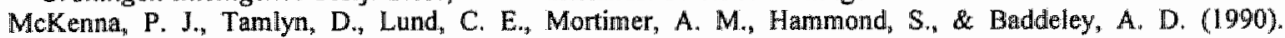
Amresic syndrome in schizophrenia. Psychological Medicine, 20, 967-972.

Mirsky, A. F., Yardley, S. L., Jones, B. P., Walsh, D., \& Kendler, K. S. (1995). Analysis of the attention deficit in schizophrenia: A study of patients and their relatives in Ireland. Jowrral of Psychiatric Resecroh. $29,23-42$. 
Morice, $\mathbb{R}$. Delahunty, A. (1996). Frontal/executive impairments in schizophrenia. Schizophrenia Bulletin. $22,125-137$.

Nelson, M. D. Saykin, A. J., Flashman, L. A., \& Riordan, H. J. (1998). Hippocampal volume reduction in schizophrenia as assessed by magnetic resonance inaging. Archives of General Psychiatry, 55, 433-440.

Nestor, P. G., Shenton, M. E, McCarley, R. W. Haimson, J, Snith, R. S., ÓDonnell, B., Kimble, M., Kikinis, R. Jolesz, F, A. (1993). Meuropsychological correlates of MRI temporal lobe abnormalities in schizophrenia. American Joumal of Psychiatry, 150, 1849-1855.

Overall, J. E, \& Gorham, D. E. (1962). The brief psychiatric rating scale, Psychological Reports, 10, 799-812.

Reitan, R. M. (1958). Validity of the Trail Making Test as an indication of organic brain damage. Perceptual and Molor skills, $8,271-276$.

Servan-Schreiber, D. Cohen, J. D., \& Steingard, S. (1996). Schizophrenie deficits in the processing of context. A test of a theoretical model. Archives of General Psychiatry, 53, 1105-1112.

Stroop, J. R. (1935). Studies of interference in serial verbal reactionis. Jourmal of Experimental Psychology, 18. 643.662 .

Swayze, V. W. d., Andreasen, N. C., Alliger, R. J., Yuh, W. T., \& Ehrhardt, J. C. (1992). Subcortical and temporal structures in affective disorder and schizophrenia: A magnetic resonance imaging study. Biological Psychlatry, $31,221-240$.

Watson, C., Andermann, F., Gloor, P, Jones-Gotman, M., Peters, T., Evans, A., Olivier, A., Melanson, D., \& Leroux, G. (1992). Anatomic basis of amygdaloid and hippocampal volume measurement by magnetic resonance imaging. Neurology, 42,1743-1750.

Wechsler, D. (1955). Wechsler Adult Intelligence Scale. Manual. New York: Psychological Corporation.

World Health Organization (1993). Composite International Diagnostic Interview (CIDI); Version I.I (R.M.W. Smeets, P.M.A.J. Dingemans, Trans.), Geneva: WHO.

Young, A. H., Blackwood, D. H., Roxborough, H., McQueen, J. K., Martin, M. J., \& Kean, D. (1991). A magnetic resonance imaging study of schizoplirenia: Brain structure and clinical symptoms. British Journol of Psychiatry, $158,158-164$. 


\title{
Cognitive performance in patients with schizophrenia and their first-degree relatives
}

\begin{abstract}
The aim of the study was to investigate the cognitive performance of patients with schizophrenia and their adult relatives in comparison to that of controls from the general population. Fifty patients with schizophrenia, 50 first-degree relatives of patients with schizophrenia, and 50 healthy controls participated in the study. The neuropsychological assessment focused on verbal memory, attentional span, speed of information processing, and cognitive flexibility. Pairivise analysis of the group differences indicated that the patients performed significantly worse than the control subjects on all measures. Compared to the controls, the relatives showed subtle deficits in memory and speed of information processing. This suggests that these cognitive deficits can be considered indicators of vulnerability to schizophrenia.
\end{abstract}




\section{Introduction}

According to the vulnerability / stress model, some individuals have a predisposition to schizophrenia that is largely determined by genetic and neurodevelopmental factors (Nuechterlein \& Dawson, 1984; Zubin \& Spring, 1977). Indicators of this vulnerability are those abnormalities that are present in patients with schizophrenia before illness onset as well as during and after psychotic episodes (Nuechterlein, Dawson \& Green, 1994). Longitudinal studies have indicated that cognitive deficits persist during clinical remission (Cantor Graae, Warkentin \& Nilsson, 1995; Goldberg et al., 1993; Nopoulos, Flashman, Flaum, Arndt \& Andreasen, 1994; Nuechterlein et al., 1994), and thus these deficits could be considered indicators of vulnerability. However, these studies differed in that some found that all cognitive deficits persisted during remission (Cantor Graae et al., 1995; Goldberg et al, 1993), whereas other studies found that certain deficits, particularly the complex attentional skills, were to some extent state dependent (Nopoulos et al., 1994; Nuechterlein et al., 1994).

In schizophrenia some degree of psychopathology persists during remission, and this may have contributed to the poor cognitive performance of subjects during remission. Likewise, negative effects of medication on performance, although presumably not very large, cannot be excluded (King, 1990). A more powerful design to identify indicators of vulnerability is therefore the study of relatives of patients with schizophrenia. First-degree biological relatives of patients with schizophrenia have a risk of developing schizophrenia about 10 times that of the general population (Kendler \& Diehl, 1993). Cognitive vulnerability indicators that are heritable should also be present in relatives, at least in those who cany the risk for schizophrenia.

There is some evidence that relatives of patients with schizophrenia exhibit subtle cognitive deficits (see Kremen et al., 1994, for a review), including impairments of attention (Harris et al, 1996), spatial working memory (Park, Holzman \& Goldman Rakic, 1995), executive functions (Goldberg et al., 1995b; Pogue-Geile, Garrett, Brunke \& Hall, 1991), and possibly verbal memory (Goldberg et al., 1995b). The aim of the present study was to investigate whether the pattern of deficits in relatives parallels that found in patients with schizophrenia. To this end, we used a comprehensive battery, focusing on the domains frequentlly mentioned to be compromised in schizophrenia. We also used two tests with subtasks of increasing difficulty (namely, Stroop Color-Word Test and Concept Shifting Test) in order to investigate effects of task difficulty on performance (cf. our previous study, Krabbendam et al., 2000). These tests involve working memory and cognitive flexibility. 


\section{Method}

\section{Subjects}

Three groups, each consisting of 50 individuals, were studied, namely patients, first-degree relatives, and controls from the general population. The diagnoses were made with the computer program OPCRIT (McGuffin, Farmer \& Harvey, 1991), which generates diagnoses of a range of operational systems for psychotic illness. For this study, we used the DSM III $R$ diagnosis (American Psychiatric Association, 1987). Most patients had a diagnosis of schizophrenia, three had a diagnosis of schizoaffective disorder and one had a diagnosis of atypical psychosis. Of the relatives, six were diagnosed as having a psychiatric disorder, namely major depression. Patients were recruited from the social psychiatric service of the Regional Institute for Ambulant Mental Health Care (RIAGG), Maastricht, and the ambulatory clinic of the psychiatric hospital Vijverdal, Maastricht, the Netherlands. Relatives were sampled via participating patients or via associations for relatives of patients with psychotic illness. The control subjects were recruited from the general population through random mailings in the local area from a listing of all eligible individuals in the general population. None of the controls had a history of psychosis or a history of psychiatric contact in a first-degree relative, and none of them used psychotropic medication.

Table 1. Means (standard deviations) and summary statistics of participant characteristics

\begin{tabular}{|c|c|c|c|c|c|c|}
\hline & $\begin{array}{l}\text { Patient } \\
(n=50)\end{array}$ & $\begin{array}{l}\text { Relative } \\
(n=50)\end{array}$ & $\begin{array}{l}\text { Controll } \\
(n=50)\end{array}$ & F & $\mathrm{p}$ & \multirow{3}{*}{$\begin{array}{l}\text { Tukey- } \\
\text { HSD test } \\
1<21\end{array}$} \\
\hline & Mean (SD) & Mean (SD) & Mean (SD) & \multicolumn{2}{|c|}{$\mathrm{df}=2,146$} & \\
\hline age & $\begin{array}{ll}31.8 & (7.5) \\
\end{array}$ & $37.6 \quad(11.3)$ & $35.6(8.8)$ & 4.96 & 0.01 & \\
\hline age range & $20.7-49.1$ & $19.3-56.1$ & $21.5-50.8$ & & & \\
\hline $\operatorname{sex}\left(M / T^{4}\right)$ & $26 / 24$ & $25 / 25$ & $25 / 25$ & & & \\
\hline level of education. & (1.4) & $(1.8)$ & $(1.7)$ & 3.12 & 0.05 & \\
\hline IQ score & $104.8(12.3)$ & $116.4(13.1)$ & $113.1(11.1)$ & 12.05 & 0.00 & 12,3 \\
\hline Brief Psychiatric Rating Scale & $41.1 \quad(10.3)$ & $28.2(5.1)$ & $25.8 \quad(2.5)$ & 57.21 & 0.00 & $1<2,3$ \\
\hline age at first psychotic symptoms & $21.9(5.8)$ & -- & -. & & & \\
\hline
\end{tabular}

11 patient, 2 relative, 3 control

Participant characteristics are shown in Table 1. Part of the patient and the control group were also involved in the study described in chapter 3. The patients were matched with the control subjects on age, but as a group they were somewhat younger than the relatives. The three groups were matched for sex and educational leve], which was measured on an 8-point scale, ranging from primary school to university degree (De Bie, 1987). The patients had a mean IQ score of 104.8 ( $\mathrm{SD}=12.3$ ), which was significantly lower than the IQ scores of the relatives and the control group. All patients were in remission or in partial remission defined as not in 
need of hospital admission. The mean total score of the patient group on the Expanded version of the Brief Psychiatric Rating Scale (BPRS; Lukoff, Nuechterlein \& Ventura, 1986; Overall \& Gorham, 1962) was $41.1(\mathrm{SD}=10.3)$. This is a 24-item scale assessing sympto matology on a series of 7-point scales. It yields a total score as well as symptom cluster scores, including Psychosis, Anxious-Depression, and Anergia.

Inelusion criteria were (i) age 18 to 60 years, (iil) sufficient command of the Dutch language to understand instructions and informed consent, (iii) normal results for a physical examination, ECG, and laboratory tests. Exclusion criteria were (i) endocrine, cardiovascular, or brain disease, (ii) use of alcohol in excess of five standard units per day, (iii) weekly use of illicit drugs, and (iv) history of head injury with loss of consciousness. Written informed consent was obtained from all subjects.

\section{Neuropsychological assessment}

The neuropsychological assessment was directed at the following cognitive domains: recall from short-term and long-term memory, attentional span, speed of information processing, and cognitive flexibility. The tests were administered to all subjects.

The Auditory Verbal Learning Task (AVLT; Brand \& Jolles, 1985) was used to evaluate retrieval from memory. The Digit Span forward and backward from the Wechsler Adult Intelligence Scale (Wechsler ${ }_{*}$ 1955) were used as measures of attentional span (Lezak, 1995, p. 357-368). As measures of speed of information processing we used the reading and color naming tasks of the Stroop Color-Word Test (SCWT; Stroop, 1935), the number tracking and letter tracking tasks of the Concept Shifting Test (CST; Houx, Vreeling \& Jolles, 1991), which is a modified version of the Trailmaking Test (Reitan, 1958), and the Letter Digit Substitution Test (LDST), which is a modified version of the Symbol Digit Modalities Test (Smith, 1968). To assess cognitive flexibility we used the interference task of the SCWT, the number/letter shifting task of the CST, and Word Fluency (Lezak, 1995). To obtain a measure of general intelligence, we used the shortened form of a widely used Dutch intelligence test, the Groningen Intelligence Test (GIT; Lutejin \& van der Ploeg, 1983). This test yields results that are comparable to those of the Wechsler Adult Intelligence Scale (Wechsler, 1955). Three subtests have proven to yield a good approximation of fullscale IQ (Luteijn \& van der Ploeg. 1983).

\section{Statistical analysis}

All statistical analyses were performed using SPSS for Macintosh, version 6.1 (SPSS, Inc, Chicago). Cognitive task performance in the patients with schizophrenia, the relatives, and the control subjects was analysed in a between-group design using multivariate analy sis of variance (MANOVA) with age as a covariate. One measure per test was used, to avoid high correla- 
tions between the dependent variables. Pairwise group comparisons were performed using one-way analysis of variance with the Tukey multiple comparison procedure. To investigate sex differences, we performed a $3 \times 2$ (group $X$ sex) MANOVA, again using one measure per test. To investigate the effect of task difficulty, MANOVA with a repeated measures design was performed for SCWT and CST separately, with group as the between-subjects variable and level of test difficulty as the within-subjects variable, analogous to a previous study (Krabbendam et al., 2000). For this analysis, a pairwise comparison was made (patient vs. control; relative vs. control). Performance on each cognitive test was converted to standard $z$-scores using the data from the control group as the reference. Correliations between cognitive performance and symptomatology (BPRS total score as well. as three factor scores) were calculated for each group separately, using Pearson's correlation coefficient.

\section{Results}

Before analysis, the cognitive variables were examined for fit between their distributions and the assumptions of multivariate analysis, using the SPSS Frequencies and Regression pro-

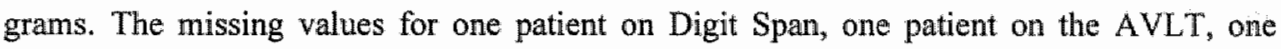
patient on the CST, and one patient on the LDST were replaced by the group mean. In five subjects (four from the patient group, one from the control group) one or two univariate outliers were found (indicated by z-scores larger than 3.29). These values were replaced by the highest group value next to the outlier. By using the Mahalanobis distance, no multivariate outliers could be identified.

The results of the MANOVA showed a significant main effect of group $(F=5.11, \mathrm{df}=$ $12,284, p=0.00$, Pillai's test). Pairwise analysis of the significant univariate group differences indicated that the patients performed significantly worse than the control subjects on all measures (see Table 2). The patients had a significantly poorer performance than the relatives on SCWT color naming and interference, on the LDST, and on Word Fluency. The relatives had a significantly poorer performance than the control subjects on AVLT short-term recall, on SCWT color reading and color naming, and on the LDST. A post hoc analysis excluding six relatives with a psychiatric diagnosis yielded essentially the same results, except for the two Digit Span tasks, which indicated significant differences between the relatives and controls (Tukey-HSD test, $p<0.05$ ), performance of the relatives being worse than that of the controls. Figure 1 depicts the performance seores converted to standard $z$-scores for the patients and the relatives, using the performance of the controls as a reference.

MANOVA indicated that no significant group $X$ sex interaction was present $(F=0.36$, $\mathrm{df}=12,280, \mathrm{p}=0.975$, Pillai's test). Univariate tests showed that there was no such interac- 
tion on any of the cognitive measures ( $\mathrm{p}$-values were in the range from 0.525 to 0.809): There was a significant main effect for sex on the verbal memory task $(F=14.37, \mathrm{df}=1,144, \mathrm{p}=$ 0.000), women performing better than men.

When the patient group and the control group were compared, the interaction between group and task difficulty was found to be significant for SCWT II and SCWT III ( $F=6.02$, df $=1,98, \mathrm{p}=0.016)$, and for CST B and CST C $(F=8.34$, df $=1,98, \mathrm{p}=0.005)$. When the relatives and the control group were compared, a significant interaction between group and task difficulty was found for CST B and CST C $(F=6.18$, df $=1,98, \mathrm{p}=0.015)$, but not for SCWT II and SCWT III $(F=0.39, \mathrm{df}=1,98, \mathrm{p}=0.535)$.

Table 2. Means (standard deviations) and F-test statistics of cognitive performance for the patients, relatives, and control group

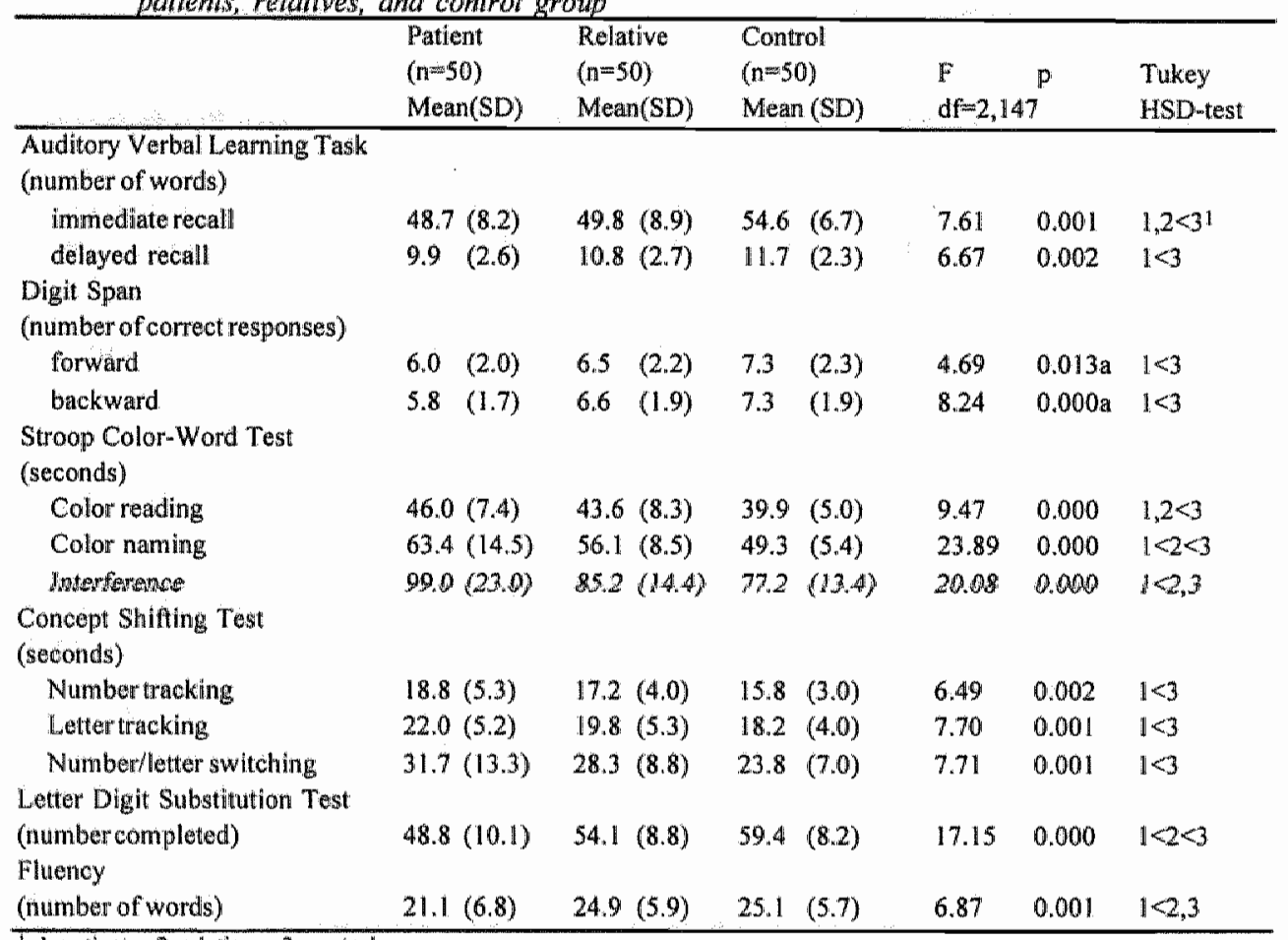

T patients; 2 relatives; 3 controls

Correlations between cognitive performance and total score on the BPRS were not significant in the patients (contations ranged from 0.02 to 0.26 ) nor in the relatives (correlations ranged from 0.03 to 0.19 ). Of the factor scores, the only significant correlation was between Anergia and Word Fluency in the patient group $(R=0.44, \mathrm{p}=0.01)$, with higher scores on Anergia being associated with poorer performance on Fluency. 
2-score

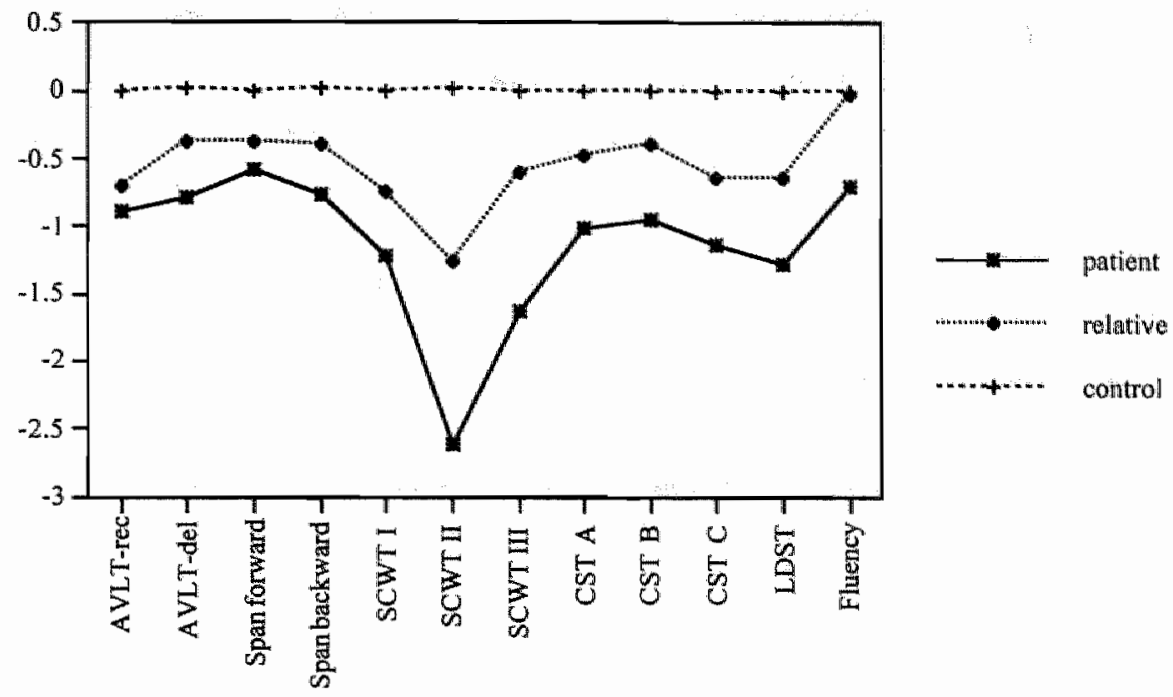

Figure $\|$. Srandardized performance scores for relatives and patients wing control group as a reference.

\section{Discussion}

The results show that the cognitive performance of first-degree relatives of patients with schizophrenia is worse than that of age- and education- matched controls from the general population. Since the control subjects were recruited through random mailings in the local area from a listing of all eligible individuals in the general population, it is unlikely that the performance differences are due to bias in the selection of controls. Performance of the relatives differed significantly from that of the controls on measures of verbal memory and speed of information processing. In fact, the performance of the relatives was somewhat worse than that of the controls in each of the cognitive domains, similar to the pattern of deficits in the patients, although less severe. These findings are con-sistent with other studies, suggesting that relatives have deficits that are qualitatively similar, but more subtle, compared to patients with schizophrenia (Faraone et al., 1995; Keefe, Silverman, Roitman, Harvey \& et al., 1994; Lyons et al., 1995). In our study, performance of the relatives was generally at the low end of average, namely less than 1 sd below the norm, which indicates that performance was in fact attenuated rather than impaired.

The cognitive profile in the relatives further parallelled that found in the patients, in that both groups had a disproportionate slowing on complex tasks involving cognitive flexibility 
and working memory, above a general slowing, although in the relatives this effect was not as robust as it was in the patients. This finding is in accordance with the view that an impairment of working memory is the core feature of the cognitive functioning in schizophrenia (Goldman Rakic, 1994; Servan-Sehreiber, Cohen \& Steingard, 1996). This impairment has been linked to disturbance of a circuitry involving at least prefrontal and temporal lobes, limbic and paralimbic structures, and the thalamus (Andreasen, 1997; Fuster, 1999; Goldman Rakic, 1994). A recent study showed that first-degree relatives of patients with schizophrenia also have volume reductions in the amygdala-hippocampal region and the thalamus compared to control subjects (Seidman et al., 1999).

By testing group $x$ sex interactions, there were no sex differences in the patients nor in the relatives. Some previous studies have suggested that male patients with schizophrenia have greater cognitive impairment than female patients (Seidman et al., 1997; Goldstein, Seidman, Santangelo Knapp, \& Tsuang, 1994), but other studies have indicated either no differences or greater abnormalities among female patients (Albus et al., 1997; Andia et al., 1995; Goldberg; Gold, Torrey \& Weinberger, 1995a). Greater abnormality in female relatives compared to male relatives was reported by Kremen et al. (1997), but this was not supported by the present study.

In contrast to the patients, the relatives did not show any change in intelligence score. Given that intelligence is a composite measure, this result is difficult to interpret in terms of specific functions. Differences between the groups with regard to educational level were only marginal. Insofar as intelligence is cllosely related to educational level, it would seem the IQ score of patients had decreased relative to that indicated by their (premorbid) educational achievements.

The results provide further support for the view that cognitive functioning is to a large extent independent from symptoms (Goldberg et al:, 1993; Nuechterlein et al., 1994). Not only were the cognitive deficits present in patients during clinical remission, there was also only one significant correlation between current symptoms and cognitive performance. Taken together with the presence of subtle deficits in the healthy relatives, the findings suggest that these cognitive deficits can be considered indicators of the cognitive vulnerability to schizophrenifa. 


\section{References}

Albus, M., Hubmann, W., Mohr, F., Scherer, J., Sobizack, N, Franz, U., Hecht, S., Bommenn, M., \& Wahlheim, C. (1997). Are there gender differences in neuropsychological perfomance in patients with firstepisode schizophrenia? Schizophrevila Research, 28, 39-50.

Andia, A. M., Zisook, S., Heaton, R. K., Hesselink, J., Jernigan, T., Kuck, J., Morganville, J., B Braff, D. L. (1995). Gender differences in schizophrenia. Journal of Nerwous and Mental Disease, 183, 522-528.

Andreasen, N. C. (1997). The role of the thalamus in schizophrenia. Canadian Journal of Psychiatry, 42,2733.

American Psychiatric Association (1987). Diagnostic and statistic manual of mental disorders. (3rd rew. ed.). Washington, D.C.". author.

Brand, N., \& Jolles, J. (1985). Learning and retrieval rate of words presented auditorily and wisually. Journal of General Psychology, $112,201-210$.

Cantor Graae, E., Warkentin, S., \& Nilsson, A. (1995). Neuropsychological assessment of schizophrenic patients during a psychotic episode: Persistent cognitive deficit? Acta Psychiarrica Scandinovica, 9I, 283288.

De Bie, S. E. (1987). Standaardvragen 1987. Voorstellen woor uniformering van wroagstellingen naar achter. grondkenmerken en interwiews [Standard questions 1987. Propasal for uniformization of questions regar. ding background variables and interviews]. (2nd ed.). Leiden: Leiden University Press.

Faraone, S. V., Seidman, L. J., Kremen, W. S., Pepple, J. R., Lyons, M. J., \& Tsuang, M. T. (1995). Neuropsychological functioning among the nonpsychotic relatives of schizophrenic patients: A diagnostic efficiency analysis. Journal of Abnornal Psychology, 104, 286-304.

Fuster, J. M. (1999). Synopsis of function and dysfunction of the frontal lobe. Acta Psychiatrica Scandinavica (stuppl 395), 101, 51-57.

Goldberg, T. E., Gold, J. M., Torrey, E. F., \& Weinberger ${ }_{i}$ D. R. (1995a). Lack of sex differences in the neuropsychological performance of patients with schizophrenia. American Journal of Psychiatry, 152, 883-888.

Goldberg, T. E., Greenberg, R. D., Griffin, S. J., Gold, J. M., Kleinman, J. E., Pickar, D., Schulz, S. C., \& Weinberger, D. R. (1993). The effect of elozapine on cogmition and psychiatric symptoms in patients with schizophrenia. British Journal of Psychiatry, 162, 43-48.

Goldberg, T. E., Torrey, E. F., Gold, J. M., Bigelow, L. B., Ragland, R. D., Taylor, E., \& Weinberger, D. R. (1995b). Genetic risk of neuropsychological impairment in schizophrenia: A study of monozygotic twins discordant and concordant for the disorder. Schizophrenia Research, 17,77-84.

Goldman Rakic, P. S. (1994). Working memory dysfunction in schizophrenia. Journal of Neuropsychiarry and Clinical Neuroscience, 6, 348-357.

Goldstein, J. M., Seidman, L. J., Santangelo, S., Knapp, P., \& Tsuang, M. T. (199.4). Are schizophrenic men at higher risk for developmental deficits than schizophrenic women? Implications for adult neuropsychological functions. Journal of Psychiatric Research, 28, 483-498.

Harris, J. G., Adler, L. E., Young, D. A., Cullum, C. M., Rilling, L. M., Cicerella, A., Intemann, P. M., Freedman, R. (1996). Neuropsychological dysfunction in parents of schizophrentics. Schizophrenia Research, $20,253-260$

Houx, P. J., Vreeling, F. W., \& Jolles, J. (1991). Age-associated cognitive declime is related to biological llifeevents. In K. Iqbal, D. R. C. MoLachlan, B. Winblad, \& H. M. Wismiewski (Eds.), Alzhaimer's Diseadse: Basic mechanisms, diagnosis and therapeutic strategles, (pp. 353-359). Chichester: Wiley.

Keefe, R. S. E., Silverman, J. M., Roitman, S. E. L., Harvey, P. D., Duncan, A.M., Alroy, D., Siever, L.J., Dawis, K.L., \& Mohs, R.C. (1994). Performance of nonpsychotic relatives of schizoplirenic patients on cognitive tests. Psychiatry Research, 53, 1-12.

Kendler, K. S. \& Diehl, S. R. (1993). The genetics of schizophrenia: A current, genetic-epidemiologic perspective. Schizophrenia Bulletin, 19, 261-285.

King, D. J. (1990). The effect of neuroleptics on cognitive and psychomotor function. British Journal of Psychiatry, 157, 799-811.

Krabbendam, $L_{n y}$ Derix, M. M. A., Honig, A., Vuurman, E. F. P. M., Havermans, A. G., Wilmink, J. T., \& Jolles, J. (2000). Performance on neurocognitive tasks in relation to MRI temporal lobe abnormalities in schizophrenic patients and normal controls. Journol of Neuropsychiarry and Clinical Neurosciences, in press.

Kremen, W. S., Goldstein, J. M., Seidman, L. J., Toomey, R., Lyons, M. J., Tsuang, M. T., \& Faraone \$ \$. V. (1997). Sex differences in neuropsychologicall function in nonpsychotic relatives of schizophrenic probands. Psychiatry Research, 66, 131-144. 


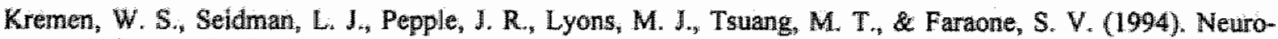
psychological risk indicalors for schizophrenia: A review of family studies; Schizophrewa Bullerin, 20, 103119.

Lexak, M. D. (1995). Newnopsychological assessment (3rd ed). New York, Oxford: Oxford University Press.

Lukoff, D. Nuechterlein, K H. \& Ventura, J. (1986). Manual for the Expanded Brief Psychiatric Rating Scale. Schizophrenta Bullerin, 12, \$94-602.

Luteljn, $\mathbb{F}_{\text {, \& }}$ van der Ploeg, $F, A$ E (1983), Handlielding Groninger Intelligentietest (GIT) (Manual Groningen Intellagence Teri. Lisse, The Wetherlands: Swets \& Zeitlinger.

Lyons, M. J., Toomey, R., Seidman, L. J., Kremen, W. S., Faraone, S. V. 2 Tsuang, M. T. (1995). Verbal learning and memory in relatives of schizophrenics: Preliminary findings. Biological Psychiatry, 37, 750. 753.

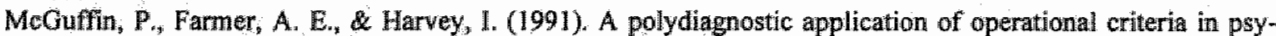
chotic illness: Development and reliability of the OPCRIT program. Archives of General Psychatry. 48 , $764-770$.

Nopoulos, P. Flashiman, L, Flaum, M., Armd, S., \& Andreasen, N. (1994). Stability of cognitive functioning early in the course of schilzophrenia. Schizophrenia Research, 14, 29-37.

Nuechterlein, K. H. Dawson, M. E. (1984). A heuristic wulnerability/stress model of schizophrenic episodes. Schizophrenia Bulletin, 10, 300-312.

Nuechterlein, K. H., Dawson, M. E., \& Green, M. F. (1994). Information processing abnomalities as neuropsychological wulnerability indicators to schizophirenda. Acta Psychiatrica Scandinavica, 90 (suppl 384). $71-79$.

Overall, J. E. \& Gorham, D. E. (1962). The brief psychiatric rating scale. Psychological Reports, 10, $799-812$.

Park, S., Holzman, P. S., \& Goldman Rakic, P. S. (1995). Spatial working memory deficits in the relatives of schizophrenic patients. Archives of General Psychiotiry, 52,821-828.

Pogue-Geile, M. F., Garret, A. H., Brunke, J. J., \& Hall, J. K. (1991). Neuropsychological impairments are increased in siblings of schizophrenic patients. [Abstract]. Schizophrenia Research, 4, 390 .

Reulan, R. M. (1958). Validity of the Trail Making Test as an indication of organic brain damage. Perceptual and Motor Skills, 8, 271-276.

Seidman, L. J., Faraone, S. V., Goldstein, J. M., Goodman, J. M., Kremen, W. S., Toomey, R., Tourville, J., Kennedy, D., Makris, N., Caviness, V. S., \& Tsuang, M. T. (1999). Thalamic and amygdala-hippocampal wolume reductions in first-degree relatives of patients with schizophrenia: An MRI-based morphometric anaHysis. Biological Psychioury, 46,941-954.

Seidman, L. J., Goldstein, J. M., Goodman, J. M., Koren, D., Tumer, W. M., Faraone, S. V., \& Tsuang, M. T. (1997). Sex differences in olfactory identification and Wisconsin Card Sorting performance in schizophrenia: Relationship to attention and verbal ability. Blological Psychiatry, 42, 104-115.

Servan-Schreiber, D., Cohen, J. D., \& Steingard, S. (1996), Schizophrenic deficits in the processing of context. A test of a theoretical model. Archives of General Psychiotry, $53,1105-1112$.

Smith, A. (1968). The Symbol Digit Modalities Test: A neuropsychological test for economic screening of learning and other cebebral disorders. Learning Disorders, 36, 83-91.

Stroop, J K. (1935). Studies of interference in serial verbal reactions. Jow inal of Experimental Psychology, 18 , 643-662.

Wechsier, D. (1955). Wachsler Adull Intelligence Scale. Manual. New York Psychological Corporation.

Zubin, J., \& Spring, B. (1977). Vulnerability - a new view of schizophrenia. Journal of Abnormal Psychology; $86,103-126$. 


\title{
Cognitive performance and white matter lesions in patients with schizophrenia and patients with bipolar disorder'
}

\begin{abstract}
The aim of the study was to compare cognitive functioning in relation to white matter lesions in bipolar disorder in remission and schizophrenia. Cognitive performance and the occurrence of white matter lesions on MRI images of the brain were assessed in 22 patients with bipolar disorder in remission, 22 patients with schizophrenia, and 22 healthy volunteers. Performance on tests of memory, speed, and cognitive flexibility was significantly impaired in both patient groups. The frequency of white matter lesions did not differ significantly between the three groups. No differences in cognitive performance were found between patients with white matter lesions and patients without such lesions. White matter lesions apparently do not underlie cognitive deficits that are found in patients with bipolar disorder in remission and in patients with schizophrenia.
\end{abstract}

1L. Krabbendam, A. Honig, J. Wiersma, E.F.P.M. Vuurman, P.A.M. Hofman, M.M.A. Derix, W.A. Nolen, J. Jolles. Cognitive functions and white matter lesions in patients. with bipolar disorder in remission. Acta Psychiatrica Scandinavica, in press 


\section{Introduction}

Several authors have questioned the view that mood disorders and schizophrenia are distinct diseases (Crow, 1990; Taylor, 1992). Instead, on the basis of family studies, brain morphology, and the frequency of intermediate forms of illness (i.e. schizoaffective disorder), it has been suggested that they are part of a continuum of liability to psychosis. In line with this suggestion, some neuropsychological studies have reported similar patterns of cognitive deficit in bipolar disorder and schizophrenia (Hoff et al., 1990; Zihl, Gron \& Brunnaue, 1998), although another study found no such pattern (Goldberg et al., 1993). However, in these studies patients with bipolar disorder were investigated in either the acute manic or acute depressed state, which makes the results difficult to interpret because these states could have affected cognitive function. Indeed, the traditional view holds that cognitive deficits in mood disorder are state-dependent, in contrast to the persistent deficits associated with schizophrenia (Bulbena \& Berrios, 1993; Kraepelin, 1913). Nevertheless, those few studies that have investigated patients with bipolar disorder in remission have suggested that some cognitive impairments may persist during clinical recovery (Coffman, Bornstein, Olson, Schwarzkopf \& Nasrallah, 1990; Morice, 1990; Van Gorp, Altshuler, Theberge, Wilkins \& Dixon, 1998).

Cognitive dysfunction during recovery would be consistent with the recent finding of structurall brain changes in patients with bipolar disorder (Videbech, 1997). Magnetic resonance imaging (MRI) studies have shown that there is ventricular enlargement and an increased frequency of white matter lesions in patients with bipolar disorder compared to healthy controls (Dupont et al., 1990; Swayze, Andreasen, Alliger, Ehrhardt \& Yuh, 1990). One study found that white matter lesions were more severe in patients with bipolar disorder than in patients with schizophrenia (Swayze et al, 1990), whereas another study found the reverse (Persaud et all, 1997). The etiology of white matter lesions is not clear, but they are possibly associated with cerebrovascullar changes (Awad, Spetzler, Hodak, Awad \& Carey, 1986; Schmidt et al., 1991). The increased occurrence of white matter lesions in bipolar disorder may underlie cognitive deficits observed during remission. Indeed, one study found that patients with bipolar disorder and white matter lesions had poorer cognitive function than did patients without lesions (Dupont et al., 1990), but this was not confirmed in another study (Swayze et al., 1990).

The present study inwestigated cognitive functioning in relation to white matter lesions in patients with bipolar disorder who were in remission in comparison to both patients with schizophrenia and healthy controls. The neuropsychological assessment focused on memory, attention and speed of information processing, and cognitive flexibility, because impairments in these domains are often seen in mood disorder (Derix \& Jolles, 1997; King \& Caine, 1996), and schizophrenia (Gourovitch \& Goldberg, 1996; Schatz, 1998). Direct comparison of pa- 
tients with bipolar disorder in remission and patients with schizophrenia will shed light on similarities and differences in the patterns of cognitive deficit in both disorders as well as on the nature of brain abnormalities that may underlie this deficit.

\section{Methods}

\section{Subjects}

Forty-five patients with bipolar disorder were screened initially. Five patients withdrew because they found the study too time-consuming and one patient dropped out due to a panic attack during MRI scanning. Seventeen patients were excluded on the basis of the exclusion criteria. The study group consisted of 22 patients with bipolar disorder, 22 patients with schizophrenia, and 22 healthy volunteers. The patients with bipolar disorder had to be in remission for at least 2 months (according to the DSM-IV criterion for full remission, American Psychiatric Association, APA, 1994). The exclusion criteria for all three groups were diagnosis of schizoaffective disorder, older than 60 years, left-handedness, a history of cardiological or cerebrovascular disease, head injury that caused unconsciousness for more than $1 \mathrm{~h}$, diabetes mellitus, hypertension, and substance abuse over the last 12 months. This information was obtained from a medical interview and the case records. Additional exclusion criteria for the control group were any history of psychiatric illness and use of psychoactive medication. Written informed consent was obtained from all participants.

Diagnoses were made by a psychiatrist according to DSM-IV criteria (APA, 1994) and verified by means of the Structured Clinical Interview for DSM-IV Disorders (First, Spitzer, Williams \& Gibbon, 1997) for patients with bipolar disorder and the Composite International Diagnostic Interview (World Health Organization, 1993) for patients with schizophrenia. Twelve patients fulfilled criteria for bipolar I disorder (296.x) and 10 for bipolar II disorder (296.89). Twelve patients were diagnosed with bipolar disorder with psychotic features and 10 with bipolar disorder without psychotic features. The patients with bipolar disorder were recruited from the Department of Psychiatry of the Academic Hospital Maastricht, and the H.C. Rumke Group in Utrecht (Stanley Foundation Bipolar Network). The patients with schizophrenia were recruited from the local psychiatric departments in the catchment area (RIAGG Maastricht and Psychomedical Center Vijverdal Maastricht). The control subjects were recruited via newspaper advertisements.

Participant characteristics are shown in Table 1. All patients were outpatients at the time of the assessment. The patients with bipolar disorder were matched with the control subjects on age, but as a group they were somewhat older than the patients with schizophrenia. The three groups were matched on educational lewel, which was measured on an 8-point scale, ranging 
from primary school to university degree (De Bie, 1987). All patients had a chronic course of their illness, as indicated by a mean number of depressive episodes of $6.2(\mathrm{SD}=5.1)$ and a mean number of manic or hypomanic episodes of $3.9(\mathrm{SD}=3.7)$ in the patients with bipolar disorder, and a mean number of years of illness duration of $13.4(\mathrm{SD}=6.3)$ in the patients with schizophrenia. Mean age at first episode was 32.2 years $(\mathrm{SD}=9.4)$ in the patients with bipolar disorder and 25.5 years $(\mathrm{SD}=7.5)$ in the patients with schizophrenia. Severity of symptomatology was assessed with the 17-item Hamilton Depression Rating Scale (Hamilton, 1960) and the Young Mania Rating Scale (Young, Biggs, Ziegler \& Meyer, 1978) in the patients with bipolar disorder, and the Brief Psychiatric Rating Scale (Overall \& Gorham, 1962) in the patients with schizophrenia. Of the patients with bipolar disorder, 16 were using lithium and six carbamazepine. Six patients were also using antidepressants and two were using benzodiazepines. Of the patients with schizophrenia, all but one were using antipsychotic medication (mean dose in chlorpromazine equivalents $=329, \mathrm{SD}=214$ ), four patients were also using anticholinergic medication, and five were using antidepressants.

Table 1. Subject characteristics

\begin{tabular}{|c|c|c|c|c|c|c|c|}
\hline$\therefore$ & $\begin{array}{l}\text { Schizophrenia } \\
(n=22)\end{array}$ & $\begin{array}{l}\text { Bipolar } \\
(n=22)\end{array}$ & $\begin{array}{l}\text { Contro } \\
(\mathrm{m}=22)\end{array}$ & & $F(2,63)$ & $\mathrm{p}$ & $\begin{array}{l}\text { Tukey } \\
\text { HSD-test }\end{array}$ \\
\hline age & $39.6 \quad(6.6)$ & $47.7 \quad(8.3)$ & 4.4 & $(11.3)$ & 4.96 & 0.01 & $1<2^{a}$ \\
\hline $\operatorname{sex}(M / F)$ & $12 / 10$ & $5 / 17$ & $10 / 12$ & & 4.89 & $0.09 \mathrm{~b}$ & \\
\hline level of education & $4.0 \quad(1.7)$ & $(2.2)$ & 4.1 & $(1.5)$ & 0.03 & 0.97 & \\
\hline IQ score & $94.6(13.0)$ & $102.4(21.4)$ & 114.2 & $(13.0)$ & 8.13 & 0.00 & $\mathbb{1}<3$ \\
\hline Hamilton Depression Rating Scale & n.a.c & $(3.0)$ & ก.a. & & & & \\
\hline Young Mania Rating Scale & n.a. & $0.77 \quad(1.5)$ & n.a. & & & & \\
\hline Brief Psychiatrio Rating Scale & 45.3 & $(10.3) \mathrm{n.a.}$ & M. a. & & & & \\
\hline
\end{tabular}

a 1 selvizoptirenili, 2 bipolar, 3 control; b Chi-square lest; ${ }^{\circ}$ nat. not assessed

\section{Newropsychological assessment}

The neuropsychological assessment was directed at the following cognitive domains: recall from short-term and long-term memory, attention and speed of information processing, and cognitive flexibility. The tests were administered to all subjects, except one patient from the bipolar group.

The Auditory Verbal Learning Task (AVLT; Brand \& Jolles, 1985) was used to evaluate retrieval from memory as well as recognition. As measures of attention and speed of information processing we used the reading and color naming tasks of the Stroop Color-Word Test (SCWT; Stroop, 1935), the numbertracking and lettertracking tasks of the Concept Shifting Test (CST; Houx, Vreeling \& Jolles, 1991), which is a modified version of the Trailmaking Test (Reitan, 1958), and the Letter Digit Substitution Test (LDST), which is a modified ver- 
sion of the Symbol Digit Modalities Test (Smith, 1968). To assess cognitive flexibility we used the interference task of the SCWT, the number/lettershifting task of the CST, and Word Fluency (Lezak, 1995). To obtain a measure of general intelligence we used the shortened form of a widely used Dutch intelligence test, the Groningen Intelligence Test (GIT; Luteijn \& van der Ploeg, 1983). This test yields results that are comparable to the Wechsler Adult Intelligenw ce Scale (Wechsler, 1955). Three subtests have proven to be a good approximation of fullscale IQ (Luteijn \& van der Ploeg, 1983).

\section{Magnetic Resonance Imaging}

MRI scans were made with a 1.5-Tesla scanner (Gyroscan ACS-II, Philips, Eindhoven, the Netherlands). Transverse spin-echo sequences (T2-weighted, TR $3000 \mathrm{~ms}$, TE 23-120 ms, TF 12, NSA 2, FOV $230 \mathrm{~mm}$, voxel dimensions $0.9 \mathrm{~mm} \times 1.2 \mathrm{~mm}$ ) were used. Twenty-four slices were obtained with a thickness of $5 \mathrm{~mm}$ and a $0.5 \mathrm{~mm}$ gap between slices. All images were blindly rated by an experienced neuroradiologist (P.H.). Periventricular lesions in the caps and the bands were rated using a semiquantitative severity rating scale from 0 to 3 . Deep white matter lesions were rated as small (less than $3 \mathrm{~mm}$ ), medium (between 4 and $10 \mathrm{~mm}$ ) or large lesions (more than $10 \mathrm{~mm}$ ). Care was taken to exclude small white matter lesions that are usually considered normal.

The MRI scans were tecorded as part of a larger study $(\mathrm{N}=300)$ into white matter lesions. Of this sample, a subset of 29 scans was measured twice. For this subset, kappa values were calculated as a measure of concordance. For the small deep white matter lesions kappa was $0.55(95 \% \mathrm{CI}=0.37-0.74)$, for the medium lesions kappa was $0.74(95 \% \mathrm{CI}=0.53-0.94)$, for the large lesions kappa was $0.65(95 \% \mathrm{Cl}=-0.15-1.00)$, for the periventricular frontal caps lesions kappa was $0.78(95 \% \mathrm{Cl}=0.62-0.94)$, for the occipital caps kappa was $0.66(95 \% \mathrm{Cl}=$ $0.49-0.84)$, and for the bands kappa was $0.83(95 \% \mathrm{CI}=0.70-0.96)$, indicating sufficient to good concordance for all parameters.

\section{Statistical analysis}

All statistical analyses were performed using SPSS for Macintosh, version 6.1 (SPSS, Inc. Chicago). Cognitive task performance in the bipolar group, the schizophrenia group, and the control group was analysed in a between-group design using multivariate analysis of variance (MANOVA) with age and sex as covariates. Significant results were analysed further using oneway analysis of variance with the Tukey multiple comparison procedure. $t$-Tests for independent samples were used to examine differences in cognitive performance between patients with bipolar I or bipolar II disorder, between patients with or without psychotic features, and between pa-tients using lithium or carbamazepine. Because of the non-normal 
distribution; group differences in the presence and the number of white matter lesions were analysed non-parametrically, using the Chi-square test and the Kruskal-Wallis test, respectively. A series of $t$-tests for independent samples was used to analyse cognitive performance in the subjects with white matter lesions compared to those without lesions. Correlations between frequency of white matter lesions and age were computed for each group separately, using Spearman rank order correlation coefficients.

\section{Results}

The results of the MANOVA showed a significant main effect of group $(F=2.01, \mathrm{df}=26,96$, $p=0.008$, Pillaits test). Pairwise analysis of the significant univariate group differences indicated that the patients with schizophrenia performed significantly worse than the control subjects on all measures, except recognition memory (see Table 2). The patients with bipolar disorder had a significantly poorer performance than the control subjects on AVLT immediate and delayed recall, on CST lettertracking and number/lettershifting, and on the LDST. Three patients with bipolar disorder and one patient with schizophrenia had an IQ score below 75 . However, post hoc analyses showed that these subjects did not contribute disproportionately to the findings.

Table 2. Means (standard deviations) and F-test statistics of cognitive performance for the schizophrenia, bipolar, and control groups

\begin{tabular}{|c|c|c|c|c|c|c|c|c|c|}
\hline \multirow{2}{*}{ Auditory Verbal Learning Test } & \multicolumn{2}{|c|}{$\begin{array}{l}\text { Schizophrenia } \\
(\mathrm{n}=22)\end{array}$} & \multicolumn{2}{|c|}{$\begin{array}{l}\text { Bipolar } \\
(n=21)\end{array}$} & \multicolumn{2}{|c|}{$\begin{array}{l}\text { Control } \\
(n=22)\end{array}$} & \multirow[t]{2}{*}{$F(2,61)$} & \multirow[t]{2}{*}{$p$} & \multirow[t]{2}{*}{$\begin{array}{l}\text { Tukey } \\
\text { HSD-test }\end{array}$} \\
\hline & & & & & & & & & \\
\hline immediate recall & 40.9 & $(11.9)$ & 43.1 & $(10.2)$ & $\$ 2.3$ & $(9.3)$ & 7.99 & .001 & $1,2<31$ \\
\hline delayedrecall & 8.4 & (2.6) & 8.3 & $(3.5)$ & 11.3 & $(2.9)$ & 6.88 & .002 & $1,2<3$ \\
\hline recognition & 13.6 & (1.9) & 14.0 & $(1.6)$ & 14.6 & $(.6)$ & 2.97 & .059 & \\
\hline \multicolumn{10}{|l|}{ Stroop Color-WordTest } \\
\hline Color reading & 53.7 & $(16.1)$ & 47.2 & $(9.4)$ & 42.4 & $(6.1)$ & 5.45 & .007 & $1<3$ \\
\hline Color naming & 73.3 & (19.1) & 64.3 & $(13.5)$ & 56.3 & $(11.3)$ & 7.08 & .002 & $1<3$ \\
\hline Interference & $\llbracket 22.2$ & $(39.5)$ & 107.7 & $(34.1)$ & 88.4 & $(22.8)$ & 5.89 & .005 & $1<3$ \\
\hline \multicolumn{10}{|l|}{ Concept Shifting Test } \\
\hline Number tracking & 24.5 & $(5.3)$ & 22.0 & (7.9) & 18.2 & $(6.4)$ & 4.98 & .010 & $1<3$ \\
\hline Letter tracking & 27.4 & $(6.4)$ & 28.5 & $(9.8)$ & 20.9 & $(5.2)$ & 6.67 & .002 & $1,2<3$ \\
\hline Number/letter shifting & 39.5 & $(15.2)$ & 40.1 & $(19.0)$ & 25.1 & $(6.5)$ & 7.45 & .001 & $1,2<3$ \\
\hline Letter Digit Substitution Test & 40.7 & $(10.1)$ & 43.9 & $(11.5)$ & 54.9 & $(7.8)$ & 12.36 & .000 & $1,2<3$ \\
\hline Fluency & 19.8 & $(5.2)$ & 21.5 & $(5.8)$ & 24.9 & $(6.7)$ & 4.18 & .020 & $1<3$ \\
\hline
\end{tabular}

11 schizophtrenia; 2 bipolar; 3 conthols. 
t-Tests for independent groups showed that the cognitive performance of the 16 patients using lithium was not different from that of the six patients using carbamazepine. No differences in cognitive performance were found between the patients with bipolar I or bipolar II disorder or between the patients with or without psychotic features. There were no significant correlations between cognitive performance and clinical variables (number of episodes and symptomatology ratings).

Table 3 shows the frequency of the white matter lesions per group. There were no significant differences between the groups in the occurrence of periventricular and deep white matter lesions, nor were there significant differences between the three groups in the severity of the periventricular lesions in the bands $\left(\chi^{2}=4.11, p=0.13\right)$ or the caps $\left(\chi^{2}=1.78, p=0.41\right)$. Of the subjects with deep white matter lesions, the patients with bipolar disorder had a mean of 5.2 lesions, the patients with schizophrenia 4.0 lesions, and the healthy subjects 3.6 lesions $\left(\chi^{2}=0.13, \mathrm{p}=0.94\right)$. In the patients with bipolar disorder, $71 \%$ of the deep white matter lesions was located in the frontal lobes, in the patients with schizophrenia this percentage was $91 \%$, and in the healthy subjects this percentage was $93 \%$. No differences were found between bipolar disorder type I and type II, or between bipolar disorder with and without psychotic features, or between male and female subjects in any of the groups. No differences in the number of white matter lesions were found between the left and the right hemispheres in any of the three groups. The cognitive performance of the subjects with deep white matter lesions did not differ from that of the subjects without lesions in any of the three groups. Post hoc power estimations indicated that the power of these analyses was between 0.15 and 0.46 . The number of subjects with periventricular lesions was considered too small (three in the patients with bipolar disorder and four in the patients with schizophrenia) to examine the possible relationship between lesions and cognitive performance deficits in these subjects. The number of white matter lesions was not correllated with age.

Table 3. The frequency (\%) of signal hyperintensities in each group

\begin{tabular}{llllll}
\hline & $\begin{array}{l}\text { Schizophrenia } \\
(\mathrm{n}=22)\end{array}$ & $\begin{array}{l}\text { Bipolar } \\
(\mathrm{n}=22)\end{array}$ & $\begin{array}{l}\text { Control } \\
(\mathrm{n}=22)\end{array}$ & $\chi^{2}$ & $\mathrm{p}$ \\
\hline $\begin{array}{l}\text { periventricular } \\
\text { bands }\end{array}$ & $18.2 \%$ & $13.6 \%$ & 0 & 4.15 & .13 \\
$\quad \begin{array}{llll}\text { caps } \\
\text { deep white matter }\end{array}$ & $18.2 \%$ & $13.6 \%$ & $4.5 \%$ & 1.99 & .37 \\
$\quad$ small & $40.9 \%$ & $63.6 \%$ & $50 \%$ & 2.31 & .32 \\
$\quad$ medium & $13.6 \%$ & $27.3 \%$ & $22.7 \%$ & 1.27 & .53 \\
large & 0 & 0 & 0 & - & $\ldots$ \\
\hline
\end{tabular}




\section{Discussion}

\section{Cognitivefunctions}

The most salient finding was that outpatients with bipolar disorder in remission have a rather diffuse pattern of cognitive deficits, similar to patients with schizophrenia. In both groups the cognitive deficits involve memory, attention and speed of information processing, and cognitive flexibility. However, the performance deficit was generally less severe than that of the patients with schizophrenia. Although there were differences between the two groups with regard to age and sex, it is unlikely that these differences can explain the findings, since we corrected for these variables in the analysis. In contrast to the results of the study by Albus et al. (1996), the presence of the cognitive impairment in bipolar disorder was not associated with the presence of psychotic features.

The groups were matched on educational level. However, it is possible that in particular the patients with schizophrenia had higher potertial abilities than the control group, as in schizophrenia the onset of illness might interfere with the educational career.

All patients with bipolar disorder were taking psychoactive medication at the time of the assessment, which may have influenced cognitive performance. However, for ethical reasons we considered it not appropriate to discontinue medication for the time of the study. Mast of the patients with bipolar disorder were taking lithium, which in a recent meta-analysis of studies was found to have a negative effect on memory and speed of information processing (Honig, Arts, Ponds \& Riedel, 1999). The evidence for negative side-effects of carbamazepine on cognitive functioning is inconsistent (Duncan, Shorvon \& Trimble, 1990; Prevey et al., 1996; Vermeulen \& Aldenkamp, 1995). In the present study, there were no differences in cognitive performance between patients taking lithium and those taking carbamazepine.

Another point of consideration is that we did not include subjects on the basis of either consecutive admissions or random selection. It is possible that the results are somewhat biased, because subjects who experience cognitive problems might be more willing to participate.

\section{White matter lesions}

There were no statistically significant differences between the three groups in the occurrence and severity of white matter lesions and in the mean number of lesions per subject. Of interest is the finding that none of the healthy subjects had periventricular lesions in the bands, whereas a minority of patients in the two patient groups did, but this finding should be replicated. Simillar to the study by Dupont et al. (1990), most deep white matter lesions were located in the frontal lobes. 
The bipolar patients included in the present study were fairly young and all had their first episode at a relatively young age. However, since they were matched for age with the control subjects, the young age cannot explain the lack of differences between the groups. Further, there is evidence for an association between high frequency of white matter lesions and late onset of affective disorder, but this effect appears to be specific to unipolar disorder (Videbech, 1997).

Our results contrast with those of some previous studies (Dupont et al., 1995; Swayze et al., 1990), but are consistent with those of other studies (Brown, Lewine, Hudgins \& Risch, 1992; Strakowski et al., 1993). These differences may be due to the different methods used. For example, the relatively low frequency of deep white matter lesions in healthy controls in the study of Swayze et al. (4.3\%) compared to the present study ( $50.0 \%$ for small lesions and $22.7 \%$ for medium lesions) and other studies (Bartzokis et al., 1991; Persaud et al., 1997) may be due to the use of eight cuts of a thickness $1 \mathrm{~cm}$ in the study by Swayze et al. compared to 24 cuts of $5 \mathrm{~mm}$ in the present study.

The view that white matter lesions are unlikely in young healthy people may be influenced by a bias in the selection of control subjects in several studies (e.g. medical staff). It has been suggested that white matter lesions are more likely to occur in people from a less privileged background (Harvey, Ron, du Boulay, Murray \& Lewis, 1990). This might explain the relatively high frequency of white matter lesions in our study, in which we matched subjects for level of education. This is, however, a tentative explanation which needs further inwestigation.

\section{Cognitive deficits and white matter lesions}

No relationship was found between cognitive deficits and white matter lesions in the two patient groups. Furthermore, healthy subjects who were cognitively normal showed a similar frequency of white matter lesions. This supports previous suggestions that white matter lesions do not necessarily have a negative effect on cognitive function (Fein et al, 1990; Tupler, Coffey , Logue, Djang \& Fagan, 1992), although severe white matter disease is probably associated with cognitive dysfunction (Boone et al., 1992). However, the estimated power of the present analyses indicate that the results must be tentatively interpreted. Indeed, some other studies did find a relation between white matter lesions and cognitive functioning (DeCarli, Murphy, Tranh \& al., 1995; Fazekas, 1989). In the present study, neuropsychological tests were used that have shown to be sensitive to cognitive deficits commonly associated with bipolar disorder and schizophrenia. Future studies should investigate whether white matter lesions are associated with deficits in other cognitive functions, such as visuospatial and executive abilities.

This lack of a relationship suggests that some other brain abnormality underlies the observed cognitive deficits in bipolar disorder and schizophrenia. One explanation could be that 
schizophrenia and mood disorders are part of a continuum (Crow, 1990). Nasrallah has argued that bipolar disorder is characterized by structural brain abnormalities similar to those of schizophrenia, which in both disorders may have a neurodevelopmental origin (Nasrallah, 1991). A second explanation for the cognitive deficits may be that they reflect long-lasting changes in the brain, which, as Post (1992) has suggested, may occur in bipolar disorder following psychosocial stressors or episodes of mania or depression. A third possibility is that hypercortisolaemia, which occurs during episodes of mania or depression, leads to structural changes in the brain, thus explaining cognitive deficits in euthymic periods (Altshuler, 1993). The lack of an association between the number of episodes of mania or depression and cognitive deficits in the present study does not support this latter hypothesis; however, the number of episodes may be too crude a measure of illness severity.

Our findings indicate that euthymic patients with bipolar disorder have persistent cognitive deficits which involve several domains, as do the cognitive deficits seen in patients with schizophrenia. White matter lesions apparently do not underlie these deficits. Indeed, small white matter lesions do not appear to affect cognitive function, because these lesions were also seen in the cognitiwely normal control group. 


\section{References}

Albus, Mi, Hubmann, W., Wahlheim, $C_{.,}$Sobizack, N., Franz, U., \& Mohr, F. (1996), Contrasts in neuro. psychological test profile between patients with first-episode schizophrenia and first-episode affective disorders. Acta Psychiatrica Scandincvica, 94, 87-93.

Alltshuler, L. L. (1993). Bipolar disorder: Are repeated episodes associated with neuroanatomic and cognitive changes? Biological Psychiafry, 33, 563-565.

American Psychiatric Association (1994). Diagnostie and statisfic mawual of mental disorders. (4th ed.). Washington, D.C.: author.

Awad, I. A., Spetzler, R. F., Hodak, J. A., Awad, C. A., \& Carey, R. (1986). Incidental subcortical lesions identified on magnetic resonance imaging in the elderly: I. Correlation with age and cerebrovasculatir risk factors. Stroke, $17,1090-1097$.

Bartzokis, G., Garber, H. J., Griswold, V. J, Oldendorf, W. H., Mintz, J., \& Marder, S. (1991). T 2 hyperintense foci on magnetic resonance images of schizophrenic patients and controls. Psychiatry Research: Neuroimaging, 40, 239-245.

Boone, K. B., Miller, B. L., Lesser, I. M., Mehringer, C. M., Hill-Gutierrez, E., Goldberg, M. A., \& Berman, N. G. (1992). Neuropsychological correlates of white matter lesions in healthy elderly subjects: $A$ threshold effect. Archives of Neurology, 49, 549-554.

Brand, N., \& Jolles, J. (1985). Learning and retrieval rate of words presented auditorily and visually. Journal of General Psychology, 112, 201-210.

Brown, F. W., Lewine, R. J., Hudgins, P. A., \& Risch, S. C. (1992). White matter hyperintensity signals in psychiatric and nonpsychiatric subjects. American Journal of Psychiairy, 149,620-625.

Bulbena, A., \& Berrios, G. E. (1993). Cognitive function int the affective disorders: A prospective study. Psychopathology, 26, 6-12.

Coffman, J. A., Bornstein, R. A., Olson, S. C., Schwarzkopf, S. B., \& Nasrallah, H. A. (1990). Cognitive impairment and cerebral structure by MRI in bipolar disorder. Biological Psychiarry, 27, 1188-1196.

Crow, T. I. (1990). The continuum of psychosis and its genetic origins: The sixty-fifth Maudsley lecture. British Journal of Psychiatry, 156, 788-797.

De Bie, S. E. (1987). Standaardvragen 1987: Voorstellen voor uniformering van vraagstellingen naar achtergrondkenmerken en interviews [Standard questions 1987: Proposal for uniformization of questions regarding background variables and interviews?. (2nd ed.). Leiden: Leiden University Press.

DeCarli, C., Murphy, D. G., Tranh, M., Grady, C. L., Haxby, J. V., Gilliette, J. A., Salerno, J. A., GonzalesAviles, A., Horwitz, B., Rapoport, S. I. et al. (1995). The effect of white matter hyperintensity volume on brain structure, cognitive performance, and cerebral metabolism of glucose in 51 healthy adults. Neurology, $45,2077-2084$.

Derix, M. M. A., \& Jolles, J. (1997). Neuropsychological abnormalities in depression: Relation between brain and behaviour. In A. Honig \& H. M. Van Praag (Eds.), Depression: Neurobiological, psychopathological and therapeusic advances, (Vol. 3, pp. 109-126). Chichester: Wiley.

Duncan, J. S. "Shorvon, S. D., \& Trimble, M. R. (1990), Effects of removal of phenytoin, carbanazepine, and valproate on cognitive function. Epilepsia, 31,584-591.

Dupont, R. M., Butters, N., Schafer, K., Wilson, T., Hesselink, J, \& Gillin, J. C. (1995), Diagnostic specificity of focal white matter abnormalities in bipolar and unipolar mood disorder. Biological Psychicory, 38, $482-486$.

Dupont, R. M., Jernigan, T. L., Butters, N. Delis, D., Hesselink, J. R., Heindel, W., \& Gillin, J. C. (1990). Subcortical abnormalities detected in bipolar affectiwe disorder using magnetic resonance imaging. Clinical and neuropsychological significance. Archives of General Psychiatry, 47, 55-59.

Fazekas, F. (1989). Magnetic resonance signal abnormalities in asymptomatic individuals: Their incidence and functional correlates. European Neurology. 29, 164-168.

Fein, G., Van Dycke, C., Davenport, L., Turetsky, B., Brant-Zawadski, M., Zatz, L., Dillon, W., \& Valk, P. (1990). Preservation of normal cognitive functioning in elderly subjects with extensive white-matter lesions of long duration. Archives of General Psychiary, 47,220-223.

First, M. B., Spitzer, R. L., Williams, J, B. W., \& Gibbon, M. (1997). Structured Clinical Invenview for DSM-IV (SCID). Washington, DC: American Psychiatric Association.

Goldberg. T. E., Gold, J. M, Greenberg, R., Griffin, S., Schull, S. C., Pickar, D., Kleinman, J. E., \& Weinberger, D. R. (1993). Contrasts between patients with affective disorders and patients with schizophrenia on a neuropsychogical test battery. American Journal of Psychiarry, 150, 1355-1362. 
Gourowitch, M. L., Goldberg. T. E. (1996). Cognitive deficits in schizophrenia: Attention, executive functions, memory and language processing. In C. Pantelis, H. E. Nelson, \& T. R. E. Barnes (Eds.), Schizophrenia: A meuropsychological perspective, (pp. 71-86). Chichester: Wiley.

Hamilton, M. (1960). A rating scale for depression. Jow of Newrology, Neurosurgery, and Psychicatry. 23, $56 \% 62$.

Harvey, I., Ron, M. du Boulay, G., Murray, R., \& Lewis; S. (1990). White matter abnormalities on magnetic resonance imaging in bipolar patients. Archives of General Psychiatry, 47, 1172-1173.

Hoff, A. L., Shukla, S, Aronson, T, Cook, B., Ollo, C., Baruch, S., Jandorf, L., \& Schwartz, J. (1990). Failure to differentiate bipolar disorder from schizophirenia on measures of neuropsychological function. Schizophrenia Research, 3, 253-260.

Honig, A., Arts, B. M. G., Ponds, R. W. H. M., \& Riedel, W. J. (1999). Lithium induced cognitive sideeffeets in bipolar disorder. A qualitative analysis and implications for daily practice. International Journal of Cinical Psychopharmacology, $14,167-171$.

Houx, P. J. Vreeling, F. W \& \& Jolles, J. (1991). Age associated cognitive decline is related to biological lifeevents. In K. Lqbal, D. R. C. McLachlan, B. Winblad, \& H. M. Wisniewski (Eds.), Alzheimer's Disease: Basic mechanisms, diagnosis and therapeutic strategies, (pp. 353-359). Chichester: Wiley.

King, D. A., \& Caine, E. D. (1996), Cognitive impainment and major depression: Beyond the pseudodementia syndrome. In I. Grant \& K. M. Adlarns (Eds.), Neuropsychological assessment of neturopsychiatric disarders, (2nd ed pp $_{\text {p }}$ 200-217). Oxford: Oxford University Press.

Kraepelin, E. (1913). Dementia praecox and paraphrenia (R.M. Barclay, 1921, Trans.). Edinburgh: Livingstone.

Lezak, M. D. (1995). Neuropsycholagical assessment. (3rd ed.). Oxford: Oxford University Press.

Luteiljn, F. \& wan der Ploeg, F. A. F. (1983). Handleiding Groninger Intelligentietest (GIT) [Manual Groningen Intelligence Test]. Lisse, The Netherlands: Swets \& Zeitlinger.

Morice, R. (1990). Cognitive inflexibillity and prefrontal dysfunction in schizophrenial and mania. British Journal of Psychiatry, 157, 50-54.

Nasrallah, H. A. (1991). Neurodevelopmental aspects of bipolar affective disorder. Biological Psychiary, 29, 1. 2.

Overall, J, E., Gortham, D. E. (1962). The brief psychiatric rating scale. Psychological Reports, 10, 799-812.

Persaud, R., Russow, H., Harwey, I.s Lewis, S. W., Ron, M., Murray, R. M., \& du Boulay, G. (1997). Focal signal hyperintensities in schizophrenia. Schizophremia Research, 27, 55-64.

Post, R, M. (1992). Transduction of psychosocial stress into the neurobiology of recurrent affective disorder. American Journal of Psychiatry, I49, 999-1010.

Prevey, M. L., Delaney, R. C., Cramer, J. A., Cattanach, L., Collins, J. F., \& Mattson, R. H. (1996). Effects of valproate on cognitive functioning. Comparison with carbamazepine. Archives of Neurology, 53, $1008-$ 1016.

Reitan, R. M. (1958). Validity of the Trail Making Test as an indication of organic brain damage. Perceptual and Motor Skills, 8, 271-276.

Schatz, J. (1998). Cognitive processing efficiency in schizophrenia: Generalized vs domain specific deficits. Schizophrenia Research, 30, 41-49.

Schmidt, R, Fazekas, F., Offenbacher, H., Lytwyn, H., Blematl, B., Niederkorn, K., Horner, S., Payer, F., \& Freidl, W. (1991). Magnetic resonance imaging white matter lesions and cognitive impairnent in hypertensive individuals. Archives of Neurology, $48,417-420$.

Smith, A. (1968). The Symbol Digit Modalities Test: A neuropsychological test for economic screening of learning and other cerebral disorders. Learning Disorders, 36" 83-91.

Strakowski, S. M., Woods, B. T., Tohen, M., Wilson, D. R., Douglass, A. W., \& Stoll, A. L. (1993). MRI subcortical signal hyperintensities in mania at first hospitalization. Biological Psychiatry, 33, 204-206.

Stroop, J. R. (1935). Studies of interference in serial werbal reactions. Journal of Experimental Psychology, 18 , $643-662$.

Swayze, V. W., Andreasen, N. C., Alliger, R. J., Ehrlhardt, J. C., \& Yuh, W. T. (1990). Stmuctural brain abnormalities in bipolar affective disorder. Ventricular enlargement and focal signal hyperintensities. Archives of General Psychiarry, 47, 1054-1059.

Taylor, M. A. (1992), Are schizophrenia and affectiwe disorder related? A selective literature review. American Journal of Psychiatry, 149, 22-32.

Tupler, L. A., Coffey, C. E., Logue, P. E., Djang, W. T., \& Fagan, S. M. (1992). Neuropsychological importance of subcortical white matter hyperintensity. Archives of Neurology, 49, 1248-1252.

Van Gorp, W. G., Altshuler, L., Theberge, D. C., Wilkins, J., Dixon, W. (1998). Cognitive impairment in euthymic bipolar patients with and without prior alcohol dependence. A preliminary study". Archives of General Psychiatry, 55, 41-46. 
Vermeulen, J., \& Aldenkamp, A. P. (1995). Cognitive side-effects of chronic antiepileptic drug treatnent: A review of 25 years of research. Epilepsy Research, 22,65-95.

Videbech, P. (1997). MRI findings in patients with affective disorder: A meta-analysis. Acta Psychiatrica Scandinavica, 96, 157-168.

Wechsler, D. (1955). Wechsler Adult Intelligence Scale. Manual. New York: Psychological Corporation.

World Health Organization (1993). Composite International Diagnostic Interview (CDDI): Version I.I (R.M.W. Smeets, P.M.A.J. Dingemans, Trans.). Geneva: WHO.

Young, R. C., Biggs, J. T, Ziegler, V. E., \& Meyer, D. A. (1978). A rating scale tor mania: Reliability, validity, and sensitivity. British Journal of Psychiarry, 133, 429-435.

Zihl, J., Gron, G., \& Bnunnauer, A. (1998). Cognitive deficits in schizophrenia and affective disorders: evidence for a final common pathway disorder. Acta Psychiatrica Scandinavica, 97, 351-357 


\title{
Cognitive performance and tardive dyskinesia in patients with schizophrenia
}

\begin{abstract}
Tardive dyskinesia may be associated with cognitive dysfunction. It is not clear whether this dysfunction occurs in the form of a global or specific cognitive deficit. A cross-sectional study was conducted in a well-defined catchment area. (Curaçao, the Netherlands Antilles). All inpatients with schizophrenia who had been taking neuroleptic medication for at least three months and who were younger than 65 years were included $(\mathrm{N}=53)$. Tardive dyskinesia was assessed with the Abnormal Involuntary Movement Scale. The neuropsychological assessment comprised tests of memory, executive function, and speed of information processing. Of the six cognitive measures only delayed recall was significantly associated with orofacial dyskinesia. Limb-truncal dyskinesia was not associated with any of the cognitive measures. The pattern of memory impairment is consistent with there being a frontal-subcortical disturbance in orofacial dyskinesia. The results underscore the importance of using specific cognitive test procedures in the search for the cognitive correlates of dyskinesia.
\end{abstract}

IL. Krabbendam, P.N. van Harten, I. Picus, J. Jolles (2000). Tardive dyskinesia is associated with impaired retrieval from long-term memory. Schizophrenia Research, 42, 41.46 


\section{Introduction}

Tardive dyskinesia is one of the most important iatrogenic disorders in psychiatry because of its frequent occurrenee and possible irreversibility. Identifying risk factors for dyskinesia is clinically relewant for prevention of the disorder. A putative risk factor is cognitive dysfunction (Paulsen, Heaton \& Jeste, 1994; Waddington \& Youssef, 1996). In a review, Waddington (1995) concluded that despite a range of potential methodological confounds, cognitive dysfunction is a robust clinical correlate of dyskinesia in schizophrenia. In particular, the orofacial form of dyskinesia appears to be associated with cognitiwe impairment (Brown, White \& Palmer, 1992; Waddington, O'Callaghan \& Kinsella, 1993; Waddington \& Youssef, 1986). It is not clear whether this dysfunction occurs in the form of a global or specific cognitive deficit, such as frontal executive functions or memory. This is due to the use of rather global cagnitive assessment methods, such as the Mini Mental State Examination (e.g., Brown \& White, 1992; Davis, Borde \& Sharma, 1992), or summary scores derived from a number of tests (e.g., Wade et al., 1989). The goal of the present study was to specify the association between cognitive dysfunctions and orofacial and/or limb-truncal dyskinesia. The study was part of a large longitudinal study on the prevalence and incidence of extrapyramidal syndromes in Curaçao (Van Harten, Hoek, Matroos, Koeter \& Kahin, 1997; Van Harten, Matroos, Hoek \& Kahn, 1996).

\section{Methods}

\section{Subjects}

The study was performed at the Dr D.R. Capriles Hospital on Curaçao, the main island of the Netherlands Antilles. The patients were selected from a sample described in detail elsewhere (Van Harten et al., 1996). Patients were eligible for the study if they met the following criteria:

(i) informed consent; (ii) diagnosed with schizophrenia according to DSM-III-R (American Psychiatric Association, 1987); (iii) no organic disorders that could cause movement disorders; (iv) a history of neuroleptic use for at least three months; and (v) younger than 65 years. The latter inclusion criterion was used to avoid the confounding effects of the aging process. $\mathrm{A}$ total of 64 patients fulfilled the inclusion criteria. Eleven patients $(17.2 \%)$ could not be assessed, because of severe agitation (7), lack of cooperation (3), or sensory deficits (1). The group consisted of 47 male and 6 female subjects. The mean age was 49.2 years $(S D=8.6)$. Mean age at first admission was 22.0 years $(\mathrm{SD}=6.3)$; mean total duration of hospitalization was 16.0 years $(\mathrm{SD}=10.3)$. Most of the patients $(75.5 \%)$ had a low level of education (primary school or vocational training for 12-16 year olds), $18.8 \%$ of the patients had a medium level of education (secondary education or vocational training for 16-18 year olds), and $5.7 \%$ of the 
patients had a high level of education (higher education or vocationall training for $18+$ ). The level of education was relatively low compared to that of other study samples described in the literature, and so this variable was incorporated in the regression analyses to adjust for education effects. All subjects took neuroleptic medication at the time of the assessment (mean dose in chlorpromazine equivalents $732 ; \mathrm{SD}=638) ; 50.9 \%$ of the patients used anticholinergics, $7.5 \%$ used antidepressants, $9.4 \%$ used lithium, and $35.3 \%$ used benzodiazepines. Because of possible effects on cognitive performance, the current use of psychoactive medication was controlled for in the analysis.

\section{Neuropsychological assessment}

The neuropsychological assessment was directed at the following cognitive domains: recall from short-term and long-term memory and recognition, general speed of information processing, and frontal executive functions. The Picture Learning Task was used to assess recall and recognition. The test is based upon the Auditory Verbal Learning Task (Brand \& Jolles, 1985). It yields scores for immediate recall, delayed recall (after 20 minutes), and delayed recognition. The Letter Digit Substitution Test was used to assess speed of general information processing. This test is a modified version of the Symbol Digit Modalities Test (Smith, 1968). The Stroop Color-Word Test (Stroop, 1935) was used to assess frontal executive functioning. This test involves three cards which display color names, colored patches, and color names printed in incongruously colored ink, respectively. Card I involves general information processing, whereas performance on card III reflects frontal executive functioning.

The assessment of tardive dyskinesia has been described in detail elsewhere (Van Harten et al., 1996). In short, tardive dyskinesia was assessed with the Abnormal Involuntary Movement Scale (AIMS; Guy, 1976) with case definition according to the criteria of Schooler and Kane (1982). The prevalence of tardive dyskinesia in the current patient group has been assessed approximately each year since 1992. In the current study, the 1996 and 1997 measurements were used. Presence of tardive dyskinesia was defined as a diagnosis of dyskinesia on both occasions. Orofacial and limb-truncal dyskinesia were defined inclusively, meaning that a patient could have either orofacial or limb-truncal dyskinesia, or both. The severity of orofacial and limb-truncal dyskinesia was computed by summing the scores for the first four items of the AIMS and for the fifth to seventh items, respectively.

The presence of parkinsonism was assessed with the Unified Parkinson Disease Rating Scale (Martínez-Martín et al., 1994), and cases were defined as described previously (Van Harten et al., 1996). 


\section{Statistical analysis}

All analyses were conducted using the SPSS statistical package for Macintosh, version 6.1 (SPSS, Ine, Chicago). Multiple logistic regression analyses and multiple linear regression analyses were performed to analyse the relationship between each cognitive measure and orofacial or limb-truncal dyskinesia, adjusted for age, sex, level of education, current dose of neuroleptics, parkinsonism, and current use of anticholinergics, antidepressants, lithium or benzodiazepines. The resulting regression coefficients and odds ratios reflect the adjusted correlations between specific cognitive dysfunctions and orofacial or limb-truncal dyskinesia.

\section{Results}

The prevalence of tardive dyskinesia was $41.5 \%$ (22 patients). Of the 22 patients, 10 had both orofacial and limb-truncal dyskinesia, 9 had orofacial dyskinesia only, and 3 had limbtruncal dyskinesia only. Parkinsonism was present in $28.3 \%$ (15) of the patients.

Table 1. Relation of specific cognitive variables to the accurrence and severity of orofacial and limb-truncal dyskinesia $(n=53)$

\begin{tabular}{|c|c|c|c|c|}
\hline \multirow[b]{2}{*}{ Cognitive variablel } & \multicolumn{2}{|c|}{ Logistic regression } & \multicolumn{2}{|c|}{ Linearregression } \\
\hline & $\begin{array}{l}\text { orofacial } \\
\text { adjusted OR } \\
(95 \% \mathrm{CD})\end{array}$ & $\begin{array}{l}\text { limb-truncal } \\
\text { adjusted OR } \\
(95 \% \mathrm{CD})\end{array}$ & $\begin{array}{l}\text { orofacial } \\
\text { B } \\
(95 \% \mathrm{Cl})\end{array}$ & $\begin{array}{l}\text { limb-truncal } \\
\mathrm{B} \\
(95 \% \mathrm{CI})\end{array}$ \\
\hline \multicolumn{5}{|l|}{ Picture Learning Test } \\
\hline inmediate recall & $\begin{array}{l}1.11 \\
(0.95=1.30)\end{array}$ & $\begin{array}{l}1.04 \\
(0.90-1.22)\end{array}$ & $\begin{array}{l}0.02 \\
(-0.34-0.37)\end{array}$ & $\begin{array}{l}-0.02 \\
(-0.23 \times 0.19)\end{array}$ \\
\hline \multirow[t]{2}{*}{ delayed riacall } & $1.55 \mathrm{a}$ & 1.26 & $0.66^{\mathrm{b}}$ & 0.12 \\
\hline & $(1.05-2.27)$ & $(0.91-1.76)$ & $(0.01-1.31)$ & $(-0.30-0.54)$ \\
\hline \multirow[t]{2}{*}{ recognition } & 1.22 & 1.71 & 0.28 & -0.11 \\
\hline & $(0.62-2.41)$ & $(0.51-5.72)$ & $(-1.60-2.17)$ & $(-1.19-0.97)$ \\
\hline \multirow[t]{2}{*}{ Letter Digit Substitution Test } & 1.07 & 1.01 & 0.05 & -0.04 \\
\hline & $(0.93-1.22)$ & $(0.87-1.18)$ & $(-0.36-0.26)$ & $(-0.22-0.15)$ \\
\hline \multirow[t]{2}{*}{ Stroop Color-Word Test card I } & 1.00 & 1.07 & -0.03 & -0.05 \\
\hline & $(0.92-1.09)$ & $(0.94-1.21)$ & $(-0.26-0.19)$ & $(-0.19-0.08)$ \\
\hline \multirow[t]{2}{*}{ Stroop Color-Wond Test card III } & 1.01 & 1.01 & 0.03 & -0.01 \\
\hline & $(0.98-1.04)$ & $(0.98-1.05)$ & $(-0.03-0.09)$ & $(-0.05-0.02)$ \\
\hline
\end{tabular}

$T$ all cognitive variables were fecoded such that higher scores meant worse performance.

a Wald $x^{2}=4.98$; d $=1 ; p<.03 ;$ ib $T=-2.05 ;$ df $=35 ; p<.05$ 
The results of the logistic and linear regression analyses for each of the cognitive variables are shown in Table 1. After adjustment for confounders the delayed recall of the Picture Learning Task was significantly associated with both the occurrence and the severity of orofacial dyskinesia, with a poorer performance being associated with a higher risk and a greater severity of orofacial dyskinesia $(\mathrm{OR}=1.55,95 \% \mathrm{CI}=1.05-2.27 ; \mathrm{B}=0.66,95 \% \mathrm{CI}=0.01$. 1.31). Without adjustment for confounders, the odds ratio for delayed recall was $1.36(95 \% \mathrm{Cl}$ $=1.08-1.71$ ), which was significant (Wald $\chi^{2}=6.74, \mathrm{df}=1, \mathrm{p}<0.01$ ). The other cognitive variables were not related to the occurrence or severity of orofaciall dyskinesia and none of the cognitive variables were associated with linb-truncal dyskinesia.

\section{Discussion}

This study shows that orofacial dyskinesia is associated with a specific cognitive dysfunction, namely, impaired active retrieval from long-term memory. Our study specifies the relationship between cognitive dysfunction in patients with tardive dyskinesia, which has been reported previously (e.g., Paulsen et al., 1994; Waddington \& Youssef, 1996). Our results are consistent with an early study that also reported the specific association with delayed recall (Thomas \& McGuire, 1986), although this study did not include a measure of recognition. Further, one other study reported a significant association between orofacial TD and picture recall (Myslobodsky, Tomer, Holden, Kempler \& Sigal, 1985). The validity of our findings is supported by the fact that (i) the analysis was adjusted for factors which may influence cognitive performance, including demographic variables, parkinsonism, as well as use of psychoactive medication, and (ii) dyskinesia was assessed at two points in time, which improves the validity of the diagnosis.

\section{Risk factor or state marker}

Due to the cross-sectional design of the study, we could not determine whether cognitive dysfunction is a risk factor for the dewelopment of orofacial dyskinesia or a state marker of the disorder (Waddington et al., 1993). There is some evidence from prospective studies that patients with schizophrenia associated with cognitive deterioration have an increased risk of dyskinesia. In one study, patients with chronic schizophrenia who had developed orofacial dyskinesia by the 5-year follow-up were not distinguishable from non-dyskinetic patients at the initial assessment (Waddington \& Youssef, 1996). However, the emergence of orofacial dyskinesia was associated with concurrent deterioration of cognitive functions. In another prospective study, poor cognitive performance was associated with greater likelihood of sub- 
sequent emergence of tardive dyskinesia in a heterogeneous outpatient population (Wegner et

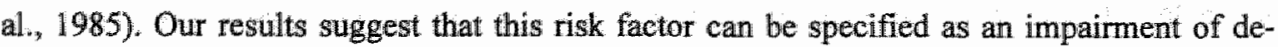
layed recall. The results further indicate that this risk factor is independent of the effect of antipsychotic medication, because the association between impaired memory and tardive dyskinesia was not affected by current exposure to antipsychotic medication. This is in line with the suggestion that there might be two factors which independently act to increase the risk of tardive dyskinesia (Van Os et $\mathrm{al}_{w,}$ 1997). One factor is exogenous (antipsychotic medication) and the other involves illness-related aspects, notably cognitive deterioration, which most likely reflects disturbed brain function.

\section{Pathophysiological implications}

Although an impairment of memory could suggest temporal lobe/hippocampal involvement (Tranel \& Damasio, 1995), the association with active recall but not recognition is more in line with the pattem of memory impairment in patients with basal ganglia pathology, such as Huntington's and Parkinson's disease (Brandt \& Rich, 1995). This suggests that similar structures underlie the cognitive impairment in orofacial dyskinesia. A detailed model of basal ganglia function proposes that five circuits subserve different areas of the prefrontal cortex (Alexander, DeLong \& Strick, 1986). These frontal-subcortical circuits, and especially those that subserve cognitive function, may be involved in schizophrenia (Pantelis \& Brewer, 1996). More severe disturbance of these circuits, as evidenced by impaired active recall, may increase the risk for orofacial dyskinesia. This hypothesis is in accordance with a recent study, in which orofacial dyskinesia was found to be associated with poor performance on a test of frontal functioning, the Wisconsin Card Sorting Test (Waddington et al., 1995). Surprisingly, in the present study there was no association between orofacial dyskinesia and another putative measure of frontal lobe functioning, performance on the Stroop Color-Word Test card III. This may indicate that this task involves frontal-subcortical circuits other than those affected in orofacial dyskinesia.

The topographical specificity of the association, that is, with orofacial as opposed to limbtruncall dyskinesia, provides further evidence that the two forms involve different pathophysiological mechanisms. "The frontal-subcortical disturbance may well be specific to orofacial dyskinesia. Limb-truncal dyskinesia may be associated with treatment-related factors, such as current medication (Bergen, Kitchin \& Berry, 1992; Glazer, Morgenstem, Niedzwiecki \& Hughes, 1988; Gureje, 1989), but this could not be confirmed in another study (Waddington, Youssef, Dolphin \& Kinsella, 1987). 


\section{Limitations}

The relatively low mean level of education in the study sample may limit the extrapolation of the results to higher educated patients. However, the effect of level of education was adjusted for in the statistical analysis.

The fact that we studied an African-Caribbean population might limit the extent to which the results can be generalized to other populations. However, the main epidemiological characteristics of the sample, such as admittance rate, percentage of patients with schizophrenia, and mean current dosage of neuroleptic medication, are similar to those of other studies (Van Harten et al., 1996).

The selected sample represented about $12 \%$ of the estimated total population of patients with schizophrenia on the island, and consisted of (i) patients who were in hospital, and who may therefore have had a more severe form of psychosis, and (ii) patients younger than 65 years. Whether the results can be generalized to the total population of patients with schizophrenia is not clear. However, there is no a priori reason to assume that the relation between tardive dyskinesia and cognitive dysfunction will be different in less severely ill patients.

\section{Conclusion}

The present study shows that orofacial dyskinesia is associated with a specific impairment of retrieval. The pattern of memory impairment is consistent with there being a frontal-subcortical disturbance in orofacial dyskinesia. The results underscore the importance of using specific cognitive test procedures in the search for the cognitive correlates of dyskinesia. 


\section{References}

Alexander, G. E, DeLong, M., \& Strick, P. E (1986). Parallel organization of functionally segregated circuits linking basal ganglia and cortex. Anmual Review of Neurosclence, 9, 357-381.

American Psychiatric Association (1987). Diagmostic and statistic manual of mental disorders. (3rd rev. ed.). Washington, D.C.: author.

Bergen, J., Kitchin, R, \& Berry, G. (1992). Predictors of the course of tardive dyskinesia in patients receiving: rieuroleptics, Biological Psychiatiny, 32, 580-594.

Brand, N., \& Jolles, J. (1985). Learning and retrievall rate of words presented auditorilly and visually. Journal of General Psychology, $112,201-210$.

Brandt, J., \& Rich, J. B. (1995). Memary disarders in the demenvias, In A. D. Baddeley, B. A. Wilson, \& F. N. Watts (Eds), Handbook of memory disorders; ( $\mathrm{pp}$. 243-270). Chichester: Wiley.

Brown, K. W., \& White, T. (1992). The influence of topography on the cognitive and psychopathological effects of tardiwe dyskinesia. American Journal of Psychiatry, 149, 1385-1389.

Brown, K. W., White, T, \& Palmer, D. (1992). Movement disorders and psychological tests of fromtal lobe function in schizophrenic patients. Psychological Medicine, 22, 69-77.

Davis, E. J. B., Borde, M., \& Sharma, L. N. (1992). TD and type II schizophrenía. British Journal of Psychia$\operatorname{try}_{1} 160,253-256$.

Glazer, W. M., Morgenstern, H., Niedzwiecki, D., \& Hughes, J. (1988). Heterogeneity of tardive dyskinesia: A multivariate analysis. British Journal of Psychiatry, 152, 253-259.

Gureje, O. (1989). The significance of subtyping tardive dyskinesia: A study of prevalence and associated factors. Psychological Medicine, 19, 121-128.

Guy, W. (Ed) (1976) ECDEU Assessment Manual for Psychopharmacology. Publication ADM 76-388. Washington DC: US Department of Health, Education and Welfare.

Martinez-Martin, P., Gill-Nagel, A., Morlán Gracia, L., Balseiro Gomez, J., Martínez-Sarriés, J., \& Bermejo, E. (1994). The Cooperative Multicentric Group: Unified Parkinson disease rating scale characteristics and structure. Movement Disorders, 9, 76-83.

Myslobodsky, M. S., Tomer, R., Holden, T., Kempler, S., \& Sigal, M. (1985), Cognitive impairments in patients with tardive dyskinesia. Journal of Nervous and Mental Disease, 173, 156-160.

Pantelis, C., \& Brewer, W. (1996). Neurocognitive and neurobehovioural patterns and the syndromes of schizophrenia: Role of frontal-subcortical networks. In C. Pantelis, H. E. Nelson; \& T. R. E. Barnes (Eds.), Schizophrenia: A neuropsychological perspective, (pp. 317-344). Chichester: Wiley.

Paulsen, J. S., Heaton, R. K., \& Jeste, D. V. (1994). Neuropsychological impainment in tardive dyskinesia. Neuropsychology, 8, 227-241.

Schooler, N. R., \& Kane, J. M. (1982). Research diagnosis for tardive dyskinesia. Archives of General Psychia. try, 39, 486-487.

Smith, A. (1968). The Symbol Digit Modalities Test: A neuropsychological test for economic screening of learning and other cerebral disorders. Learning Disorders, 36, 83-91.

Stroop, J. R. (1935). Studies of interference in serial verball reactions. Joumal of Experimental Psychology. 18 , $643-662$

Thomas, P., \& McGuire, R. (1986). Orofacial dyskinesia, cognitive function and medication. British Journal of Psychiaty, 149,216-220.

Tranel, D., \& Damasio, A. R. (1995). Neurobiological foundations of human memory. In A. D. Baddeley, B. A. Wilson, \& F. N. Watts (Eds.), Handbook of memory disorders, (pp. 27-50). Chichester: Wiley.

Van Harten, P. N., Hoek, H. W., Matroos, G. E., Koeter, M., \& Kahn, R. S. (1997). The interrelationships of tardive dyskinesia, parkinsonism, akathisia and tardive dystonia. The Curaçao Extrapyramidal Syndromes Study: 11. Schizophremia Research, 26, 235-242.

Van Harten, P. N. Matroos, G. E., Hoek, H. W. \& Kahn, R. S. (1996). The prevalence of tardive dystonia, tardive dyskinesia, parkinsonism and akathisisa. The Curaçao Extrapyramidal Syndromes. Study: I. Schizophrentia Researich, 19, 195-203.

Van Os, J., Falyy, T., Jones, P., Harvey, I. Toone, B., \& Murray "R. (1997). Tardive tysskinesia: Who is at risk? Acta Psychiatrica Scandinawica, 96, 206-216.

Waddington, J. L. (1995). Psychopathological and cognitive correlates of tardive dyskinesia in schizophrenia and other disorders treared with neuroleptic drugs. In W. J. Weiner \& A. E. Lang (Eds.), Behavioral Neurology of Movement Disorders, (Vol. 65, pp. 211-229). New York: Raven.

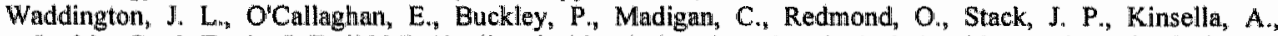
Larkin, C. \& Enmis, J. T. (1995). Tardive dyskinesia in schizophrenia. Relationship to minor physical anomalies, frontal lobe dysfunction and cerebral structure on magnetic resonance imaging. British Journal of Psychiatry, 167, 41-44. 
Waddington, J. L., O'Callaghan, E., \& Kinsella, A. (1993). Cognitive dysfunction in schizophrenia: Organic vulnerability factor or state marker for tardive dyskinesia? Brain and Cognition, 23, 56-70.

Waddington, J. L., \& Youssef, H. A. (1986). An unusual cluster of tardive dyskinesia in schizoplirenia: Association with cognitive dysfunction and negative symptoms. American Jounal of Psychiatry, 1483, 11621165 .

Waddington, J. L., \& Youssef, H. A. (1996). Cognitive dysfunction in chronic schizophrenia followed prospectively over 10 years and its longitudinal relationship to the emergence of tardive dyskinesia. Psychological Medicine, 26, 681-688.

Waddington, J. L., Youssef, H. A., Dolphin, C., \& Kinsella, A. (1987). Cognitive dysfunction, negative symptoms, and tardive dyskinesia in schizophrenia. Archives of General Psychiatry, 44, 907-912.

Wade, J. B., Lehmann, L., Hart, R., Linden, D., Novak "T., \& Hamer, R. (1989). Cagnitive changes associnted with tardive dysinesia. Neuropsychiatry, Newropsychology, and Behovioral Neurology, 1, 217-227.

Wegner, J. T., Kane, J. M.s Weinhold, P., Woemer, M., Kinon, B., \& Lieberman, J. (1985). Cognitive inpair" ment in tardive dyskinesia. Psychiatry Research, 16, 331-337. 


\title{
Deficits of executive functions in patients with schizophrenia'
}

\begin{abstract}
Recent research into the cognitive dysfunctions in schizophrenia has focused on executive deficits. This study investigates performance of patients with schizophrenia on the recently developed Behavourial Assessment of the Dysexecutive Syndrome (BADS). Matched groups of 24 patients with schizophrenia and 17 healthy volunteers were administered the BADS, the Modified Card Sorting Test (MCST), the Tower of London (TOL), a test of general intelligence, and measures of daily functioning. Performance of the patients with schizophrenia was significantly below that of the control group on the BADS and the MCST, but not on the TOL. The BADS correlated weakly with the MCST. Both tests showed a modest correlation with daily functioning. The BADS appears to offer a useful contribution to the assessment of executive deficits in schizophrenia.
\end{abstract}

1L. Krabbendam, M.E. de Vugt, M.M.A. Derix, J. Jolles (1999). The Behavioural Assessment of the Dysexecutive Syndrome as a tool to assess executive functions in schizophrenia. The Clinical Neuropsychologist, 13, 370.375 


\section{Introduction}

Recent accounts of the cognitive dysfunctions in schizophrenia focus on executive deficits, such as lack of volition, impaired plaming, and disturbed self-monitoring (Frith, 1992, Morice \& Delahunty, 1996). Theoretically, these deficits can be explained as a failure at the level of the Supervisory Attentional System (SAS; Norman \& Shallice, 1986). The SAS normally comes into action when the routine control of behaviour is unsatisfactory, for example, in nowel situations or in situations that require the suppression of dominant or habitual responses. The SAS may be compromised in other neuropsychiatric disorders as well (Derix, 1994).

Dysfunctions at the level of the SAS can be observed most clearly in daily life, where novel and unstructured situations put high demands on planning capacities. They are, however, difficult to assess with formal neuropsychological testing procedures. The problem with most neuropsychological tests is that they focus on the individual components of executive functioning. Yet, what is impaired in patients with deficits of executive functions is the ability to initiate, integrate ${ }_{*}$ and monitor the use of these components (Shallice \& Burgess, 1991). Consequently, patients with gross difficulties in daily life may perform within normal limits on standard executive tests. The degree to which task demands correspond to the requirements of daily life is generally referred to as the ecological validity of tests. In view of the relevance of good ecological validity to the clinical use of tests, this domain has received little attention (Cripe, 1996; Green, 1996).

In the present study, a new test battery is used that requires intact functioning of the SAS for its execution. The Behavioural Assessment of the Dysexecutive Syndrome (BADS; Wilson, Alderman, Burgess, Emslie \& Evans, 1996) presents the subject with a series of unstructured tasks that are designed to reflect daily life situations. Although a recent study suggested that the BADS can indeed identify executive deficits in schizophrenia (Evans, Chua, McKenna \& Wilson, 1997), it remains to be demonstrated whether the test adds to the information yielded by standard executive tests and whether performance is related to daily life functioning.

\section{Methods}

\section{Subjects}

Twenty-four patients with schizophrenia and 17 healthy control volunteers participated in the study. The patients were recruited from the social psychiatric service of the Regional Institute for Ambulant Mental Health Care (RIAGG), Maastricht, and the ambulatory service of the psychiatric hospital Vijverdal, Maastricht, the Netherlands. Patients were diagnosed 
according to DSM-IV criteria (American Psychiatric Association, 1994) by the psychiatrists who were in attendance. Subject characteristics are shown in Table 1. The two groups were matched for age, sex, and level of education. Psychopathology was assessed with the Brief Psychiatric Rating Scale (BPRS; Overall \& Gorham, 1962). All patients used stable doses of antipsychotic medication, $29.2 \%$ of the patients used anticholinergics, $25.0 \%$ used antidepressants, and $16.7 \%$ used benzodiazepines.

Exclusion criteria for both groups were: (1) heavy use of alcohol or drugs in the past year, (2) any history of neurological disease, and (3) a history of head injury causing unconsciousness for more than $1 \mathrm{hr}$. Additional exclusion criteria for the control group were any history of psychiatric symptoms, and use of psychoactive medication. Voluntary informed consent was obtained from all subjects.

Table 1. Subject characteristics

\begin{tabular}{|c|c|c|c|c|c|c|}
\hline & \multicolumn{2}{|c|}{ Patient $(\mathrm{N}=24)$} & \multicolumn{2}{|c|}{ Control $(N=17)$} & \multirow[b]{2}{*}{$i$} & \multirow[b]{2}{*}{$p$} \\
\hline & Mean & (SD) & Mean & (SD) & & \\
\hline Age & 30.7 & $(6.6)$ & 30.6 & $(7.4)$ & 0.07 & 0.95 \\
\hline Educational level 1 & 3.9 & $(2.0)$ & 4.2 & (1.5) & 0.63 & 0.51 \\
\hline IQ score? & 98.3 & $(1.5 .3)$ & 107.9 & (11.3i) & 2.29 & 0.03 \\
\hline $\operatorname{Sex}(m / f)$ & $20 / 4$ & & $15 / 2$ & & & \\
\hline In/Outpatient & $2 / 22$ & & -- & & & \\
\hline Hllness duration (years) ${ }^{3}$ & 8.2 & (5.9) & -- & & & \\
\hline Age at first admission & 24.9 & (6.4) & - & & & \\
\hline $\begin{array}{l}\text { Total length of admissions } \\
\text { (months) }\end{array}$ & 11.4 & $(\mathbb{3}, 4)$ & -- & & & \\
\hline Brief Psychiatric Rating Scale & 39.9 & $(11.7)$ & -- & & & \\
\hline Life Skills Profile 4 & 127.2 & $(11.6)$ & -. & & & \\
\hline DysexecutiveQuestionnaire 5 & 30.7 & $(11.5)$ & $-=$ & & & \\
\hline
\end{tabular}

measured on an 8-point scale ranging from primary school to university degree

2 om the basis of a sthortened version of the GIT (Groningen Intelligence Test)

3 based on age at which psychiatric symptons emerged according to the case history

4higher scores reflect better functioning (range 39 to 156)

$s$ higher scores reflect more problems (range 0 to 80)

\section{Procedure}

The following tests of executive functions were administered to all subjects: Tower of London (TOL; Shallice, 1982), Modified Card Sorting Test (MCST; Nelson, 1976) and the Dutch version of the Behavioural Assessment of the Dysexecutive Syndrome (Wilson et al., 1996) which has recently been developed (Krabbendam \& Kalff, 1997).

The BADS consists of six tasks. For each of the tasks a summary profile score is obtained (with a maximum of 4 and a minimum of zero) and these are summed to obtain a total profile 
score (maximum $=24$ ). The Rule Shift Cards test examines the ability to shift from the use of a simple rule for responding to another more complex rule. The Action Program test requires the subject to remove a cork from a small tube, making use of certain tools. In the Key Search test the subject must draw the path he would take to search a large imaginary field in order to find some lost keys. In the Temporal Judgment test the subject is asked to estimate the time length of some activity. The Zoo Map test examines the ability to plan a route according to several rules. The Modified Six Elements test requires the subject to organize the execution of six tasks in ten minutes according to certain rules.

A shortened form of the Groningen Intelligence Test (GIT; Luteijn \& van der Ploeg, 1983) was administered as a measure of general ability. The GIT is a test of general intelligence that is used as much as the Wechsler Adult Intelligence Scale (WAIS; Wechsler, 1955) in the Netherlands. There is general agreement on which subtests are to be used to arrive at a good approximation of a full scale IQ (Lutejin \& van der Ploeg, 1983): (1) 'Doing sums' involves the correct completion of as many sums as possible in $1 \mathrm{~min}$; (2) 'Mental rotation' requires the subject to indicate which two-dimensional shapes from a larger set are needed to exactly fill up a given space on the test page; (3) 'Analogies" can be regarded as a multiple-choice version of the well-known 'Similarities' subtest of the WAIS: the task is to indicate which of five alternatives is related in the same way to a given word as two words in an example.

Problems in daily life functioning in the patients with schizophrenia were rated by a relative or caregiver using the Life Skills Profile (LSP”, Rosen, Hadzi-Pavlovic \& Parker, 1989) and the Dysexecutive Questionnaire (DEX; Wilson et al., 1996) which is part of the BADS.

\section{Statistical analysis}

Group differences on the executive tests were analysed using a series of $t$-tests for independent samples with Bonferroni correction for multiple comparisons. Performances on the individual BADS subtests as well as on the MCST (number of categories) were analysed using the Mann-Whitney $\mathrm{U}$ test, because of non-nomal distribution. All tests were two-tailed.

To examine the degree to which performance on the BADS was related to the other executive tests and to daily life functioning, Pearson correlation coefficients were computed for each group separately. Spearman rank-order correlation coefficients were computed in case of non-normal distribution.

To control for the effects of general intellectual decline, a post hoc analysis was performed, which excluded those subjects with an IQ score below 90 . 


\section{Results}

Performance of the patient group was significantly below that of the control group on BADS and on the MCST (see Table 2). No differences were found on the TOL. Notydum metric analysis of performance differences on the individual BADS tests showed sugnificant differences on two tests, Action Program (Mann Whitney $U=93.5, \mathrm{p}=0.00$ ) and $200 \mathrm{Map}$ $(U=125.5, \mathrm{p}=0.03)$.

The age-controlled classification of performance on the BADS described in the test manual, which is derived from a sample of 216 normal control subjects, was used to classify patients as either impaired, borderline, low average, average, high average, or supenior. Results are depicted in Figure 1.

Correlations between performance on the BADS and the number of errors as well as the number of categories on the MCST were nonsignificant in both groups (range of the correlat tion coefficients was $R=-0.30, \mathrm{p}=0.15$ to $R=0.28, \mathrm{p}=0.18$ ). In the patients with schizo* phrenia, performance on the BADS correlated significantly with performance on the TOL $(R$ $=0.49, \mathrm{p}=0.02)$ and $\mathrm{IQ}$ score $(R=0.65, \mathrm{p}=0.001)$. In the control subjects these correlations were nonsignificant $(R=0.27, \mathrm{p}=0.31$ for the BADS and the TOL; $R=0.21, \mathrm{p}=$ 0.41 for the BADS and IQ score).

The correlation analysis of executive test performance and daily life functioning in the patients with schizophrenia yielded significant correlations in the expected direction between BADS and LSP $(R=0.41, \mathrm{p}=0.05)$, between MCST (number of errors) and LSP ( $R=-0.40$, $\mathrm{p}=0.05$ ), and between MCST (number of errors) and $\mathrm{DEX}(R=0.46, \mathrm{p}=0.02)$. Other correlations were nonsignificant. The correlation between IQ score and LSP was not significant $(R=0.32, \mathrm{p}=0.14)$.

Table 2. Performance on executive tests for patient and control group

\begin{tabular}{|c|c|c|c|c|c|c|}
\hline & \multicolumn{2}{|c|}{$\begin{array}{l}\text { Patient } \\
(\mathrm{N}=24)\end{array}$} & \multicolumn{2}{|c|}{$\begin{array}{l}\text { Control } \\
(N=17)\end{array}$} & \multirow[b]{2}{*}{$t$} & \multirow[b]{2}{*}{$p^{\prime}$} \\
\hline & Mean & (SD) & Mean & $(\mathrm{SD})$ & & \\
\hline BADS totall score & 16.1 & (3.8) & 19.1 & $(2.2)$ & 3.13 & 0.003 \\
\hline MCST number of errors & 13.3 & $(9.6)$ & 4.1 & (3.1) & 4.35 & 0.000 \\
\hline MCST number of categories & 4.5 & $(1.7)$ & 5.9 & $(0.3)$ & 3.922 & 0.001 \\
\hline TOL number in minimum moves & 6.1 & $(2.4)$ & 6.8 & (1.4) & 1.15 & 0.596 \\
\hline
\end{tabular}

1 following Bonferroni conrection the significance level was set at .0125

2 Mann-Whitney $U$-test

Abbreviations: BADS = Behavioural Assessment of the Dysexceutive Syndrome; MCST TOL $=$ Tower of London 


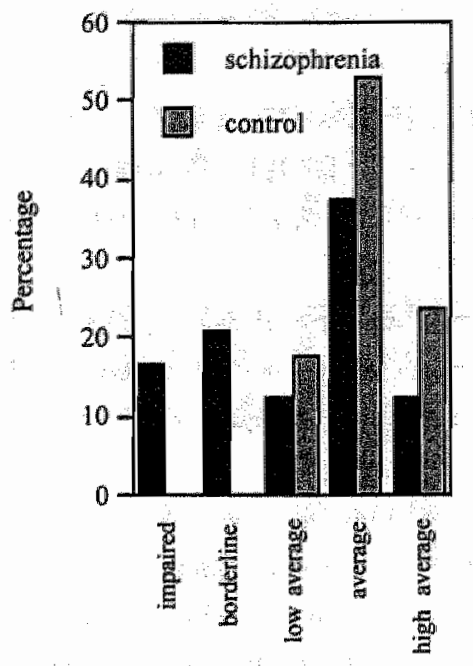

Figure 1. Percentage of subjects in each of the BADS performance categortes

A post hoc analysis, in which 7 patients with schizophrenia with an IQ-score below 90 were excluded, yielded significant performance differences on the MCST (number of errors: $t=$ $2.81, \mathrm{p}=0.01$; number of categories achieved: $\left.U^{*}=78.5, \mathrm{p}=0.04\right)$, but not on the BADS ( $t=$ $-1.33, p=0.19$ ).

\section{Discussion}

This study demonstrates that patients with schizophrenia show deficits on a series of everyday executive tasks. Deficits were allso apparent on a standard executive test $t_{;}$the MCST. The lack of performance deficits on the TOL suggests that this test is less sensitive to executive deficits than the BADS and the MCST.

Performance on the BADS correlated only weakly with performance on the MCST. The MCST focuses on one aspect of executive functions in particular, namely, cognitive flexibility. The BADS appears to offer a more comprehensive assessment of the functions of the SAS, in that the test not only involves cognitive flexibility (e.g, the Rule Shift Cards Test), but also the planning of behavior in novel situations (e.g., the Action Program Test), even over longer time periods and in the face of several competing tasks (e.g., the Modified Six Elements Task).

The finding that approximately half of the patient group performed in the average or high 
average BADS performance category calls into question the hypothesis that all patients with schizophrenia are impaired on executive tests. On the other hand, the BADS presumably does not test all possible functions of the SAS (Evans et al., 1997). In a relatively mildly impaired patient group such as we studied, namely outpatients, perhaps even more complex and unstructured tasks should be used (e.g., the Multiple Errands Test; Shailice \& Burgess, 1991).

Two points of consideration emerge from the study. First, performance on the BADS was strongly related to general intelligence in the patients with schizphrenia. When the range of IQ was restricted by excluding subjects with scores below 90 , group differences on the BADS disappeared. This may indicate that there is some overlap between executive functions and general intellectual ability as assessed with neuropsychological test procedures, at least in patients with schizophrenia. In particular, it is likely that deficits of executive functioning have a general negative influence on test performance, for example, as a consequence of reduced error monitoring or impaired volition. Despite this apparent overlap, the BADS was a better predictor of daily life functioning than IQ score.

Second, performance deficits on the BADS as well as the MCST were related to problems of daily life functioning, but the strength of the associations was only modest. Previous studies using standard executive tests in relation to functional measures obtained figures in the same range (Brekke, Raine, Ansel, Lencz \& Bird, 1997; Velligan et al., 1997). A possible explanation for the lack of strong relations between test performance and functional measures is that, although tests can be designed that reflect everyday activities as closely as possible, differences will remain between the demands of the test setting and those of daily life (Acker, 1990). In the context of schizophrenia, the most important difference might well be that everyday life requires self-motivation and persistence, whereas in the testing situation motivation is often aided and persistence encouraged by the examiner.

Further, the reduction of complex human actions to numerical index will lead to a limited understanding of the reality from which the score was extracted (Cripe, 1996). According to Cripe, a better method to assess executive functions is to use both "objective qualitative and quantitative methods" (p. 194). Executive functions comprise the integration and monitoring of cognitive functions, involving how things get done rather than just what gets done. These processes are poorly assessed with quantitative methods (summary scores). Therefore, direct observation of these processes adds significant information to the assessment of executive functions. Our clinical experience with the BADS suggests that the test yields qualitative information, which is sometimes lost when profile scores are computed. Examples of qualitative scores that can be obtained with the BADS are (a) a clearly inefficient approach to the Modified Six Elements Test, that is, continued switching between the six tasks, instead of allocating the time evenly across the tasks in a planned manner; (b) perseveration of an unsuccessful approach to the Action Program Test, that is, trying to reach the cork in the tube with the metal 


\section{CHAPTER 8}

rod; (c) marked hesitation to make a guess at the Temporal Judgment Test; (d) difficulty grasping the level of abstraction that is needed in the Key Search Test, that is, to understand that the square on the paper refers to a large field. Further research should pay attention to the development of a scoring system for the BADS which is also sensitive to these qualitative aspects of the process of performance. Using the test to obtain both qualitative and quantitative information may offer a more comprehensive assessment of the functions of the SAS. 


\section{References}

Acker, M. B. (1990). A review of the ecological walidity of neuropsychological tests. In D. E. Tupper $R$. K. Cicerone (Eds.). The neuropsychology of everydoy life: Assessment and basic competenciex, (pp. 19-56). Baston: Kluwer Academic Publishers.

American Psychiatric Association (1994). Diagnostic and statistic manwal of mental disonders. (4th ed.). Washington, D.C.: author.

Brekke, J. S., Raine, A., Ansel, M. Lencz, T. \& Bird, L. (1997). Neturopsychological and psychophysiological contelates of psychosocial functioning in schizophrenia. Schirophrenia Bulletin, 23, 19-28.

Cripe, L. I. (1996). The ecological validity of executive function testing. In R. J. Sbordone \& C. J. Long (Eds.), Ecological validity of newropsychological testing, (pp. 171-202). Delray Beach. Florida: GR. Press/St. Lucie Press.

Derix. M. M. A. (1994). Neuropsychological differentiation of dementia syndromes. Lisse: Swets \& Z.itlinger.

Evans, J. J., Chua, S. E., McKenna, P. J., \& Wilson, B. A. (1997). Assessment of the dysexecutive syndrome in schizophrenia. Psychological Medicine, 27, 635-646.

Frith, C. D. (1992). The cognitive mewropsychology of schizophrenia. Hove: Lawrence Erlbaum Associates.

Green, M. F. (1996). What are the functional consequences of neurocognitive deficits in schizophrenia? American Journal of Psychiatry, 153,321-330.

Krabbendam, L., \& Kalff, A. C. (1997). The Behawioural Assessment of the Dysexecutive Syndrome - Dutch version. Lisse, the Netherlands: Swets \& Zeitlinger.

Luteijn, F., \& van der Ploeg, F. A. E. (1983). Handleiding Groninger Intelligentiefest (GIT) (Manwal Groningen Intelligence Test]. Lisse, The Netherlands: Swets \& Zeitlinger.

Morice, R., \& Delahunty, A. (1996). Frontalfexecutive impaiments in schizophrenia. Schizophrenia Bulletin, $22,125-137$.

Nelson, H. E. (1976). A modified card sorting test sensitive to frontal lobe defects. Cortex, 12, 313-324.

Norman, D. A., \& Shallice, T. (1986). Attention to action." Willed and automatic control of behavior. In R. II. Davidson, G. E. Schwartz, \& D. Shapiro (Eds.), Consciousness and selfregulation, (Vol. 4, pp. 1-l8). New York: Plenum.

Overall, J. E., \& Gomam, D. E. (1962). The brief psychiatric rating scale. Psychological Reporrs, 10, 799-812.

Rosen, A., Hadzi-Pavlovic, D., \& Parker, G. (1989). "The Life Skills Profile: A measure assessing function and disability in schizophrenia. Schizophrena Bulletin, 15, 325-337.

Shallice, T. (1982). Specific impaiments of planning. Philosophical Transactions of the Royal Society of London. Series B: Biological Sciences, 298, 199-209.

Shallice, T., \& Burgess, P. W. (1991). Deficits in strategy application following frontal lobe damage in man. Brain, 1/4, 727-74.

Velligan, D. I., Mahurin, R. K., Diamond, P. L., Hazleton, B. C., Eckert, S. L.» \& Miller, A. L. (1997). The functional significance of symptomatology and cognitive function in schizophrenia. Schizophrenia Researeh" $25,21-31$.

Wechsler, D. (1955). Wechsler Adult Intetligence Scale. Manual. New York: Psychologicall Corporation.

Wilson, B. A Alderman, N., Burgess, P. W. Enislie, H. E., Evans, J. J. (1996). Behoulowral Assessment of the Dysexecutive Syndrome. Bury St Edmunds, Eugland: Thames Valley Test Company. 


\section{Epilogue}

We examined the nature of the cognitive deficits in schizophrenia. Our aim was not to add another cognitive deficit to an already impressive list. Instead, we wanted to identify deficits that may be central to the cognitive impairment in this disorder. First, we analysed the memory impairment in schizophrenia, using speed of information processing as a possible elementary process in memory performance. Second, we investigated the extent to which the cognitive impairment in schizophrenia is better characterized by a generalized versus a specific deficit, again using speed of information processing as the starting point. The nature of the cognitive deficits was further investigated in first-degree relatives of patients with schizophrenia. Furthermore, to investigate the disease specificity of the cognitive deficits, we compared the cognitive profile of patients with schizophrenia to that of patients with bipolar disorder. Several hypotheses were tested concerning the structural brain abnormalities that may be associated with the cognitive deficits in schizophrenia as well as bipolar disorder. A separate chapter was devoted to the presence of cognitive deficits in schizophrenia as a risk factor for the emergence of tardive dyskinesia. The remainder of the thesis concerned the assessment of the functional consequences of cognitive executive deficits in schizophrenia. We will summarize the findings and discuss implications for further research as well as for clinical practice. 


\section{Summary and implications of findings}

General slowing of information processing is a significant aspect of memory performance in schizophrenla

By examining the associations between test performance in a hierarchical multiple regression analysis, it could be demonstrated that a general slowing of information processing accounted for defective memory performance in schizophrenia (chapter 3). This result contrasts with the view expressed by other authors (Landrø, 1994; McKenna et al., 1990), namely, that memory deficit is a primary component of the cognitive profile in schizophrenia. Instead, the deficit may be secondary to a general slowing, which acts as a fundamental limiting factor. Whether this accounts for other cognitive domains as well should be elucidated by further research.

The mediating role of speed in memory performance is not incompatible with the hypothesis of working memory dysfunction as the key deficit in schizophrenia. The two functions may be related. For example, general pracessing speed has been shown to be relevant for improvement of working memory capacity in children (Fry \& Halle, 1996). Salthouse (1996) has outlined a mechanism that can explain the relationship between processing speed and working memory in cognitive aging. The basic idea of this 'simultaneity mechanism' is that a slower speed of information processing results in the loss of the products of early processing by the time that later processing is completed. This leads to a reduction in the amount of simultaneously available information, which can be conceptualized as working memory. Thus, slowing of cognitive processing could be the mechanism by which the capacity of working memory is reduced in schizophrenia. Alternatively, it is possible that mental slowing is not the critical mediating factor. Instead, it may be the manner in which differences in processing. efficiency become manifest in speed tests, while some other factor determines these differences in efficiency, for example the control of processing resources.

The role of processing speed in memory impairment suggests that a simple coping strategy may be useful, namely, to take more time to process information. Unfortunately, according to the simultaneity mechanism described by Salthouse (1996), this strategy will not be successful. Because the critical limitations are based on internal dynamics, the detrimental effect of mental slowing on memory will occur regardless of the amount of time allowed for processing. Nonetheless, there is no direct evidence that the simultaneity mechanism truly accounts for the effect of processing speed in schizophrenia. The best proof might well be to investigate whether or not memory performance increases with increased encoding time (cf. the study in aged people by Rabinowitz, 1989). 
The cognitive deficit in schizophrenia is characterized by a disproportionate slowing on complex cognitive tasks which involve the maintenance of a certain cognitwe set over time Using timed tests that involve subtasks with increasing complexity, we were able to demonstrate specific deficits in the performance of complex cognitive processing tasks, which occurred over and above a general slowness on simple tasks (chapter 4). This pattern of impairment was also present in a subsample of patients who had an average or above average IQ score. The specific slowing in this type of processing is in accordance with recent proposals that the core cognitive deficit in schizophrenia is an impairment of the maintenance of contextual information, or working memory, and of the ability to use this information to inhibit inappropriate responses (Goldman Rakic, 1994; Servan-Schreiber, Cohen \& Steingard, 1996). Such a deficit may account for the common feeling of people with schizophrenia of being overloaded by environmental triggers. The working memory system guides the interpretation of impressions and enables individuals to suppress responses to irrelevant stimuli that catch their attention (Van den Bosch, 1995). When this system fails, the result is a cognitive overload with fragmentary impressions.

Being relatively independent of the presence of psychotic symptomatology, this working memory deficit can be considered part of a lasting vulnerability to schizophrenia, together with other deficits involving early sensory-perceptual processing (Nuechterlein, Dawson \& Green, 1994). In this view, reduced working memory is seen as a core deficit because it is persistent and not closely linked to psychotic symptoms. The relationship between symptoms and cognitive functions has also been approached from the opposite position. Taking a particular symptom of schizophrenia as a starting point, investigators have triled to identify dysfunctional cognitive mechanisms that can explain this symptom. This kind of research has provided cognitive models for individual symptoms such as hallucinations (for example, Bentall, 1990; Bentall, Baker \& Havers, 1991) and those of alien control (for example, Frith, 1992).

The vulnerability approach and the symptom approach complement rather than exclude each other. The symptom approach clearly offers more clues to the understanding of single symptoms. A significant advantage of this approach is that it is not impeded by the uncertain validity of the schizophrenia diagnosis (Costello, 1992 see also below). Howewer, the symptom approach fails to account for the finding that some cognitive deficits endure in non-symptomatic periods (Cantor Graae, Warkentin \& Nilsson, 1995), and nor does it account for the presence of stable cognitive deficits in children who go on to develop schizophrenia in adulthood (Mirsky, Ingraham \& Kugelmass, 1995). Although the vulnerability approach can as yet not adequately explain if and how cognitive vulnerability is involved in the development of the disorder, it probably has more potential to resolve this issue than the symptom approach.

With regard to clinical neuropsychological practice, it seems fair to say that the emphasis 
until now was on the vulnerability indicators rather than on the mechanisms underlying single symptoms. The tests that are used are generally sensitive to impaired attention, memory, and executive functions. These tests yield information about the nature and severity of the cognitive vulnerability, but do not tell us much about the origins of psychotic symptoms. Perhaps the current neuropsychological instrumentarium should be supplemented with tests of, for example, reality monitoring (Bentall et al., 1991), theory of mind (Frith \& Corcoran, 1996), and the judgment of contingencies (Brugger \& Graves, 1997).

The cognitive performance of first-degree relatives of patients with schizophrenia is characterized by subtle deficits in several cognitive domains

Further support for the view that the cognitive deficits in patients with schizophrenia are to some extent part of a lasting vulnerability to the disorder came from the study in first-degree relatives (chapter 5). First-degree biological relatives of patients with schizophrenia have a risk of developing schizophrenia about 10 times that of the general population (Kendler \& Diehl $_{3}$ 1993) . Cognitive deficits which are part of the genetic vulnerability should also be present in the relatives who carry the risk for schizophrenia. Our study yielded evidence for significant impairments in verbal memory and speed of information processing in relatives compared to matched controls from the general population. Overall, the performance of the relatives tended to be worse than that of the controls in each of the cognitive domains, similar to the pattern of deficits in the patients, although less severe. The pattern of deficits in the relatives further parallelled that found in the patients, in that both groups had a disproportionate slowing on complex tasks involving cognitive flexibility and working memory, above a general slowing. The cognitive deficits that were observed in the relatives cannot be secondary to illnesserelated factors, such as effects of medication and psychopathology, as they were found in healthy individuals. These findings are consistent with other studies, suggesting that relatives have deficits that are qualitatively similar, but more subtle compared to patients with schizophrenia (Faraone et al., 1995; Keefe et al., 1994; Lyons et al., 1995). The results suggest that this profile of cognitive impairment can be considered an indicator of the cognitive vulnerability to schizophrenia.

The cognitive deficits in schizophrenia are not disease specific, but are found in bipolar disorder as well

Outpatients with bipolar disorder in remission have a pattern of cognitive deficits which resembles that seen in patients with schizophrenia (chapter 6). In both groups, the cognitive deficits involve memory, attention and speed of information processing, and cognitive flexibility. However, the performance deficit was generally less severe in patients with bipolar 
disorder than in patients with schizophrenia. Whether the cognitive deficit in bipolar disorder resembles that in schizophrenia in other respects as well, (ie, a significant role of speed in memory performance) should be elucidated by future studies.

The pattern of cognitive deficits may represent a final common pathway for both types of disorder (Zihl, Gron \& Brunnauer, 1998), even though different types of brain abnormality are involved. For example, in the case of bipolar disorder, a negative effect of repeated episodes of mania or depression has been proposed (Altshuler, 1993). Alternatively, bipolar disorder and schizophrenia may both be characterized by brain abnormalities of a neurodevelopmental origin (Nasrallah, 1991). This would be in accordance with suggestions that bipolar disorder and schizophrenia are related disorders (Crow, 1990; Taylor, 1992).

The lack of differentiated cognitive profiles is in accordance with the limited predictive value of the categorical representations with regard to other clinical variables, such as treatment and symptom course (Johnstone, Crow, Frith, \& Owens, 1988; Van Os et al., 1996, 1999; Van Praag, 1992). A dimensional representation of psychopathology appears to be more useful. Studies investigating the full range of psychotic symptoms have typically generated at least four dimensions, namely positive, negative, manic, and depressive (Van Os et al., 1999). It might be that cognitive deficits occur in the context of specific dimensions of psychopathology. For example, in the study by Van Os et al., impaired cognitive performance was found in relation to the negative dimension, independent of the psychiatric diagnosis.

The implications of our study for clinical neuropsychological practice should not go unnoticed. Patients with schizophrenia and those with bipolar disorder cannot be qualitatively distinguished with sufficient reliability on the basis of their cognitive performance. In both disorders, cognitive deficits are present during relatively non-symptomatic periods and the pattern of deficits is only quantitatively different.

The cognitive deficut in schizophrenia may be related to medial temporal pathology, but overall there is a lack of significant associations between structural brain abnormalities and cogmiltive functioning in schizophrenia

In the study reported in chapter 4 we found evidence for a significant association between the volume of the parahippocampal gyrus and performance on the Stroop Color-Word Test, although the volume of this structure in the patient group was not smaller than that of the control group. A significant association between parahippocampal gyrus and cognitive performance has been reported before (Nestor et al., 1993). Overall, however, findings regarding a relationship between cognitive functioning and the volume of brain structures are ambiguous (e.g., DeLisi et al., 1995; Goldberg, Torrey, Berman \& Weinberger, 1994; Nestor et al., 1993; Seidman et $\mathrm{al}_{\text {, }}$ 1994). As in our study, it is not unusual to find one or two positive correlations when a rather large number of correlational analyses are performed. 
It might well be that the relationship between brain abnormalities and cognitive functions is more complicated than is assumed in the search for structural correlates of abnomal cognition. Converging lines of evidence point to disturbed interactions between brain areas. Thus, a computer simulation of reduced communication between brain areas, developed by Hoffman and McGlashan (1993), has suggested that this type of pathology leads to a fragmented network, parts of which produce autonomously their own output and thereby disturb the functioning of the system as a whole. Hoffman and McGlashan hypothesized that excessive cortical pruning during dewelopment leads to reduced cortico-cortical connectivity. Several authors have proposed that this dysconnectivity specifically relates to fronto-temporal circuits (Gold \& Weinberger, 1995; Goldberg et al., 1994), but alternative views implicate frontal-striatal disturbances (Pantelis et al., 1997) or defects in the circuitry connecting the thalamus, frontal cortex, and cerebellum (Andreasen, 1997).

If distributed rather than focal pathology is associated with schizophrenia, then the search for brain correlates of cognitive dysfunction should use parameters that reflect this dysconnectivity. An example may be the abnormal correlations between the volume of different brain areas. Some recent studies have applied correlational and multivariate analyses of structural MRI data (Bullmore et al., 1998; Woodruff et al., 1997). Given that the volumes of densely interconnected areas, such as prefrontal and superior temporal cortices, are highly correlated, the authors predicted that these correlations would be reduced when there is a disturbed connectivity, such as occurs in schizophrenia. The results of these two studies supported this hypothesis. However, another study found stronger than normal relationships between volumes in these areas (Wible et al., 1995).

\section{Compared to matched controls, there is no increase in white matter lesions in patients with bipolar disorder or schizophrenia}

One possible cause of the disturbed connectivity discussed above might be an increase in the number or" extent of white matter lesions, since such lesions can damage fiber tracts (Leuchter et al., 1994). Schizophrenia is associated with obstetric complications (Dalman, Allebeck, Cullberg, Grunewald \& Köster, 1999), and these may cause an increased prevalence of such lesions (Baenziger et al., 1993). Some studies have investigated the prevalence of white matter lesions in schizophrenia (Bartzokis et al., 1991; Persaud et al., 1997; Swayze, Andreasen, Alliger, Ehrhardt \& Yuh, 1990). In the study by Persaud et al. patients with schizophrenia had significantly greater areas of the brain affected by white matter lesions than did healthy controls and Bartzokis et al. reported more large white matter lesions in patients with schizophrenia compared to healthy controls. However, the study by Swayze et al. did not find any differences between patients with schizophrenia and healthy controls. Our data also did not support the notion of a higher than normal prevalence of white matter lesions in patients with 
schizophrenia nor in patients with bipolar disorder (chapter 6). Neither was the number of lesions related to cognitive functioning, which suggests that some other factor underlies the cognitive deficits. Small white matter lesions apparently did not affect cognitive functioning. since these lesions were also seen in the cognitively normal control group.

The cognitive dysfunction associated with orofacial dyskinesia can be specified as an impairment of active retrieval from long-term memory

Cognitive dysfunction is a robust clinical correlate of tardive dyskinesia in schizophrenia (Waddington, 1995). In particular, the orofaciall form of dyskinesia appears to be associated with cognitive impairment (Brown, White \& Palmer, 1992; Waddington, O'Callaghan \& Kinsella, 1993; Waddington \& Youssef, 1986). Our study showed that this impairment occurs in the form of a specific deficit of active retrieval from long-term memory (chapter 7). Although an impairment of memory could suggest temporal lobe/hippocampal involvement (Tranel \& Damasio, 1995), the association with active recall but not recognition is more in line with the pattern of memory impairment seen in patients with basal ganglia pathology, such as Huntington's and Parkinson's disease (Brandt \& Rich, 1995). The results emphasize the importance of using specific cognitive test procedures in the search for the cognitive correlates of dyskinesia.

Relevant to clinical practice is the question whether it is possible to predict who is at risk for subsequent tardive dyskinesia. Because tardive dyskinesia is a rare disorder, prediction is rather difficult. In a study of a range of risk factors, Van Os et al. (1997) concluded that the presence of individual risk factors was of little use in the prediction of subsequent dyskinesia, although prediction was better when a combination of risk factors was present. Furthermore, the cognitive dysfunctions do not necessarily precede the development of dyskimesia. In a prospective study, Waddington and Youssef (1996) found that dyskinesia and cognitive deterioration occurred in the same time frame. It seems thus not wery likely that the presence of cognitive deficits can be used to predict the future emergence of tardive dyskinesia.

\section{Deficits of executive functions should be assessed with both quantitative and qualitative methods}

The cognitive deficits in schizophrenia restrict a person's ability to function in social and vocational roles, possibly even more than the psychotic symptoms do (Green, 1996). Daily life functioning will be particularly hampered by impaired executive functions, for instance when planning capacities are insufficient to handle novel and unstructured situations. The functional consequences of impaired executive functions are, however, difficult to judge on the basis of formal neuropsychological testing procedures. Thus, patients with gross difficulties in daily 
life, may perform within normal limits on well-known standard tests of executive functioning.

In the study described in chiapter 8 , we used a new test battery that assesses executive functions in a comprehensive manner. The Behavioural Assessment of the Dysexecutive Syndrome (BADS; Wilson, Alderman, Burgess, Emslie \& Evans, 1996) presents the subject with a series of unstructured tasks that are designed to reflect daily life situations. These tasks were performed poorly by patients with schizophrenia who were otherwise relatively mildly impaired. Performance deficits on the BADS were related to problems with daily life functioning. However, the strength of the associations was only modest. This can probably partly be explained by the fact that there will always be differences between the demands of the test setting and those of daily life (Acker, 1990). For schizophrenia, the most important difference might well be that everyday life requires self-motivation and persistence, whereas in the testing situation motivation is often aided and persistence encouraged by the examiner.

On the other hand, the capacity of the BADS to predict functional consequences of deficits can presumably be increased further. Executive functions involve how things get done rather than just what gets done. These processes are poorly assessed with quantitative methods. Therefore, direct observation of these processes adds significant information to the assessment of executive functions. Our clinical experience with the BADS suggests that the test yiellds qualitative information which is sometimes lost when profile scores are computed. These qualitative scores may be the starting point for the development of a scoring system for the BADS which is also sensitive to the process of performance.

\section{The nature of causality}

A final comment refers to the nature of the causality of brain and behavioral abnormalities in schizophrenia. The prevailing wiew holds that the brain abnormalities cause the behavior, probably via disturbed cognitive processing. For example, altered dopamine levels lead to an interruption of the capacity to integrate current sensory input with stored memories, which in turn causes symptoms such as disorganized speech and thought. Yet, while a causal link between, for example, cognition and symptoms may sound plausible, a more mundane explanation is that the cognitive deficits are merely markers of vulnerability and are not causally involved. There is some evidence from longitudinal studies that does suggest a causal role of cognitive abilities (David, Malmberg, Brandt, Allebeck \& Lewis, 1997; Serper, Davidson \& Harvey, 1994), but definite evidence is hard to obtain, because experimental manipulation of the presumed causal factors is not easy to achieve.

Even if one assumes a causal link from brain abnormalities via cognitive processes through symptoms, the nature of this causality might be different from the type found in the physical sciences. Bolton and Hill (1997) have argued that in the biological sciences, including psychiatry, the nature of causality is intentional. The intentional causal process in human behavior is 
the pursuit of the experience of continuity, coherence, and efficacy. Consider, for example, the information processing deficit in schizophrenia according to Gray and colleagues (Gray, Feldon, Rawlins, Hemsley \& Smith, 1991; Hemsley, 1993). The experience of the individual with such a deficit will be fragmented and discontinuous (i.e., disorganization) and will render action impossible (i.e., negative symptoms). Thus, the information processing deficit will lead to chaotic experience and behavior, and to apathy. In contrast, particular symptoms of schizophrenia, namely delusions and hallucinations, are often unambiguous and have clear implications for actions. These psychotic symptoms may well be the outcomes of coping strategies that attempt to restore the integrity of the experience and to provide a basis for action. In this sense, these phenomena are more than just the consequences of altered dopamine levels. Clearly, this is only one framework for viewing the disorder, but it serves to illustrate that the range of phenomena associated with schizophrenia can only be understood as a combination of a non-intentional disruption of neurophysiology with intentional processes that operate to restore meaning and action.

\section{Conclusion}

The use of specific cognitive tests can elucidate the nature of the cognitive deficits in schizophrenia. By using these methods, it was demonstrated that cognitive speed is an important determinant of the memory impairment in schizophrenia. Further, in addition to a general impairment of processing speed, there was evidence for a disproportionate slowing on a particular type of information processing, namely in relation to working memory tasks. The general impairment, but also the disproportionate slowing on working memory tasks, was also present in those who carry the risk for schizophrenia, but are not ill themselves. This suggests that this pattern of cognitive deficits is part of a lasting vulnerability to schizophrenia. The results further indicate that such a pattern of deficit is not specific to schizophrenia, but is found in bipolar disorder as well. The importance of using specific test procedures was further emphasized in the search for the cognitive correlates of tardive dyskinesia. Patients with schizophrenia who have developed tardive dyskinesia had a more pronounced deficit than those who did not, and this deficit was specifically related to retrieval from long-term memory. Cognitive assessment can also have as its aim to predict the consequences of cognitive deficits for daily life skills. In that case, qualitative assessment methods should complement the quantitative procedures.

In conclusion, the studies described in the thesis demonstrate that the cognitive perspective can contribute significantly to the research into schizophrenia. The investigation of cognitive deficits provides information on both the brain abnormalities and the behavioral disorders that 


\section{8 | CHAPTER}

accompany schizophrenia. In this way, the cognitive perspective can provide a means to integrate the biological and behavioral aspects of this complex disorder. 


\section{References}

Acker, M. B. (1990). A review of the ecological validity of neuropsychological tests. In D. E. Tupper \& K. D. Cicerone (Eds), The newropsychology of evenyday lafe: Assessmen ama basic comperonches, (pp. 19-56). Boston: Kluwer Academic Publishers.

Altshuler, L. L. (1993). Bipolar disorder: Are repeated episodes assoctated with neuroanatomic and cognitive changes? Biological Psychratry, 33, 563-565.

Andreasen, N. C. (1997). The role of the thalamus in schizophnenia. Canadian Jownal of Psychamy, 42, 27. 33.

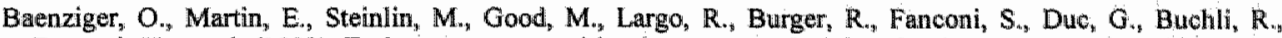
Rumpel, $H_{n}$ et al. (1993). Early pattern recognition in severe perinatal asphyxia: A prospective MRI study. Neturoradiology, $35,437-442$.

Bartzokis, G., Garber, H. J., Griswold, V. J., Oldendorf, W. H., Mintz, J. \& Marder, S. (1991) "T2 hyper. intense foci on magnetic resonance images of schizophrenic patients and controls. Psychiatry Research: Newroimaging, 40, 239-245.

Bentall, R. P. (1990). The illusion of reality: A review and integration of psychological research on hallucinations. Psychological Bulletin, 107, 82-95.

Bentall, R. P. Baker, G. A., \& Havers, S. (1991). Reality monitoring and psychotic hallucinations. British Jowrnal of Clinical Psychology, 30, 213-222.

Bolton, D., \& Hill, J. (1997). Mind, meaning and mental disorder. The mature of causal explamation in psychology and psychiatry. Oxford: Oxford University Press.

Brandt, J** \& Rich, J. B. (1995). Memory disorders in the dementias. In A. D. Baddeley, B. A. Wilson, \& F. N. Watts (Eds.), Handbook of memory disorders, (pp. 243-270). Chichestier: Wiley.

Brown, K. W., White, T., \& Palmer, D. (1992). Mowement disorders and psychological tests of frontal lobe function in schizophrenic patients. Psychological Medicine, 22, 69-77.

Brugger, P., \& Graves, $\mathbb{R}$. E. (1997). Testing vs. believing hypothesis: Magicall ideation in the judgment of contingencies. Cognitive Neuropsychiary, 2, 25 1-272.

Bullmore, E. T., Woodruff, P. W., Wright, I. C., Rabe-Hesketh, S., Howard, R. J., Shuriquie, N., \& Murray, R. M. (1998). Does dysplasia cause anatomical dysconmectivity in schizophrenia? Schizophrenio Reseorch, $30,127-135$.

Cantor Graae, E., Warkentin, $\mathrm{S}_{.,}$\& Nilsson, A. (1995). Neuropsychological assessment of schizophrenic patients during a psychotic episode: Persistent cognitive deficit? Acta Psychiatrica Scandinavica, 91, 283288.

Costello, C. (1992). Research on symptoms versus research on syndromes. Arguments in favour of allocating more research time to the study of symptoms. British Journal of Pspchiary, 160, 399-412.

Crow, T. I. (1990). The continum of psychosis and its genetic origins: The sixty-fifth Maudsley lecture. British Journal of Psychiatry, 156,788-797.

Dalman, C., Allebeck, P., Culberg, J., Grunewald, C., Koster, M. (1999). Obstetric complications and the risk of schizophrenia. Archives of General Psychiatry, 56, 234-240.

David, A. S., Malmberg, A., Brandt, L., Allebeck, P., Lewis, G. (1997). IQ and risk for sohizophrenia: A population-based cohort study. Psychological Medicine, $27,11311-1323$.

DeLisi, L. E.., Tew, W., Xie, S Hoff, A. L., Sakuma, M., Kushner, M., Lee, G., Shedlack, K., Smith, A.

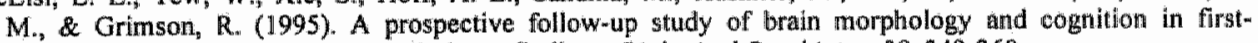
episode schizophrenic patients: Prelimnary fundings. Biologgical Psychialy, 38, 349-360.

Faraone, S. V., Seidman, L. J., Kremen, W. S., Pepple, J. R., Lyons, M. J., Re Truang "M. T. (1995). Neuropsychological functioning among the nonpsychotic relatives of selizophrenic patients: A diagnostic efficiency analysis. Journal of Abnormal Psychology, 104, 286-304

Frith, C. D. (1992). The cognitive neuropsychalogy of schizophrenia. Hove: Lawrence Erlbaum Associates.

Frith, C. D., \& Corcoran, R. (1996). Exploring 'theory of mind' in people with schizophrenta. Psychological Medicine, $26,521-530$.

Fry. A. F. \& Halle, S. (1996). Processing speed, working memory, and fluid intelligence: Evidence for a developmental cascade. Psychological Science, 7, 237-241.

Gold, J. M. \& Weinberger, D. R. (1995). Cognitive deficits and the neturobiology of schizophrenia. Current Opinion in Neurabiology, 5, 225-230.

Goldberg. T. E., Torrey, E. F., Berman, K. F., \& Weinberger, D. R. (1994). Relations between neuropsychological performance and brain morphological and physiological measures in monozygotic twins discordant for schizophrevia Psychiary Research, $55,51-61$.

Goldman Rakic, P. S. (1994). Working memory dysfunction in schizophremia. Journal of Neuropsychiarry and Clinical Netriosciences, $6,348-357$. 
Gray, J. A., Feldon, I., Rawlins, J. N. P., Hernsley, D. R. \& Smith, A. D. (199.1). The newropsychology of schizophrenia. Behurvoral and Brain Sciences, 14,1-84.

Green, M. F. (1996). What are the functional consequences of neurocognifive deficits in schizophrenia? Americon Journal of Pychatry, 153,321-330.

Hensley, D. R. (1993). A simple (or simplistic?) cognitive model for schizophrenia. Beharour Research and Therapy, $3 /, 633-645$

14ofman, R. E. McGisthan, T.H. (1993). Parallel distributed processing and the emergence of schizophrenic synuptoms. Schizophrenia Bulletin, 19. 119-139.

Johnstone, E.C., Crow, T.J., Frith, C.D., \& Owens, D.G. (1988). The Northwick Park "functional' psychosis study: Diagnosis and treatment response, Lancet, $11,119-125$.

Keefe, R. S. E. Silverman, J. M. Rotman, S. E. L., Harvey, P. D., Duncan, A. Mf, Alroy, D., Siever, L. J Davis, K. L., \& Mohs, R. C. (1994). Performance of nonpsychotic relatives of schizophrenic patiemts on cognitive tests. Psychiatry Rerearch, $53,1-12$.

Kendler, K, S., \& Diehl, S. R. (1993). The genetics of schizophrenia: A current, genetic-epidemialogic perspective. Sohtzophrenia Bulletio, $19,261-285$.

Landro, W. I. (1994). Menory function in schizophrenia. Acta Psychiatrica Scandinavica, 90 (suppl 384), 8794.

Letuhter, A. F, Durkin, J. J., Lufkin, R. B., Anzail, Y., Cook, 1. A., \& Newton, T. F. (1994). Effect of white matter disease on functional connections in the aging brain. Journal of Neurology Neurosurgery, and Pisychioby, $57,1347-1354$

Lyons M. $_{\text {., }}$ Toomey, R., Seidman; L. J., Kremen, W. S., Faraone, S. V., \& Tsuang, M. T. (1995). Verbal leaming and memory in rellatives of schizophrenics: Preliminary findings. Biological Psychiatry, 37, 750753.

McKenna, P. I., Tamilyn, D., Lund, C. E., Mortimer, A. M., Hammond, S. \& Baddeley, A. D. (1990). Amnesic syndrome in schizophrenia. Psychological Medicine, 20, 967-972.

Mirsky, A. F. Ingraham, L. J., \& Kugelmass, S. (1995). Neuropsychologicall assessment of attention and its pathology in the Israeli cohort. Schizophenta Buherir, 21, 193-204.

Nasrallah, H. A. (1991). Neurodevelopmental aspects of bipolar affective disorder. Biological Psychiatry, 29. 12.

Nestor, P. G, Shenton, M. E., McCarley, R. W., Haimson, J., Smith, R. S, Obonnell, B., Kimble, M., Kikinis, R., \& Jolesz, F. A. (1993). Neuropsychological correlates of MRI temporal lobe abnomalities in schizophrenia. American Joumal of Psychiary, 150, 1849-1855.

Nuectuterlein, K. H., Dawson, M. E., \& Green, M. F. (1994). Information processing abnormalities as neuropsychological vulnerability indicators to schizophrenia. Acta Psychiatrica Scandinavica, 90 (suppl 384), 71 79.

Pantelis, C., Barnes, T. R., Nelson, H. E., Tanner, S., Weatherley, L, Owen, A. M., \& Robbins, T. W. (1997). Frontal-striatal cognitive deficits in patients with chronic schizophrenia. Brain, 120, 1823-1843.

Persaud, R., Russow, H., Harvey, I., Lewis, S. W., Ron, M., Murray, R. M., \& du Boulay, G. (1997). Focal signal hyperintensities in schizophrenia. Schizophrenia Research, 27, 55-64.

Rabinowitz, J. C. (1989). Age deficits in recall under optimil study conditions. Psychology and Aghth, 4, 378380.

Salthouse, T. A. (1996). The processing-speed theory of adult age differences in cognition. Psychological Review, $103,403-428$.

Seidman, L. J, Yurgelun Todd, D. Kremen, W. S., Woods, B. T., Goldstein, J. M., Faraone, S. V., \& Tsuang. M. $\Upsilon^{*}$ (1994). Relationship of prefrontal and temporal lobe MRI measures to neuropsychological performance in chronic schizophtrenia. Biological Psychiatry, 35, 235-246.

Serper, M. R., Davidson, M., \& Harvey, P. D. (1994). Attentional predictors of clinical change during neuroleptic treatment in schizophrenia. Sconzophenta Research, 13, 65-71.

Servan-Schreiber, D., Cohen, J. D., \& Steingard, S. (1996). Schizophrenic deficits in the processing of context. A test of theoretical model. Apchives of Generd Psychiatin, 53, 1105-1112.

Siwayze, V. W. Andreasen, N. C., Alliger, R. J., Ehrhardt, J. C., \& Yuh, W. T. (1990). Structural brain abnormalities in bipolar affective disorder. Ventricular enlargement and fockl signal hyperintensities. Archives of Genaral Psychiary, 47, 1054-1059.

Taylor. M. A. (1992). Are schizophrenia and affective disorder related? A selective literature review. American Jownal of Pychiatry, 149, 22-32.

Tranel, D. \& Damasio, A. R. (1995) . Neurobiological foundations of human memory. In A. D. Baddeley, B. A. Wilson, F. N. Watts (Eds.), Homabook of memory disorders, (pp. 27-50), Chichester: Wiley.

Van den Bosch, R. J. (1995), Context and cognition in schizophrenia. In I. A den Boer, H. G. M. Westenberg, \& H. M. wan Praag (Eds.), Aduances in the neurobiology of schizophrenia, (Vol. 1, pp. 343-366). Chichester: Willey. 
Van Os, J., Fahy, T., Jones, P., Harvey, I., Lewis, S., Sham, P., Toone, B., Murray, R. (1996). Psychopathological syndromes in the functional psychoses: Associations with course and outcome. Psychological Medicine, 26, 203-208.

Van Os, J., Fahy, T., Jones, P., Harvey, I., Toone, B., Murray, R. (1997). Tardive dyskinesia: Who is at risk? Acta Psychiatrica Scandinavica, $96,206-216$.

Van Os, J., Gilvarry, C., Bale, R., Van Horn, E., Tattan, T, White, I., Murray, R., on behalf of the UK700 Group (1999). A comparison of the utility of dimensional and categonical representations of psychosis. Psychological Medicine, 29, 595-606.

Van Praag, H. M. (1993). "Make-believes" in psychiatry, or, the perils of progress. New York: Brunner I Mazell.

Waddington, J. L. (1995). Psychopathological and cognitive correlates of tardive dyskinesia in schizophrenia and other disorders treated with neuroleptic drugs. In W. J. Weiner \& A. E Lang (Eds.), Behowiaral Neurology of Movement Disorders, (Vol. 65, pp. 211-229). New York: Raven.

Waddington, J. L., O'Callaghan, E., \& Kinsella, A. (1993). Cognitive dysfunction in schizophrenia: Organic vulnerability factor of state marker for tardive dyskinesia? Brain and Cognition, 23, 56-70.

Waddington, J. L., \& Youssef, H. A. (1986). An unusual cluster of tardive dyskinesia in schizophrenia: Association with cognitive dysfunction and negative symptoms. American Journal of Psychiatry, 143, 11621165.

Waddington, J. L., \& Youssef, H. A. (1996). Cognitive dysfunction in chronic schizophrenia followed prospectively over 10 years and its longitudinal relationship to the emergence of tardive dyskinesia. Psychologiv cal Medicine, 26, 681-688.

Wible, C. G., Shenton, M. E., Hokama, H., Kikinis, R., Jolesz, F. A., Metcalf, D, \& McCarley, R. W. (1995). Prefrontal cortex and schizophrenia. A quantitative magnetic resonance imaging study. Archives of General Psychiatry, 52, 279-288.

Wilson, B. A., Alderman, N., Burgess, P. W., Emslie, H. E., \& Evans, J. J. (1996). Behowioural Assessment of the Dysesecutive Symdrome. Bury St Edmunds, England: Thames Valley Test Company.

Woodruff, P. W., Wright, I. C., Shuriquie, N., Russouw, H., Howard, R. J., Graves, M., Bullmore, E. T., \& Murray, R. M. (1997). Structural brain abnormalities in male schizophrenics reflect fronto-temporal dissociation. Psychological Medicine, 27, 1257 1266

Zihl, J., Gron, G., \& Brunnauer, A. (1998). Cognitive deficits in schizophrenia and affective disorders: Evidence for a final common pathway disorder. Acra Psychiatrica Scandinavica, 97, 351-357. 
$\therefore \quad, \quad, \quad$ 


\section{Summary}

The range of cognitive deficits in schizophrenia is very broad. It includes deficits of verbal and visual memory, attention, mental speed, and executive functions. The main theme of this thesis is the nature and specificity of these deficits. Several issues are addressed, including (i) whether a particular deficit, namely decreased processing speed, is central to the cognitive impairment, (ii) whether the cognitive impairment can be characterized better in terms of a generalized or a specific deficit, (iii) the relationship between cognitive deficits and brain abnormalities, (iv) cognitive functioning in first-degree biological relatives of patients with schizophrenia, (v) the specificity of the cognitive profile in schizophrenia compared to that in bipolar disorder, (vi) the cognitive correlates of tardive dyskinesia in schizophrenia, and (vii) the assessment of executive functions in schizophrenia.

Chapters 1 and 2 provide an introduction to these topics and a concise overview of relevant studies. As an illustration of the type of cognitive deficits in schizophrenia, commonly reported deficits in the domains of attention, memory, and executive functions are selected for discussion. It is argued that the challenge is not to add another deficit to the list of documented impairments, but instead to focus on the nature of the cognitive profile in schizophrenia. Therefore, the cognitive research in schizophrenia should use methods that yield insight into specific underlying deficits. It is suggested that speed of information processing may be a useful starting point, analogous to the research into cognitive aging. The relation between symptomatology and cognitive deficits is discussed shortly, as is the effect of medication. It is concluded that, although symptomatology and medication may affect cognitive performance to some degree, it is not likely that they can fully account for the cognitive deficits in patients with schizophrenia. This notwithstanding, the study of first-degree healthy relatives of patients with schizophrenia is mentioned as a useful line of research to examine the true nature of the cognitive functioning in schizophrenia vulnerability.

Chapter 3 reports a study that investigated whether memory deficits in schizophrenia can be accounted for by a decrease in processing speed, analogous to the assumed mediating role of processing speed in age differences in memory. This hypothesis was tested in a sample of 30 patients with schizophrenia and 30 healthy controls, who were matched for age, sex, and education. The mediating role of speed was investigated by using statistical control measures, namely, hierarchical multiple regression analyses. A distinction was made between sensorimotor and cognitive aspects of speed. The results showed that speed can account for a large 
part of the group differences in immediate recall performance, more so than a measure of attentional span. The effect of slowing on recall did not primarily reflect sensory and motor aspects, but involved speed measures that require more cognitive operations. This result contrasts with the view that the memory deficit is a primary component of the cognitive profile in schizophrenia. Instead, the deficit may be secondary to a general cognitive slowing, which acts as a fundamental limiting factor. The tentative suggestion is made that the slowing of cognitive processing can be the mechanism by which the capacity of working memory is reduced in schizophrenia.

Chapter 4 is directed at the question whether the cognitive impairment in schizophrenia is better characterized by a generalized versus a specific deficit. A study is reported, in which 27 outpatients with schizophrenia were compared with 19 matched healthy controls. The study also examined whether possible specific cognitive deficits were related to the volume of temporal and limbic structures, as measured with MRI. Using timed tests that involve subtasks with increasing complexity, it was demonstrated that patients with schizophrenia have specific deficits in the performance of complex cognitive processing tasks, which occur over and above a general slowness on simple tasks. No group differences were found with regard to temporal and limbic volume, but in the patient group the volume of the parahippocampal gyrus was correlated with cognitive performance, worse performance being associated with smaller volumes. The specific slowing on the complex processing tasks is in accordance with the hypothesis that the key cognitive deficit in schizophrenia is an impairment of the maintenance of contextual information, or working memory, and of the ability to use this information to inhibit inappropriate responses. The correlation of this deficit with the smaller volume of the parahippocampal gyrus is in accordance with a disturbance in the circuitry connecting dorsolateral prefrontal and temporal and limbic areas, a network which is thought to be important for working memory functions. However, since only one correlation between cognitive performance and brain structure volume was significant, it is concluded that the possibility of a chance finding cannot be excluded and so this finding needs to be replicated.

Chapter 5 presents the findings of a study on the cognitive performance in first-degree adult relatives of patients with schizophrenia. Previous studies have shown that biological relatives of patients with schizophrenia may have subtle cognitive impairments, which are part of the vulnerability to the disorder. The study was conducted in 50 patients with schizophrenia, 50 first-degree relatives of patients with schizophrenia, and 50 healthy controls from the general population. The groups were matched on age, sex, and level of education. All participants performed tasks of verbal memory, attentional span, speed of information processing, and cogni- 
tive flexibility. The performance of the relatives was slightly worse than that of the controls in each of the cognitive domains, similar to the pattern of deficits in the patients, although less severe. The pattern of deficits in the relatives further parallelled that found in the patients, in that both groups had a disproportionate slowing on complex tasks involving cognitive flexibility, above a general slowing, although in the relatiwes this effect was not as robust as it was in the patients. Current symptomatology in the patient group was not related to cognitive performance. These results provide strong support for the view that cognitive deficits in schizophrenia are an integral part of the vulnerability to the disorder, and cannot be considered secondary effects of illness related factors (i.e., medication, psychopathology).

Chapter 6 reports the results of a comparison of the cognitive performance in patients with schizophrenia and with bipollar disorder in remission. It has been suggested that schizophrenia and bipolar disorder are related, but this has not been examined from the point of view of cognitive functioning. Since bipolar disorder has been associated with an increased prevalence of white matter lesions, and some recent studies have reported a similar phenomenon in schizophrenia, the study also investigated this particular type of brain abnomality "Cognitive per formance and the occurrence of white matter lesions on MRI images were assessed in 22 patients with bipolar disorder in remission, 22 patients with schizophrenia, and 22 healthy volunteers. The most salient finding was that patients with bipolar disorder in remission have a rather diffuse pattern of cognitive deficits, similar to patients with schizophrenia, although less severe. In both groups the cognitive deficits involve memory, speed of information processing, and cognitive flexibility. The finding of cognitive deficits during the euthymic phase in bipolar disorder is emphasized, as the traditional view holds that cognitive deficits in mood disorder are state dependent. There were no statistically significant differences between the three groups in the occurrence and severity of white matter lesions, nor were there any relationships between cognitive deficits and white matter lesions in the two patient groups. "This lack of a relation suggests that some other brain abnormality underlies the observed cognitive deficits in bipolar disorder and schizophrenia.

Chapter 7 introduces a disorder which some patients with schizophrenia develop during the course of their illness. Tardive dyskinesia is characterized by involuntary, choreoathetoid movements of the orofacial region, limbs and trunk. It has been suggested that patients at risk for developing tardive dyskinesia are characterized by a more pronounced cognitive impair"ment, which is thought to reflect disturbed brain function. To specify the association between cognitive dysfunctions and tardive dyskinesia, a cognitive study was conducted as part of a large longitudinal project on the prevalence and incidence of extrapyramidal syndromes in 
Curaça. Fifty three patients with schizophrenia who had been taking neuroleptic medication for at least three months and who were younger than 65 years were included in this study. The neuropsychological assessment comprised tests of memory, cognitive flexibility, and speed of information processing. Of the six cognitive measures, only delayed recall was significantly associated with the orofacial form of tardive dyskinesia. It is suggested that this pattern of memory impairment is consistent with there being a frontal-subcortical disturbance in orofacial dyskinesia. Due to the cross-sectional design of the study, we could not determine whether this deficit precedes the development of orofacial dyskinesia. Nevertheless, our findings are in line with the suggestion that an illness-related factor, namely, cognitive deterioration, acts to increase the risk of tardive dyskinesia.

Chapter 8 describes a study which aim it was to assess the consequences of impaired executive functions. Executive funetions comprise the integration and monitoring of cognitive functions, involving how things get done rather than just what gets done. They are notoriously difficult to assess, because the structured testing situation does not give much opportunity to see how well someone can structure for oneself. We report the results of a study in which a new test battery is used that presents the subject with a series of unstructured tasks. The Behavioural Assessment of the Dysexecutive Syndrome (BADS) was designed to reflect daily life situations. Matched groups of 24 patients with schizophrenia and 17 healthy control volunteers were administered the BADS and standard tests of executive functions. To investigate the degree to which performance on the BADS predicted daily life skills, problems in daily life functioning in the patients with schizophrenia were rated by a relative or caregiver using standardized instruments. Performance of the patients with schizophremia was significantly below that of the control group on the BADS. In the patient group, scores on the BADS correlated weakly with those on another test of executive functions. Both tests showed a modest correlation with daily functioning. A possible explanation for the lack of strong relations between test performance and functional measures is given, namely, that although tests can be designed that reflect everyday activities as closely as possible, differences will remain between the demands of the test setting and those of daily life. Yet, it might be possible to increase the capacity of the test to predict functional consequences of deficits, by using qualitative information about the process of performance. Our clinical experience with the BADS suggests that the test yields significant qualitative information, which is sometimes lost when profile scores are computed. Several examples of qualitative scores that can be obtained with the BADS are discussed in this chapter. 
Chapter 9 provides a summary of the findings and a discussion of implications for further research and for clinical practice. Speed of processing is an important determinant of the memory performance in patients with schizophrenia. In this group the slowing of speed of processing is disproportionate on complex tasks compared to that on simple tasks. Further research can investigate the role of speed in cognitive functions other than memory. A specific deficit, namely, impaired recall from long-term memory, is found in relation to the presence of tardive dyskinesia in schizophrenia; it is, however, not possible to identify those at risk for tardive dyskinesia on the basis of their memory performance. Our findings point to the usefulness of specific cognitive test procedures in the analysis of the cognitive profile in schizophrenia. There also is a paftern of diffuse impairments on a range of cognitive domains, not only in patients with schizophrenia, but also in their well relatives. This indicates that the impairment is independent of symptomatology and not due to effects of medication or psychopathology. Patients with bipolar disorder have a similarly diffuse cognitive impairment during remission, although less severe. The correlations between this impairment and volume reductions in specific brain areas are generally not very high, possibly because the impairment most likely reflects distributed brain pathology. Future studies should use parameters of brain dysfunction that reflect this distributed pathology.

In conclusion, the studies described in the thesis demonstrate that the cognitive perspective can contribute significantly to the schizophrenia research. The investigation of cognitive deficits provides information on the nature of the brain abnormalities that are associated with schizophrenia and also on the behavioral disorders and problems in daily functioning that often occur. In this way, the cognitive perspective can provide a means to integrate the biological and behavioral aspects of this complex disorder. 


\section{Samenvatting}

Bij schizofrenie treedt vaak een reeks van cognitieve stoornissen op, onder andere van het geheugen, de aandacht, het mentaal tempo, en de planning en organisatie van gedrag. Deze cognitieve stoornissen vormen het onderwerp van dit proefschrift. Verschillende vraagstellingen komen aan de orde, namelijk (i) of een verminderd mentaal tempo gezien kan worden als de "basisstoornis", die aan de andere stoornissen ten grondslag ligt, (ii) of het cognitive profiel gezien moet worden als een gegeneraliseerde stoornis, of als een specifieke stoornis in eén of meer domeinen, (iii) in hoeverre de cognitieve stoornissen gerelateerd zijn aan bepaalde afwijkingen in de hersenen, (iv) in hoeverre cognitieve stoornissen voorkomen bij eerstegraads familieleden van patiënten met schizofrenie, (v) de specificiteit van de cognitieve stoornissen bij schizofrenie in vergelijking tot bipolaire stoornis, (vi) de aard van de cognitieve stoornissen die samenhangen met tardieve dyskinesie bij patiënten met schizofrenie, (vii) de samenhang tussen stoornissen in planning en organisatie van gedrag bij schizofrenie en problemen in het dagelijksfunctioneren.

In hoofdstuk 2 wordt een beknopt overzicht gegeven van het onderzoek naar cognitieve stoornissen bij schizofrenie. Ter illustratie worden stoornissen in de gebieden aandacht, geheugen en planning en organisatie van gedrag besproken. Geconcludeerd wordt dat het er nu niet zozeer om gaat om nog een stoornis aan de lijst toe te voegen, maar in plaats daarvan te zoeken naar een "basisstoornis" die mogelijk aan deze reeks stoomissen ten grondslag kan liggen. Geopperd wordt dat de verminderde snelheid van informatieverwerking een goed uitgangspunt kan zijn; verminderde snelheid wan informatieverwerking wordt vaak gevonden bij schizofrenie en uit de literatuur over cognitieve veroudering is gebleken dat verminderde snelheid consequenties heeft voor het cognitief functioneren. De samenhang tussen cognitieve stoornissen en symptomatologie wordt kort besproken, evenals de effecten van psychoactieve medicatie op het cognitief functioneren. Zowel symptomatologie als medicatie kunnen het cognitief functioneren enigszins beïnvloeden, maar niet het scala aan cognitieve stoornissen afdoende verklaren. Niettemin biedt het onderzoek bij mensen met een genetisch bepaalde kwetsbaarheid voor schizofrenie (bijvoorbeeld, eerstegraads familieleden) een goed alternatief om een zo zuiver mogelijk beeld te krijgen van de cognitieve stoornissen die deel uitmaken van deze kwetsbaarheid.

In hoofdstuk 3 wordt een onderzoek beschreven naar de invloed van verminderde snelheid van informatieverwerking op de prestatie op een geheugentaak bij patienten met schizofrenie, naar 
analogie van de rol van snelheid in achteruitgang in het geheugen bij het ouder worden. Dertig patiënten met schizofrenie en 30 gezonde controleproefpersonen werden onderzocht. De groepen waren gematcht op leeftijd, geslacht en opleidingsniveau. De mediërende rol van snelheid werd onderzocht met behulp yan een statistische methode, namelijk hiërarchische multipele regressie-analyse. Onderscheid werd gemaakt tussen cognitieve en sensomotorische aspecten van snelheid. Uit de arialyses bleek dat snelheid een groot deel van de groepsverschillen in de prestatie op de onmiddellijke reproduktie van de geheugentaak kon verklaren. Snelheid bleek hierbij van meer belang dan een andere onderzochte functie, aandachtsspanne. De invloed van snelheid had vooral te maken met de cognitieve, en minder met de sensomotorische aspecten van snelheid. De geheugenstoornis lijkt dus niet een primaire stoornis te zijn, maar een stoornis die voor een groot deel secundair is aan de verminderde cognitieve snelheid bij schizofrenie. De suggestie wordt gedaan dat verminderde snelheid van informatieverwerking ook ten grondslag kan liggen aan verminderde capaciteit van het werkgeheugen bij schizofrenie.

In hoofdstuk 4 staat de vraag centraal of de cognitieve stoornissen bij schizofrenie gezien moeten worden als een gegeneraliseerde stoornis of als een specifieke stoornis in één of meer domeinen. Dit werd onderzocht in een steekproef van 27 patiënten met schizofrenie en 19 op leeftijd, geslacht en opleiding gematchte controleproefpersonen. Daarnaast werd onderzocht of de cognitieve stoornissen gerelateerd waren aan het volume van temporale en limbische structuren in de hersenen, gemeten met MRI. Door gebruik te maken van tests voor snelheid van informatieverwerking, opgebouwd uit taken met toenemende moeilijkheidsgraad, kon worden aangetoond dat patiënten met schizofrenie een specifieke stoornis hebben in de complexe informatieverwerking. Deze stoornis was disproportioneel ten opzichte van de algemene traagheid op eenvoudige taken. Er waren geen verschillen tussen de groepen wat betreft het volume van de temporale en limbische hersenstructuren. In de patientgroep was de cognitieve prestatie echter gerelateerd aan het volume van de parahippocampale gyrus, waarbij een zwakkere prestatie samenhing met kleiner volume. De specifieke stoomis in de complexe informatieverwerking is in overeenstemming met de hypothese dat het werkgeheugen gestoord is bij schizofrenie. De correlatie tussen deze stoornis en het volume van de parahippocampale gyrus kan wijzen op een verstoring in het circuit dat de temporale en limbische structuren verbindt met de prefrontale cortex, een netwerk dat mogelijk betrokken is bij functies van het werkgeheugen. Er werd echter maar éen significante correlatie gevonden tussen cognitieve prestatie en volume van hersenstructuren, zodat de bevinding gerepliceerd zal moeten worden. 
In hoofdstuk 5 worden de resultaten besproken van een onderzoek naar het cognitief functioneren bij eerstegraadsfamilieleden van patiënten met schizofrenie. Er zijn aanwijzingen dat bij deze groep subtiele cognitieve stoornissen worden gevonden, die deel uitmaken van de kwetsbaarheid voor schizofrenie. Aan het onderzoek werd deelgenomen door 50 patiënten met schizofrenie, 50 eerstegraadsfamilieleden van patienten met schizofrenie en 50 gezonde controles uit de algemene populatie. De groepen waren gematcht op leeftijd, geslacht en opleiding. Het neuropsychologisch onderzoek bestond uit taken met betrekking tot aandachtsspanne, snelheid van informatieverwerking, verbaal geheugen en cognitieve flexibiliteit. De prestatie van de familieleden lag op alle taken enigszins lager dan de prestatie van de controlegroep. Het profiel van cognitief functioneren was daarmee gelijk aan dat van de patiënten met schizofrenie, hoewel de afwijkingen in bij de familieleden minder enstig waren. De familieleden hadden, net als de patiënten, specifiek moeite met complexe informatieverwerkingstaken, hoewel dit effect bij de familieleden minder duidelijk was dan bij de patiënten. De cognitieve prestaties waren onafhankelijk van de huidige symptomatologie in de patiëntgroep. De resultaten ondersteunen de opvatting dat de cognitieve stoornissen bij schizofrenie deel uitmaken van de kwetsbaarheid voor de stoornis, en niet secundair zijn aan andere factoren, zoals psychopathologie en medicatie.

In hoofdstuk 6 wordt een onderzoek beschreven naar de specificiteit van de cognitieve stoornissen bij schizofrenie in vergelijking tot bipolaire stoornis. Verschillende auteurs hebben gesuggereerd dat schizofrenie en bipolaire stoornis verwante aandoeningen zijn, maar dit is nog nauwelijks onderzocht vanuit de invalshoek van het cognitief functioneren. Er zijn aanwijzingen dat bij bipolaire stoornis een specifiek type hersenafwijkingen wordt gevonden, namelijk een toegenomen frequentie van witte-stof lesies. Eenzelfde bevinding is recent ook gedaan bij schizofrenie. In het onderzoek werd daarom ook de frequentie van witte-stof lesies in de hersenen bepaald. Bij 22 patiënten met bipolaire stoornis in remissie, 22 patiënten met schizofrenie en 22 gezonde controleproefpersonen werd een neuropsychologisch onderzoek afgenomen en een MRI-opname van de hersenen gemaakt. De belangrijkste bevinding was dat patiënten met bipolaire stoornis in remissie een diffuus patroon van cognitieve stoornissen vertonen, net alls de patiênten met schizofrenie, zij het minder ernstig. In beide groepen werden stoornissen gevonden op het gebied van snelheid van informatieverwerking, geheugen en cognitieve flexibiliteit. De bevinding van cognitieve stoornissen bij patienten met bipolaire stoornis gedurende remissie is van belang, omdat volgens de klassieke opvatting de cognitieve stoornissen bij stemmingsstoornissen alleen voorkomen tijdens manische of depressieve episodes. Er waren geen significante verschillen tussen de drie groepen wat betreft frequentie en ernst van de witte-stof lesies. De frequentie van de witte-stof lesies was niet gerelateerd aan de cognitieve stoornissen in de beide patiêntgroepen. Dit doet vermoeden dat een andere 
hersenafwijking ten grondslag ligt aan de cognitieve stoomissen in bipolaire stoornis en schizofrenie.

In hoofdstuk 7 wordt verslag gedaan van een onderzoek naar de cognitieve stoornissen die samenhangen met het optreden van tardieve dyskinesie bij schizofrenie. Tardieve dyskinesie is een bewegingsstoornis die gekenmerkt wordt door onwillekeurige choreatiforme bewegingen in het orofaciale gebied of in de axiale musculatuur en extremiteiten. Gedacht wordt dat de stoornis het gevolg is van langdurig gebruik van antipsychotica. Er zijn aanwijzingen dat de patiênten met schizofrenie die tardieve dyskinesie ontwikkelen ernstigere cognitieve stoornissen vertonen dan zij die geen tardieve dyskinesie ontwikkelen. Om de relatie tussen cognitieve stoornissen en tardieve dyskinesie verder te verduldelijken werd een deelonderzoek uitgevoerd in het kader van een groot longitudinaal onderzoek naar de prevalentie van bewegingsstoornissen op Curaçao. Bij 53 patiènten met schizofrenie, die allen minimaal 3 maanden antipsychotica gebruikt hadden, werden tests afgenomen op het gebied van geheugen, planning en organisatie van gedrag en snelheid van informatieverwerking. Alle patienten waren jonger dan 65 jaar. Er werd een significant verband gevonden tussen de aanwezigheid en de emst van orofaciale dyskinesie en zwakke prestatie op de uitgestelde reproduktie van de geheugentaak. Geopperd wordt dat dit patroon van geheugendisfunctie past bij een frontaal-subcorticale stoornis bij orofaciale dyskinesie. Omdat het onderzoek een cross-sectionele opzet had, kon niet worden nagegaan of de geheugenstoornis aan het ontstaan van de orofaciale dyskinesie voorafging. De bevindingen sluiten wel aan bij de opvatting dat een ziekte-gerelateerde factor, namelijk cognitieve achteruitgang, het risico op het ontstaan van tardieve dyskinesie verhoogt.

Het onderzoek dat wordt beschreven in hoofdstuk 8 was gericht op de functionele gevolgen van stoornissen in de planning en organisatie vari gedrag bij schizofrenie. Dergelijke stoornissen hebben vaak grote gevolgen voor het dagelijks functioneren, maar deze zijn niet makkelijk te woorspellen met behulp wan standaard neuropsychologische testmethoden. De standaard tests zijn veelal te gestructureerd on te kunnen onderzoeken in hoeverre een patiënt het vermogen heeft zelf structuur aan te brengen. In het onderzoek werd gebruik gemaakt van een nieuwe test, die speciaal ontwikkeld is om problemen in het dagelijks leven te voorspellen. De Behavioural Assessment of the Dysexecutive Syndrome (BADS) bestaat uit 6 onderdelen die elk een beroep doen op het vermogen tot plannen en organiseren van gedrag. De BADS werd tezamen met enkele standaard tests afgenomen bij 24 patiënten met schizofrenie en 17 gezonde controleproefpersonen, gematcht op leeftijd, geslacht en opleiding. Problemen in het dagelijks leven werden vastgesteld met behulp van gevalideerde vragenlijsten die ingevuld werden 
door een onafhankelijke beoordelaar, zodat het verband tussen prestatie op de BADS en dagelijks functioneren onderzocht kon worden. De patiènten presteerden significant slechter op de BADS dan de controleproefpersonen. In de patiêntgroep was er een significant verband tussen de prestatie op de BADS en de prestatie op een standaard test, en de prestatie op beide tests vertoonde een significante matig-sterke relatie met het functioneren in het dagelijks leven. Geopperd wordt dat het vermogen van de BADS om problemen in het dagelijks leven te voorspellen wellicht vergroot kan worden door meer gebruik te maken van kwalitatieve informatie. De klinische ervaring leert namelijk dat de BADS belangrijke kwalitatieve informatie oplevert, die niet altijd meegenomen wordt in de berekening van de profielscores. Verschillende voorbeelden van dergelijke kwalitatieve scores worden in het hoofdstuk gegeven.

In hoofdstuk 9 worden de belangrijkste bevindingen samengevat en wordt ingegaan op de betekenis ervan voor toekomstig onderzoek en voor de klinische praktijk. Verminderde snelheid van informatieverwerking blijkt een belangrijke bepalende factor te zijn in de verminderde geheugenfunctie bij mensen met schizofrenie. De achteruitgang in snelheid is disproportioneel op comlexe informatieverwerkingstaken, vergeleken met de snelheid op eenvoudige taken. Toekomstig onderzoek kan de invloed van verminderde snelheid op andere functies dan geheugen onderzoeken. Een specifieke stoornis in het geheugen, namelijk een gestoorde prestatie bij het actief ophalen van nieuw geleerde informatie uit het lange-termijngeheugen werd gevonden bij patiënten met schizofrenie die een tardieve dyskinesie hebben ontwikkeld; het is echter niet mogelijk om op basis van de geheugenfunctie te bepalen wie een verhoogd risico heeft op deze bewegingsstoornis. De resultaten onderstrepen de waarde van specifieke cognitieve testmethoden in de analyse van het cognitieve profiel bij schizofrenie. Behalve de specifieke stoornissen is er bovendien sprake van een diffuus patroon van cognitieve tekorten, niet alleen bij patienn ten met schizofrenie, maar ook bij hun gezonde biologische verwanten. Dit betekent dat de cognitieve stoornissen deels onafhankelijk zijn van de psychiatrische symptomatologie en ook niet toegeschreven kunnen worden aan de effecten van antipsychotische medicatie. Patiesnten met bipolaire stoornis in remissie vertonen eenzelfde diffuus patroon van stoornissen, zij het minder emstig dan patiënten met schizofrenie. De correlaties tussen de cognitieve stoornissen en verminderd volume van bepaalde hersenstructuren waren niet erg hoog, mogelijk omdat de stoornissen niet zozeer met focale als wel met verspreide pathologie in de hersenen samenhangen. Toekomstig onderzoek zou gebruik moeten maken van parameters die deze verspreide pathologie weerspiegelen.

Tenslotte, de onderzoeken die werden beschreven in dit proefschrift laten zien dat de cognitieve invalshoek een belangrijke bijdrage levert aan het onderzoek naar schizofrenie. Onderzoek naar de cognitieve stoornissen geeft enerzijds informatie over de aard van de hersenafwijkingen die bij schizofrenie een rol kunnen spelen en anderzijds over de mogelijke stoornissen in het 
gedrag en de problemen in het dagelijks functioneren. Op deze manier kan het cognitieve onderzoek een schakel vormen tussen de biologische en de gedragsmatige kanten van deze complexeaandoening. 


\section{Dankwoord}

Veel mensen hebben de afgelopen jaren op éen of andere wijze aan het onderzoek uit dit proefschrift bijgedragen. Een aantal van hen wil ik hier noemen.

Jelle Jolles, promotor, dank voor de mogelijkheid om dit onderzoek te doen. Ik heb genoten van onze samenwerking, vanwege je betrokkenheid, je enthousiasme, je vermogen steeds weer nieuwe hypothesen te bedenken en je gevoel voor humor. Mayke Derix, co-promotor, dank voor wat ik van je heb geleerd. Je hebt niet alleen een bijdrage aan het onderzoek geleverd, maar ook supervisie willen geven aan mijn activiteiten in de klinische neuropsychologie. Dat je daarnaast ook af en toe informeerde of ik wel genoeg sliep en at heb ik alleen maar gewaardeerd.

De leden van de leescommissie dank ik voor het beoordelen van het manuscript. Harald Merckelbach, je hebt steeds je enthousiasme voor het cognitieve onderzoek bij schizofrenie getoond en ik ben blij dat we nu een gezamenlijk project zijn begonnen. Jim van Os, dank voor je betrokkenheid bij mijn onderzoek en voor je eindeloze energie voor nieuwe projecten, ik vind het een voorrecht om met je samen te werken.

Mijn oprechte dank gaat uit naar alle 334 proefpersonen die zich aan het onderzoek hebben willen onderwerpen; zij hebben door hun deelname de meest concrete bijdrage aan dit proefschrift geleverd. De behandelaren van PMS Vijverdal en de RIAGG Maastricht ben ik erkentelijk voor hun inzet bij het werven van deelnemers aan het onderzoek.

Ik wil Rob Havermans, Adriaan Honig, Willem Nolen, Eric Vuurman en Jan Wiersma bedanken voor de prettige samenwerking bij de onderzoeken naar schizofrenie en bipolaire stoornis. De MRI-studies konden worden uitgevoerd dankzij Paul. Hofman en professor Wilmink van de afdeling Radiologie van het AZM. Het onderzoek naar cognitieve stoornissen en tardieve dyskinesie in de Caprileskliniek op Curaçao was mogelijk dankzij Peter van Harten, Glenn Matroos en Irving Picus. Peter, dank voor je inzet als co-auteur en voor je aanwijzingen hoe je een manuscript kort kunt houden. Machteld Marcelis, bedankt voor de samenwerking bij de MAPS, wetenschap is een stuk vrolijker met jou. Barbara and Michael Wilson, thank you for the opportunity to make a Dutch translation of the BADS. Marjolein de Vugt, je hebt een grote bijdrage geleverd aan het eerste Nederlandse BADS-onderzoek, waarwoor dank.

Alle (oud-)medewerkers van de Academische Afdeling Neuropsychologie: door jullie is de AAN een prettige werkplek, bedankt! Vooral wil ik noemen: Tijn van Diemen, die te hulp schoot wanneer op de valreep een presentatie werd voorbereid, Femie Kengen, die met overgave de lay-out van dit proefschrift heeft verzorgd, Karen van Hoof, die keer op keer 
nieuwe proefpersonen wist te werven, Paul Ganzevles, die ieder gesprek een bijzondere wending kan geven en Lilian Huijnen, die door haar aanwezigheid een lange grijze gang gezellig makat. Dankzij Hans Maessen is de bibliotheek van Vijverdal een prettige leesplek geworden. Alle collega's van UNS50 en DRT10 dank ik voor hun ondersteuning wanneer dat nodig was. Nico Rozendaal was er tegen iedere vorm van computer-stress en maakte de Mackrab in orde. Elsa Misdom wist het ongemak dat het werken op twee plekken met zich meebrengt tot een minimum te beperken.

Jane Sykes dank ik voor het conrigeren van het Engels wan verschillende hoofdstukken.

Ilk wil mijn ouders bedanken voor hun betrokkenheid en hun steun. Van mijn vrienden wil ik in het bijzonder noemen: Elvire, ik vind het fijn dat ik je heb leren kennen, dank voor je aanbod om wanneer dan ook bij te komen in je grote huis. Carlein, dank voor je vriendschap, ik ben blij dat je paranimf wilt zijn. Ariane, het was een groot geluk om 4 jaar een werkkamer en veel lief en leed met je te kunnen delen, dank voor al je hulp en voor je openheid. Jurgen, dank voor je warmte en je lieve zorgen, voor je vermogen je te verbazen en voor je andere kijk op het biologische van de psychiatrie. 


\section{Curriculum vitae}

Lydia Krabbendam werd op 10 juni 1971 geboren in Beverwijk: Na het afronden van het VWO in Amersfoort ging zij psychologie studeren, eerst aan de Vrije Universiteit te Amsterdam en later aan de Katholieke Universiteit te Nijmegen. Tijdens haar studie liep zij stage op de afdeling Psychodiagnostiek \& Neuropsychologie van Psychiatrisch Centrum Rosenburg in Den Haag en op de afdeling Research \& Ontwikkeling van de St. Maartenskliniek in Nijmegen. Daarnaast werkte zij als student-assistent ten behoeve van een onderzoek naar fijne motoriek bij depressie bij de vakgroep Functieleer van de Katholieke Universiteit Nijmegen. Na wat omzwervingen bij sociologie en taal- en spraakpathologie studeerde zij in februari 1995 af in de neuro- en revalidatiepsychologie. Aansluitend werd zij als assistent in opleiding aangesteld bij de vakgroep Psychiatrie en Neuropsychologie van de Universiteit Maastricht. Werkplek was Psychomedisch Streekcentrum Vijverdal, Maastricht, waar het onderhavige onderzoek werd uitgevoerd en opgeschreven. Sinds september 1999 is zij als neuropsycholoog ten behoeve van gezondheidszorg en wetenschappelijk onderzoek verbonden aan de Academische Afdeling Neuropsychologie van dezelfde instelling. 


\section{List of publications}

\section{Articles}

Hawermans, A. G, Honig, A., Vurman, E. F. P. M., Krabbendam, L., Wilmink, J Lamers, Th, Verhaecke, C. J., Jolles, J., Romme, M. A. J., Van Prag, H. M. (1999). A controlled study of temporal lobe structure volumes and $\mathbf{P} 300$ responses in schizophrenic patients with persistent auditory hallucinations. Sichizophromio Research, 38, 151-158.

Ganzewles, P. G. J, Krabbendam, L., Wester, A. Is alcoholism a true confounder in Chronic Encephalopathy Diagnosis? Submitted.

Kalf, A.C., Krabbendam, L., Van Hoof, K. (1999). De Behavioural Assessment of the Dysexecutive Syndrome: Een mieuw neuropsychologisch instrument voor planningsstoomissen. De Psyoholoog, 34, 57-62.

Krabbendam, L., De Vugt, M. E., Derix, M. M. A., Jolles J. (1999). The Behavioural Assessment of the Dysexecutive Syndrome as a tool to assess executive functions in schizophrenia. The Cliwical Newropsychologist, 13,370-375.

Krabbendam, L., Derix, M. M. A., Honig. A., Vuurman, E. F. P. M. Havermans, A. G., Wilmink, J. T., Jolles, $J$. (in press). Performance on neurocognitive tasks in relation to MRI temporal lobe abnormalities in schizophrenic patients and normal controls. Jowrwal of Newropsychiatry and Clinical Newrosciences.

Krabbendam, L., Honig, A., Wiersma, J., Vuurman, E. F. P. M. Hotman, P. A. M., Derix, M. M. A., Nolen, W. A., Jolles, J. (in press). Cognitive dysfunctions and white matter lesions in patients with bipolar disorder in remission. Acta Psychiatrica Scandinavica.

Krabbendarn, L., Van Harten, P. N., Picus, I., Jolles, J. (2000). Tardive dyskinesia is associlated with impainred retrieval from long-term memory. Schizophrenia Research, $42,41-46$.

Krabbendam, L., Visser, P. J, Derix, M. M. A., Verhey, F. R. J., Hofman, P. A. M., Verthoeven, W. M. A., Tuinier, $S$, Jolles, J. (2000) Normal cognitive performance in patients with chronic alcoholism in contrast to patients with Korsakoff's syndrome. Jownal of Netwopsychiaty and Clinical Neurosciences, 12, 44-50.

Visser, P. J., Krabbendam, L., Verhey, F. R. J., Hofman, P. A. M, Verhoeven, W. M. A., Tuinier, S., Van den Berg, Y. W. M. M., Goessens, L. E. M., Van der Werf, Y. D., Jolles, J. (1999). Brain correlates of memory dysfunction in alcoholic Korsakoff's syndrome. Jownal of Neurology, Newosurgery, and Psychiatry, 67, 774-778.

\section{Abstracts}

Ganzevles, P.G.J., Krabbendam, L., Wester, A. J. (1999). Ist chronische toxische Encephalopathie leicht zu verwechsetn mit chronischem Alkoholismus? Zeitschriff fir Newropsychologie, 10, 220.

Krabbendam, L., Jolles, J., Derix, M. M. A. (1996). Neuropsychological evaluation of schizophremic patients with and without auditory hallucinations. Paper presented at the conference of the International Neuropsychalogical Society, Veldhoven, the Netherlands (19-22.June). Jowrnal of the Intersational Neuropsychological Sociery, 2, 204.

Krabbendam L., De Vugt, M. E., Derix, M. M. A, Jolles, J. (1998). Assessment of executive finnctions in schizophrenia. Poster presented at the Ninth Biennall Winter Workshop on Schizophrenia, Davos, Swiltzerland (7-13 February). Schizophrenia Research, 29, 44

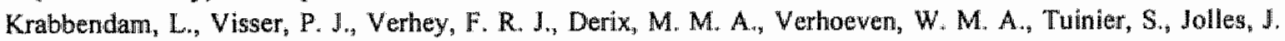
(1998). Cognitief functioneren bij chronisch alcoholgebruik. Paper presented at the Woorjaarscongres Nederlandse Vereniging woor Pgych hatrie, Noordwijk, the Netherlands (2-4 April). 


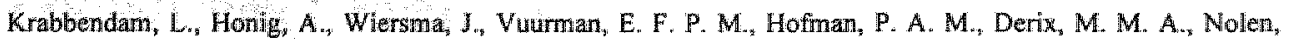
W. A. Jolles, J. (1999) Cognitive dysfunctions and white matter lesions in patients with bipolar disorder in remission. Paper presented at the 22nd International Conference of the International Neuropsychological Sactety, Durban, South-Africa (22-26 June). Journal of the International Neuropsychological Society, 5,281 . Krabbendarn, L, Marcelis, M, Van Os, J. (2000). Cognitive functions in patients with schizophrenia and their first-degree relatives. Paper presented at the Voorjaarscongres Nederlandse Vereniging voor Psychiatrie, Maastricht, the Metherlands (29-31 March).

Visser, P. J., Krabbendaum, Li, Hofnam, P. A. M., Verhey, F. R. J., Verhoeven, W. M. A., Tuinier, S., Van den Berg, Y. W. M. M, Jolles J. (1997). Memory dysfunction in allcoholism: Brain correlates. Poster presented at the Vith Symposium of the International Sociery for Neuroimaging in Psychiatry, Groningen, the Netherlands (27-29 November), Psychiatry research: Neuroimaging, 83, 53 .

\section{Miscellaneaus}

Krabbendam, L. Kalff, A.C. (1997). Nederlandse handleiding bij de Behavioural Assessment of the Dysexecutive Syndrome (Wilson et al, 1996). Lisse, Swets \& Zeitlinger. 